The Free Internet Journal

for Organic Chemistry
Review

Arkivoc 2019, part 0-0 to be inserted by editorial office

\title{
The synthesis of 1,2,4-benzotriazines
}

\section{Ghodsi Mohammadi Ziarani, ${ }^{* a}$ Madine Mostofi, ${ }^{a}$ Parisa Gholamzadeh, ${ }^{a}$}

Maryam Mohammadi-Khanaposhtani, ${ }^{b}$ and Hossein Yavari c

a Department of Chemistry, Alzahra University, Vanak Square, P.O. Box 1993893973, Tehran, Iran

${ }^{b}$ Cellular and Molecular Biology Research Center, Health Research Institute, Babol University

of Medical Sciences, Ganjafroz Street, P.O. Box 4717647745, Babol, Iran

${ }^{c}$ Department of Medicinal chemistry, Faculty of Pharmacy and Pharmaceutical Sciences Research Center,

Tehran University of Medical Sciences, P.O. Box14176, Tehran, Iran

Email:gmziarani@hotmail.com,gmohammadi@alzahra.ac.ir

Received 10-18-2018

Accepted 03-14-2019

Published on line 06-03-2019

\section{Abstract}

The 1,2,4-benzotriazine nucleus fused to a benzene ring is a prominent heterocyclic substructure present in numerous pharmacologically active compounds. To date, many 1,2,4-benzotriazine analogues possessing a wide spectrum of potent pharmacological activities are known. This review compiles information on the synthesis, chemical reactions, medicinal chemistry aspects and applications of 1,2,4-benzotriazines.

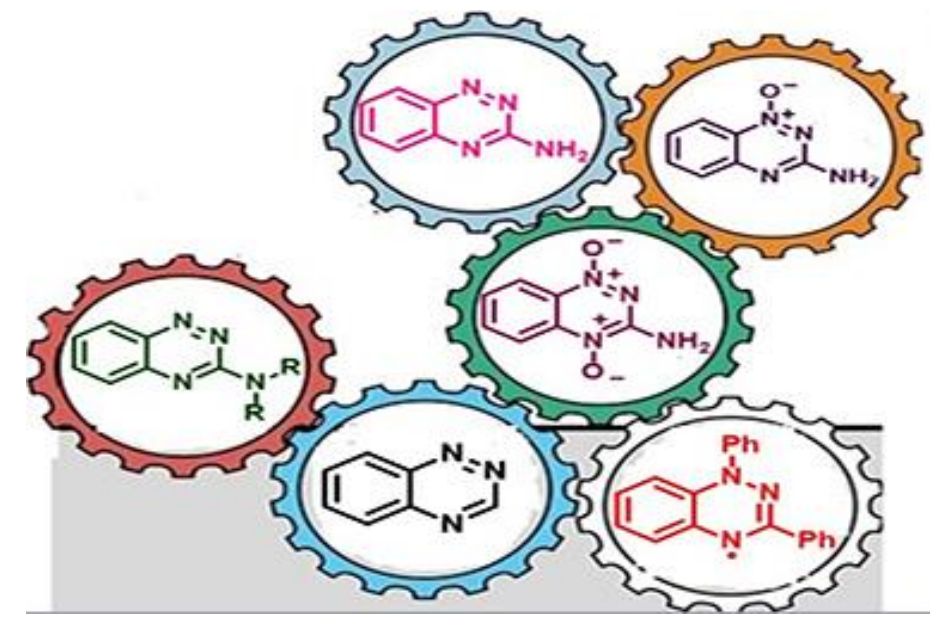

Keywords: 1,2,4-Benzotriazines, 1,2,4-benzotriazine N-oxides, 1,2,4-benzotriazine 1,4-dioxides, 3-amino-1,2,4benzotriazine $N$-oxides 


\section{Table of Contents}

1. Introduction

2. 1,2,4-Benzotriazines
2.1 3-Amino-1,2,4-benzotriazines
2.2 3-Aryl-1,2,4-benzotriazines
2.3 3-Aroyl-1,2,4-benzotriazines
2.4 1,2,4-Benzotriazine-3-thiones
2.5 3-(1-Iminoalkyl)-1,2,4-benzotriazines
2.6 3-Spiro-1,2,4-benzotriazines
2.7 Bis-1,2,4-benzotriazines

3. 1,2,4-Benzotriazines Fused to Five-membered Rings
3.1 Cyclopenta[f][1,2,4]benzotriazines
3.2 Pyrrolo[2,1-c][1,2,4]benzotriazines
3.3 Imidazo[1,2-c][1,2,4]benzotriazines
3.4 Pyrazolo[1,2-a][1,2,4]benzotriazines
3.5 Oxazolo[2,3-c][1,2,4]benzotriazines
3.6 Thiazolo[2,3-c][1,2,4]benzotriazines
3.7 Triazolo[5,1-c][1,2,4]benzotriazines
3.8 Indolo[4,3-a][1,2,4] benzotriazines
$3.9 \quad[1,2,4]$ Triazino[5,6,1-jk]carbazol-6-one

3.10. $[1,2,5]$ Thiadiazolo[3,4- $b][1,2,4]$ triazino[1,6,5-Im]carbazol-7-one

4. 1,2,4-Benzotriazines Fused to Six-membered Rings
4.1 Triazino[3,4-c][1,2,4] benzotriazines
4.2 Thiazino[2,3-c][1,2,4]benzotriazines
4.3 [1,2,4]Triazino[5,6-b]phenazin-11-ium
4.4. Tetraphenylhexaazaanthracene

5. 1,2,4-Benzotriazinyl Radicals

6. 1,2,4-Benzotriazine $N$-oxides

6.1 3-Amino-1,2,4-benzotriazine $\mathrm{N}$-oxides

6.2 3-Aminoalkyl-1,2,4-benzotriazine $N$-oxides

6.3 3-Alkyl- and 3-aryl-1,2,4-benzotriazine $N$-oxides

6.4 3-Ureido-1,2,4-benzotriazine $N$-oxides

6.5 3-Alkylthio-1,2,4-benzotriazine $N$-oxides

7. Conclusions

Acknowledgements

References

\section{Introduction}

Benzotriazines are the benzo-fused analogues of the triazines, six-membered rings containing three nitrogen atoms. There are two possible isomeric systems, the 1,2,4-benzotriazines (1), and the 1,2,3-benzotriazines (2). The former are considerably more important and more widely studied (Figure 1). 


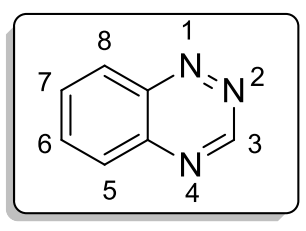

1

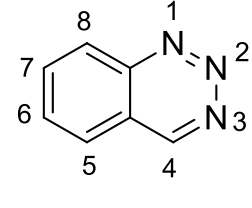

2

Figure 1. Numbering of the two isomeric benzotriazines.

Although the first synthesis of 1,2,4-benzotriazine was performed at the end of the 19th century, new methods for their preparation are still being developed. The first synthesis of 1,2,4-benzotriazine and its 3methyl derivative was reported by Bischler in $1889 .{ }^{1}$ An overview on the recent developments of 1,2,4triazines as anticancer compounds was reported by Cascioferro et al. ${ }^{2}$ Furthermore, recent progress in the synthesis of 1,2,4-benzotriazines was reviewed by Obijalska and Kowalski. ${ }^{3}$ 1,2,4-Benzotriazines and their derivatives are an important class of heterocycles which display a wide range of biological properties. ${ }^{4}$ Various methods have been reported for the synthesis of substituted 1,2,4-benzotriazines and the products have been screened for pharmacological activities with encouraging findings. The development of novel benzotriazines for drug discovery has been reviewed by Palanki et al. ${ }^{5}$ Some analogues exhibit potential therapeutic effects and may be considered as lead structures for application in numerous areas of medicinal chemistry. ${ }^{6}$ The preclinical study of 3-amino-1,2,4-benzotriazine analogues (3) and (4) have shown anti-tumor effects against sarcoma ${ }^{7}$ due to their activities as inhibitors of Src kinases, and they may be effective as antineoplastic agents against pancreatic and breast, and stomach cancer cell lines (Figure 2 ). ${ }^{8}$

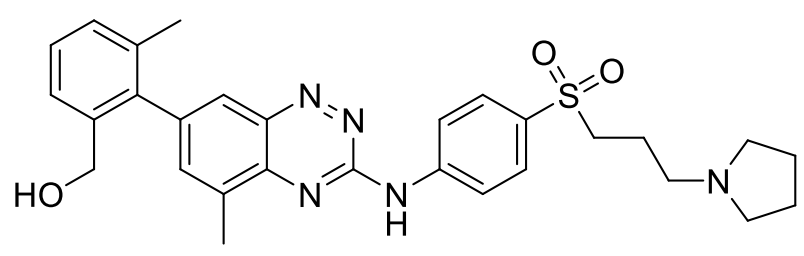

3

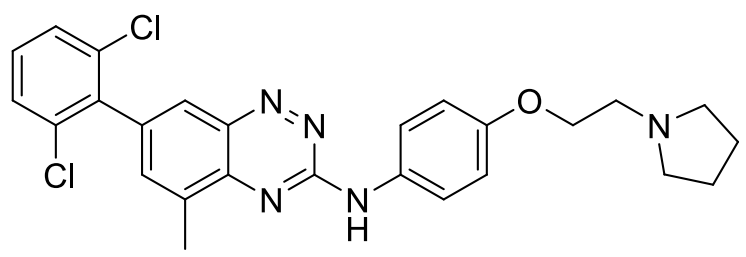

4

Figure 2. 1,2,4-Benzotriazines with antitumor effects.

1,2,4-Benzotriazinyl radicals, a subclass of the hydrazyls, have attracted attention because of their enhanced air and moisture stability. Although they were first prepared by Blatter in the late 1960s, only sporadic work on this radical class has been reported, in stark contrast to the closely related verdazyl radicals. The majority of 1,2,4-benzotriazinyls are stable in terms of $\sigma$ or $\pi$ dimerization in the solid state; only 1,3diphenyl-7-trifluoromethyl-1,4-dihydro-1,2,4-benzotriazin-4-yl (5) has a singlet ground state, arising from a $\pi-\pi$ interaction rather than a true bond, with a thermally excited triplet state. 1-Phenyl-3-trifluoromethyl-1,4dihydro-1,2,4-benzotriazinyl (6) is the first example of a hydrazyl radical that undergoes a spin transition between a paramagnetic and a diamagnetic phase and one of the few air-and moisture-stable radicals that demonstrated this behavior (Figure 3). ${ }^{9}$

1,4-Dihydro-1,2,4-benzotriazinyl radicals (7), first reported in 1968, are air, moisture, and thermally stable and show fully reversible redox behavior. They can be readily reduced to the 1,4-dihydro-1,2,4-benzotriazines whereas strong reductants can lead to the formation of benzimidazoles via a reductive ring contraction. Treatment with oxidants affords 1,2,4-benzotriazin-7-ones (8). Introduction of groups at the C7 position, such as the $\mathrm{CF}_{3}$ group, can block the oxidation leading to exceptionally oxidatively stable radicals, e.g., the 1,3- 
diphenyl-7-trifluoromethyl-1,2,4-benzotriazinyl (5). The 1,3-dipyrid-2-yl-7-trifluoromethyl-1,2,4-benzotriazinyl radical (9) could not be isolated and the $\mathrm{C}-\mathrm{N}$ coupled species (8) was obtained in its place. ${ }^{10}$

A $3-\mathrm{CF}_{3}$ substituted 1,2,4-benzotriazin-7-one has shown inhibition of the thioredoxin (Trx)-thioredoxin reductase TrxR, although the parent compound 1,3-diphenyl-1,2,4-benzotriazin-7-one (8) was more cytotoxic against cancer cell lines. 1,2,4-Benzotriazin-7-ones (8) exhibited different degrees of reversible inhibition of TrxR, and cyclic voltammetry showed characteristic quasi-reversible redox processes. Cell viability studies indicated a strong dependence of cytotoxicity on substitution at the 6-position of the 1,3-diphenyl-1,2,4benzotriazin-7-one ring. ${ }^{11}$<smiles>FC(F)(F)c1ccc2c(c1)N(c1ccccc1)N=C(c1ccccc1)N2</smiles>

5<smiles>FC(F)(F)C1=NN(c2ccccc2)c2ccccc2N1</smiles>

6<smiles>[R]C1=NN([R])c2ccccc2N1</smiles>

7

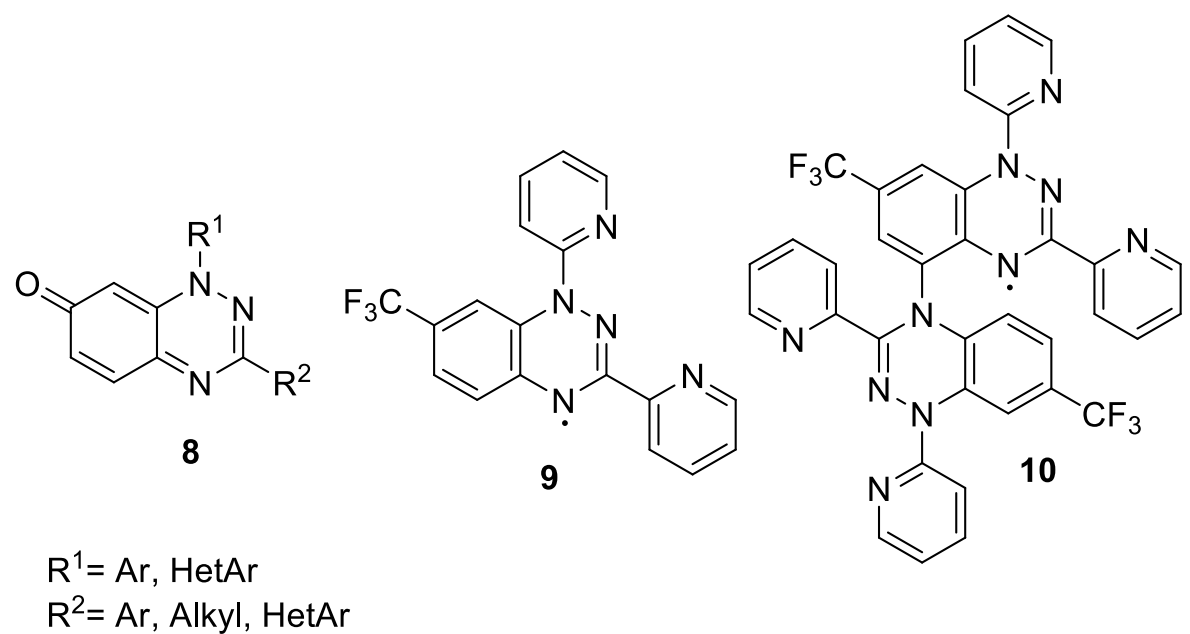

Figure 3. 1,2,4-Benzotriazinyls (5-10) and the oxidation product 1,2,4-benzotriazin-7-one (8).

Ciciani et al. reported the synthesis of pyrazolo[5,1-c][1,2,4]benzotriazines (11), and their open analogues as cytotoxic agents in normoxic and hypoxic conditions. On the other hand, El Massry et al. reported the synthesis and structure elucidation of fused 1,2,4-benzotriazines as potent inhibitors targeting CYP1A1 activity. ${ }^{12,13}$

The pyrazolo[5,1-c][1,2,4]benzotriazine 5-oxide (11) displays high selectivity as a ligand for the benzodiazepine site on the $\mathrm{GABA}_{\mathrm{A}}$ receptor. ${ }^{14}$ Pyrazolo[5,1-c][1,2,4]benzotriazines (11) have been recently reviewed by Mohammadi Ziarani et al. ${ }^{15}$

3-Amino-1,2,4-benzotriazine 1,4-dioxide (tirapazamine, TPZ) (12) is an experimental anticancer drug which is converted into a toxic radical at low concentrations of oxygen. ${ }^{16}$ Such levels of oxygen are common in solid human tumors, a phenomenon known as tumor hypoxia. Thus, TPZ is converted into its toxic form preferentially in the hypoxic areas of solid tumors. The tumor cells in these regions are resistant to the toxic effects of radiotherapy and anticancer drugs. Thus, a combination of TPZ with conventional anticancer treatments is particularly effective. ${ }^{17}$ Since 2006, TPZ has been examined in phase III clinical trials in patients with head and neck cancer and gynecological cancer, and similar trials are being undertaken for other solid 
tumor types. ${ }^{18-20}$ TPZ has recently been reviewed by the reseach group of Reddy and Williamson ${ }^{21}$ as well as Marcu and Olver, seperately. ${ }^{22}$ Interestingly, compound (13) in which TPZ is linked to a 9-aminoacridine DNAbinding unit via an alkyl chain was more potent than TPZ in killing hypoxic cells. ${ }^{23}$ Furthermore, 3-(3morpholinopropyl)-7,8-dihydro-6H-indeno[5,6-e][1,2,4]triazine 1,4-dioxide (14), an analogue of the bioreductive prodrug TPZ, and 3-(2-carboxyethyl)-7,8-dihydro-6H-indeno[5,6-e][1,2,4]triazine 1-oxide (15) as a product of oxidative photodegradation exhibited improved activity against hypoxic cells in tumor xenografts (Figure 4). ${ }^{24}$

A myriad of other 1,2,4-benzotriazines, such as the dioxide (12), have been used as dyes. ${ }^{25}$ In addition, herbicidal, ${ }^{26}$ Src kinase inhibitor, ${ }^{27}$ antitumor, ${ }^{28}$ antimicrobial, ${ }^{29,30}$ antibacterial, ${ }^{31}$ antimalarial, ${ }^{32,33}$

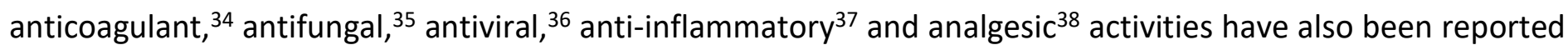
for compounds of this type.

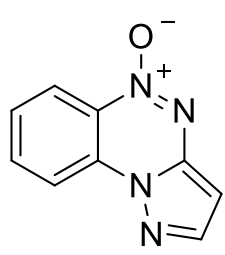

11

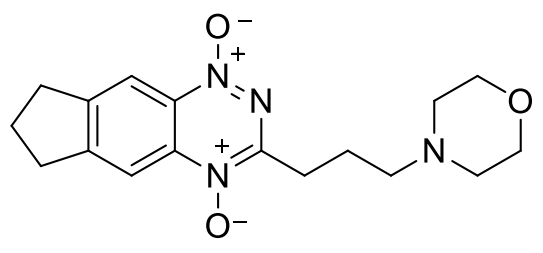

14

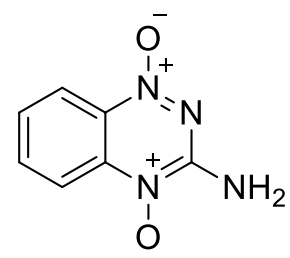

12

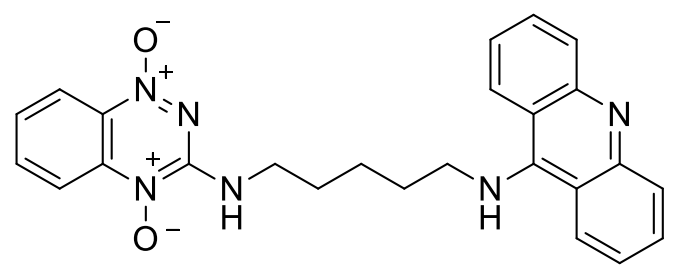

13

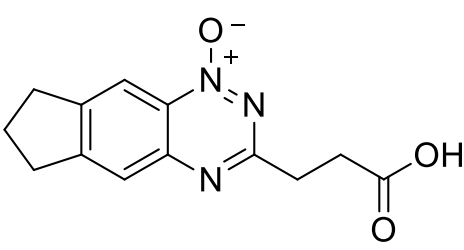

15

Figure 4. Bioactive 1,2,4-benzotriazine $N$-oxide-containing compounds.

Because of the importance of 1,2,4-benzotriazine compounds in different areas of science, we herein describe effective procedures for the synthesis of such heterocycles which have been reported since 1954 . We also consider the applications of 1,2,4-benzotrazines in organic reactions.

\section{1,2,4-Benzotriazine}

\subsection{3-Amino-1,2,4-benzotriazines}

Rozhkov and Shevelev developed novel benzotriazine based compounds as a new class of Src inhibitors. They nitrated 1-alkoxy-3,5-dinitrobenzenes and 1-alkoxy-5-halo-3-nitrobenzenes (16) using a mixture of concentrated $\mathrm{HNO}_{3}$ and $\mathrm{H}_{2} \mathrm{SO}_{4}$ to afford 1-alkoxy-2,3,5-trinitrobenzenes and 1-alkoxy-5-halo-2,3-dinitrobenzenes (17). The latter were treated with guanidine (18) to form the corresponding intermediate of (2alkoxy-4,6-dinitrophenyl)- or (2-alkoxy-4-halo-6-nitro)guanidines (19). When derivatives of intermediate (19) were treated in situ with one equivalent of $\mathrm{KOH}$, the corresponding 5-alkoxy-3-amino-7-nitro- or 7-halo-1,2,4benzotriazine 1-oxides (20) were formed. ${ }^{39}$ Reduction using Raney nickel produced 3-amino-7halobenzotriazines (21) and subsequent treatment with arylboronic acids under Suzuki coupling conditions ${ }^{40}$ gave the aryl-substituted benzotriazines (22). Finally, N-arylated derivatives (24) were prepared from (22) in 
good yields by Buchwald-Hartwig cross-coupling ${ }^{41,42}$ using tris(dibenzylideneacetone)dipalladium $\left(\mathrm{Pd}_{2}\left(\mathrm{dba}_{3}\right)\right.$ in the presence of 4,5-bis(diphenylphosphino)-9,9-dimethylxanthene (xantphos) (23) (Scheme 1). ${ }^{43}$

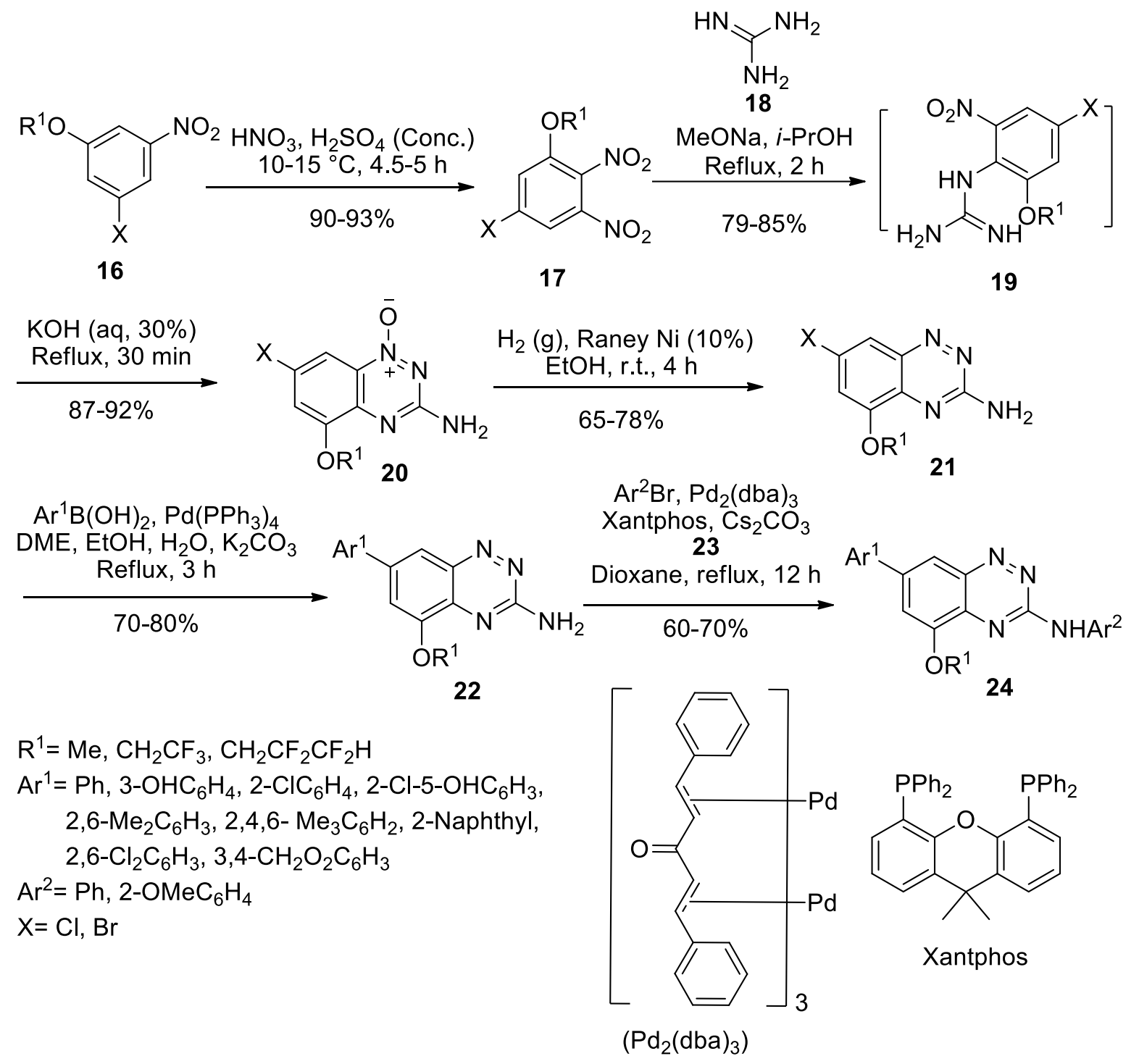

Scheme 1. Synthesis of 6,7-disubstituted-5-alkoxy-3-amino-l,2,4-benzotriazines (24).

\subsection{3-Aryl-1,2,4-benzotriazines}

$\mathrm{Ma}$ and coworkers reported a Cu-catalyzed coupling of 2-haloaryl or arylamide (25) and N-protected hydrazine to form N'-arylated products (27) in the presence of $1 \mathrm{H}$-pyrrole-2-carboxylic acid (26) as a ligand. Subsequent copper-catalyzed oxidation in air proceeded at room temperature to afford azo compounds (28). Finally, deprotection with trifluoroacetic acid (TFA) and in situ cyclization gave 1,2,4-benzotriazines (29) in excellent yields (Scheme 2 ). ${ }^{44}$ 


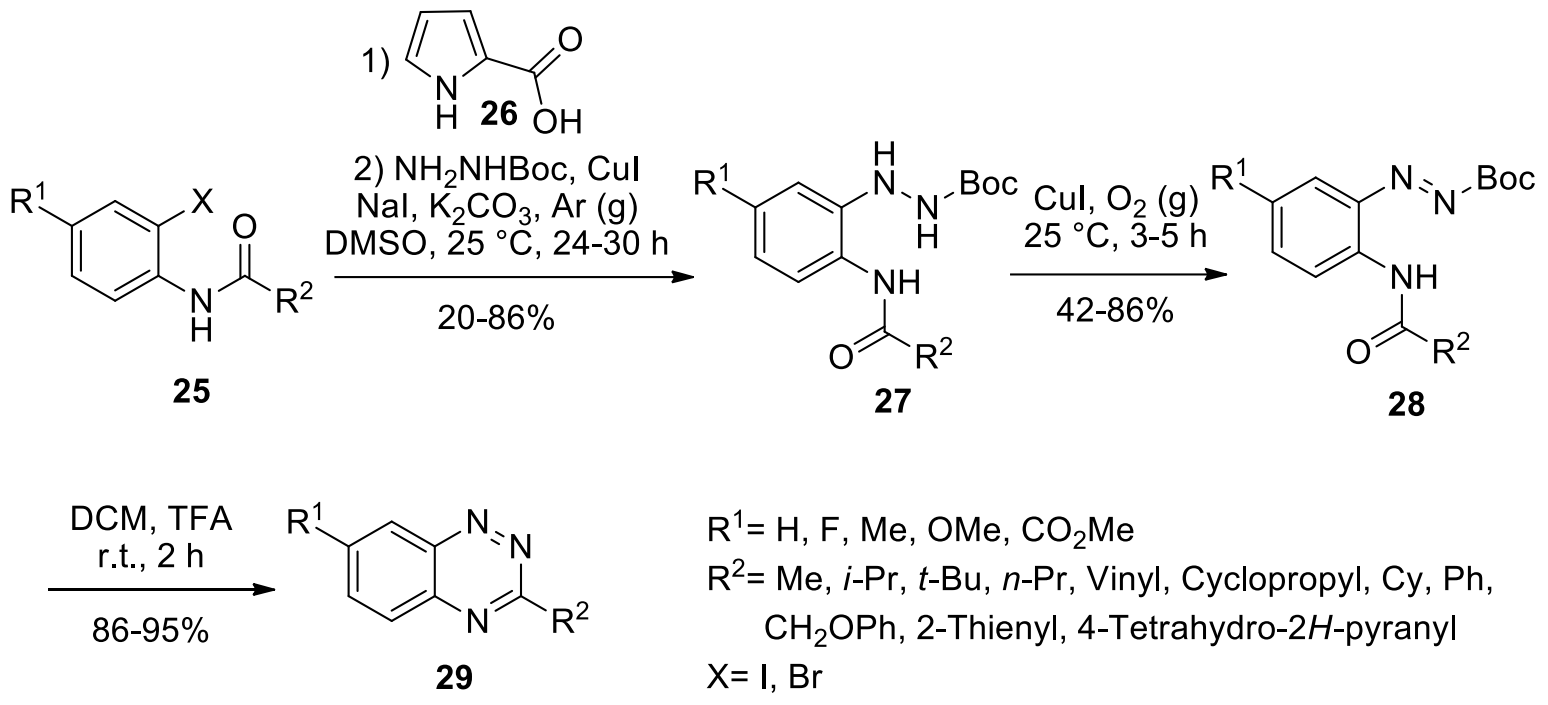

Scheme 2. Synthesis of 1,2,4-benzotriazines (29) by a coupling reaction.

Considerably earlier, Rees, Storr et al. had found that oxidation of 1-amino-2-quinoxalinones (31) by lead tetraacetate gave 1,2,4-benzotriazines (34) in good yields. The 1-amino-2-quinoxalinones (31) were readily obtained by direct amination of the quinoxalinones (30) with hydroxylamine-O-sulfonic acid. It was suggested that conversion of (31) to (34) proceeded through a mechanism including ring expansion of the nitrene (32) following by electrocyclic ring closure of the trienone (33) and loss of carbon monoxide (Scheme 3). ${ }^{45}$

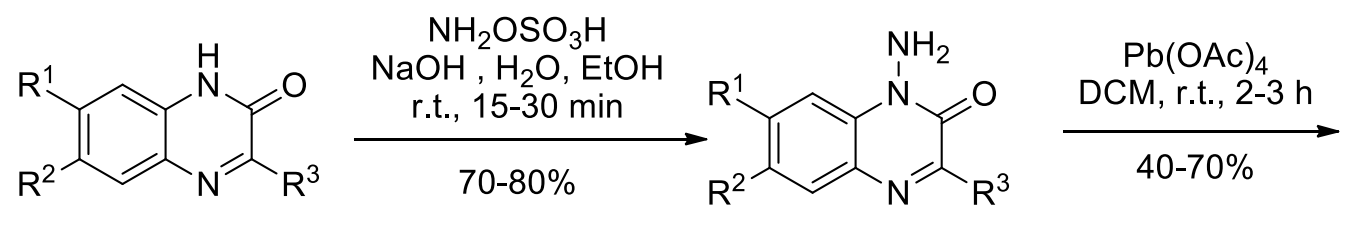

30

31

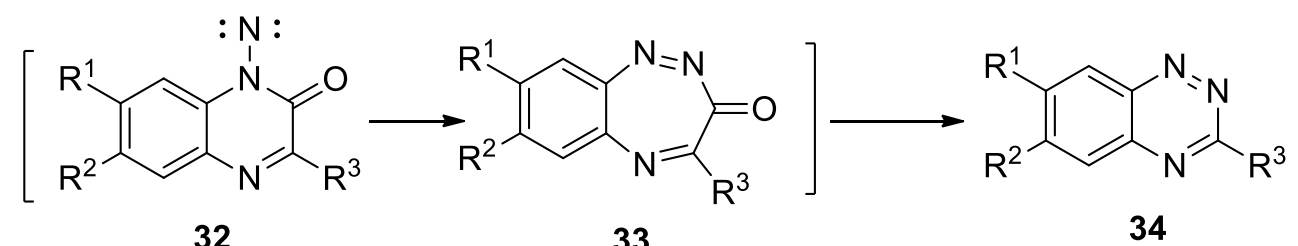

$R^{1}, R^{2}, R^{3}=H, M e, P h$

Scheme 3. Synthesis of 1,2,4-benzotriazines (34).

Sparatore and coworkers prepared 2-aminophenylhydrazones (36) through the reduction of (2-nitrophenyl)hydrazones (35). Ring closure by ethanolic $\mathrm{HCl}$ afforded 3-substituted-1,2,3,4-tetrahydro-1,2,4benzotriazines (37). The latter were readily oxidized by air to form 3,4-dihydro-1,2,4-benzotriazines (38) and further oxidation of the former gave the 3-substituted-1,2,4-benzotriazines (39) (Scheme 4). ${ }^{46}$ 

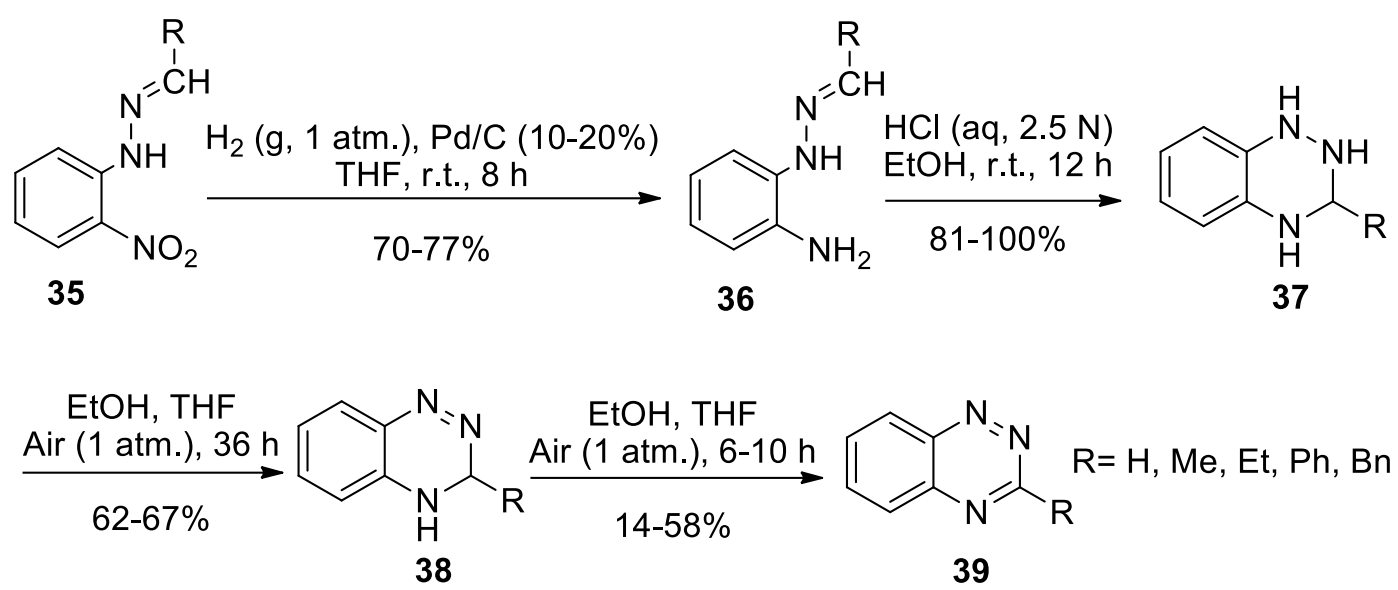

Scheme 4. Oxidation and acid-catalyzed cyclization of 2-aminophenylhydrazones (36).

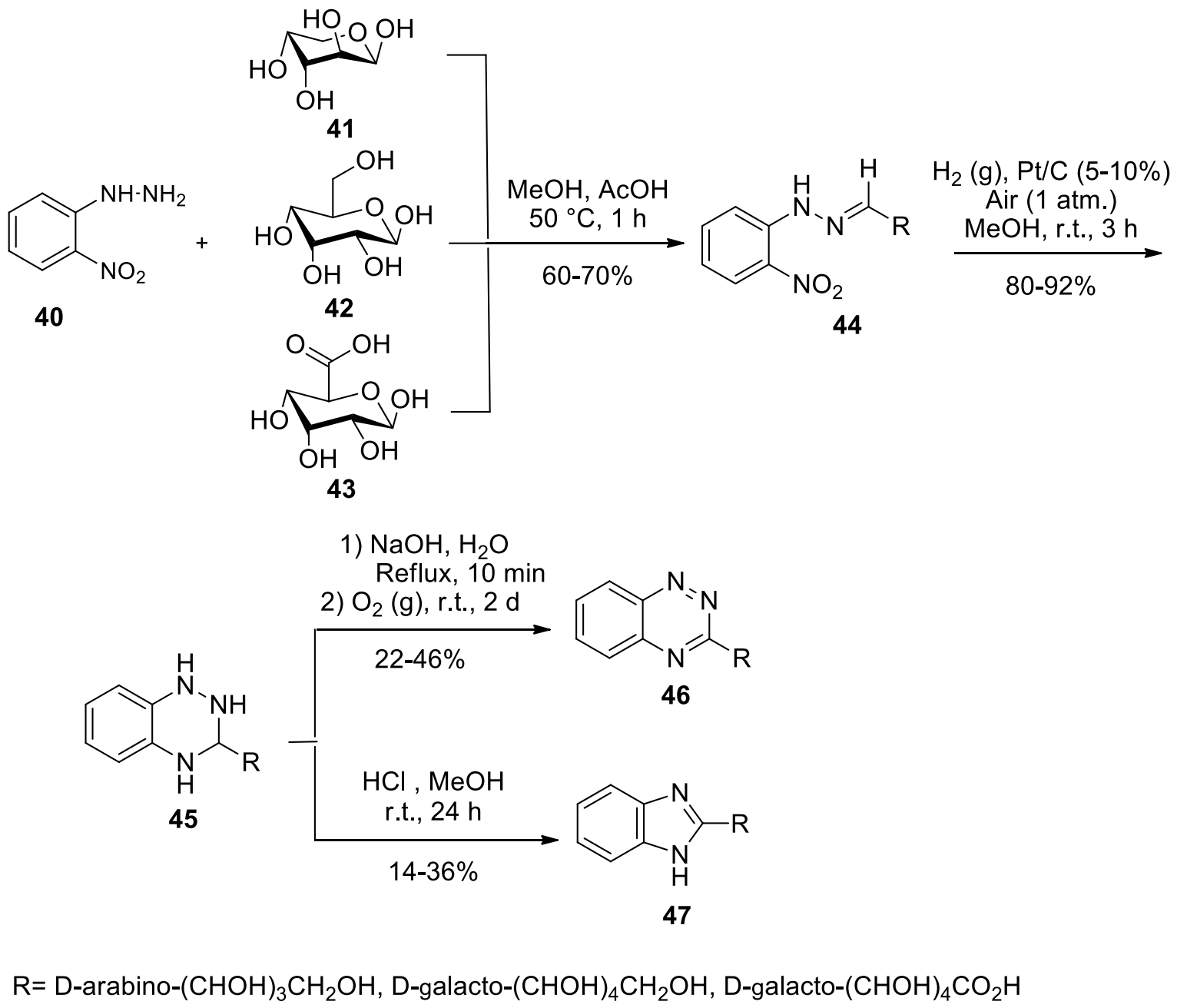

Scheme 5. Reductive cyclization of 2-nitrophenylhydrazone (44).

2-Nitrophenylhydrazine (40) was reacted with D-arabinose (41), D-galactose (42) and D-galacturonic acid (43) to form the 2-nitrophenylhydrazones (44). Catalytic hydrogenation of the nitro compounds (44) in methanol over Pt on carbon at ambient pressure afforded the related amines, which cyclized to the 3- 
substituted 1,2,3,4-tetrahydrobenzotriazines (45). Upon air oxidation of the latter in alkaline solution, functionalized 1,2,4-benzotriazines (46) were produced. In contrast, compound (45) formed the benzoimidazole (47) under acid catalysis (Scheme 5). ${ }^{47}$

Imidazolin-2-ones (49) was efficiently synthesized by ring contraction of 1,2,4-benzotriazin-3-ones (48) upon treatment with hydroxylamine-O-sulfonic acid in aqueous alkali upon heating. Furthermore, dihydro1,2,4-benzotriazine (50) was electrochemically reduced with an excess of sodium dithionite in formic acid at $\mathrm{pH} 4$ to benzimidazole (51) (Scheme 6). ${ }^{48}$<smiles>O=c1nc2ccccc2n[nH]1</smiles>

48<smiles>O=S(=O)(c1ccccc1)c1ccccc1NC=Nc1ccccc1</smiles>

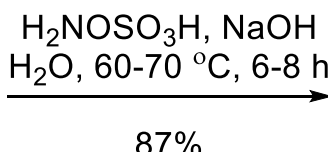

$87 \%$

$\mathrm{Na}_{2} \mathrm{SO}_{4}, \mathrm{HCO}_{2} \mathrm{H}$ $\mathrm{EtOH}, 78^{\circ} \mathrm{C}, 7-8 \mathrm{~h}$

$75 \%$<smiles>O=c1[nH]c2ccccc2[nH]1</smiles>

49<smiles>c1ccc(-c2nc3ccccc3[nH]2)cc1</smiles>

Scheme 6. Ring contraction of 1,2,4-benzotriazines (48) and (50).

The 2-nitrophenylhydrazines (52) were condensed with sodium pyruvate (53) to form the hydrazones (54) (>90\% yields), hydrogenation with $\mathrm{PtO}_{2}$ in ethanol led directly to the 3-methyl-1,2,4-benzotriazines (55). When the hydrazines (52) were treated with ethyl benzimidate (56) the hydrazono-ethers (57) were formed, and a similar hydrogenation led to the 3-phenylbenzotriazines (58) (Scheme 7). ${ }^{49}$

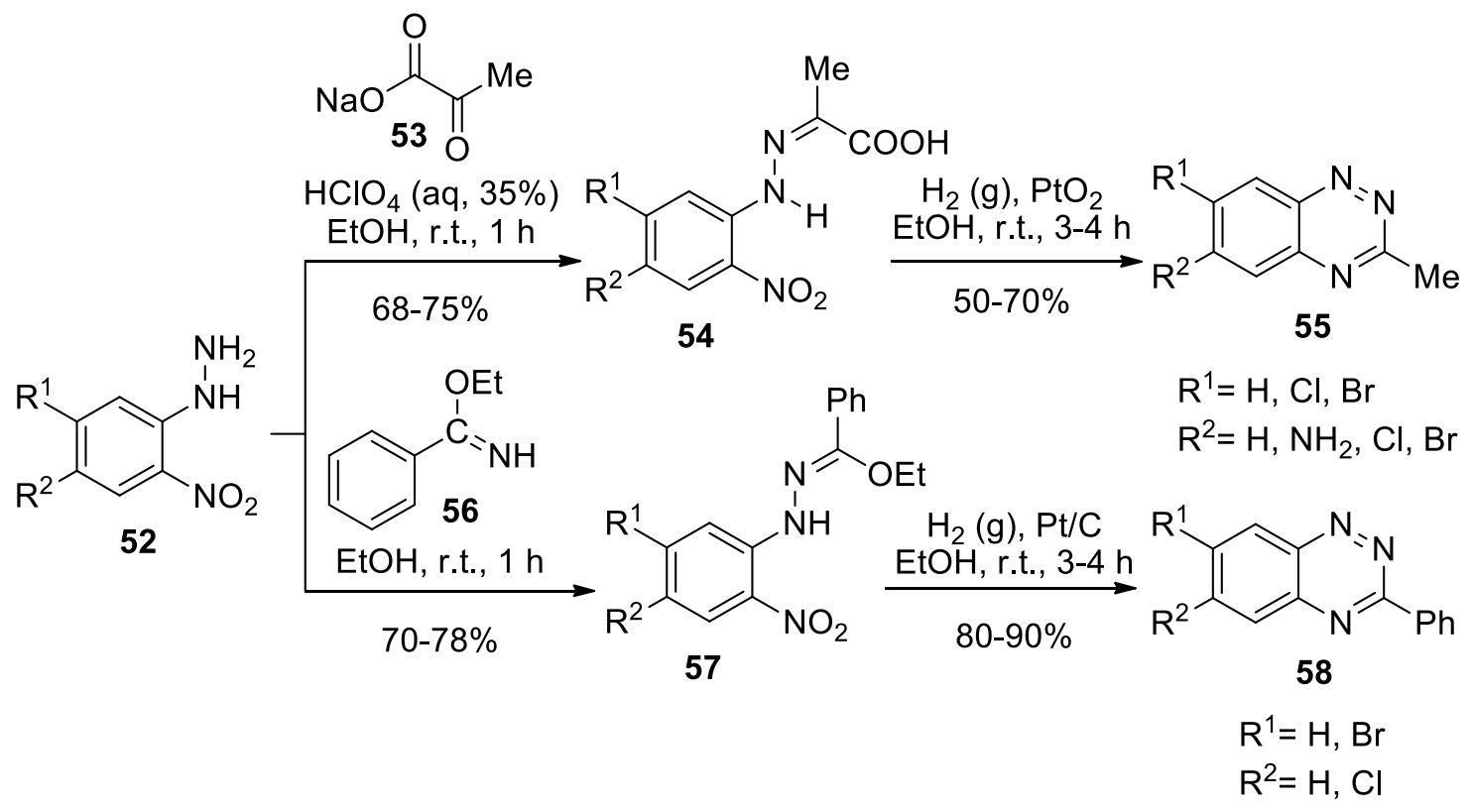

Scheme 7. Synthesis of 6,7-disubstituted 3-methyl and 3-phenyl-1,2,4-benzotriazines (55) and (58). 
In early work by Haddadin and Issidorides, benzofuroxan (59) and diethylamine gave o-benzoquinone dioxime (60) and the imine (61). The two products interacted to form the imine oxide intermediate (62) which was converted into 3-methyl-1,2,4-benzotriazine (39) and 1-hydroxy-2-methylbenzoimidazole 3-oxide (63) (Scheme 8). ${ }^{50}$
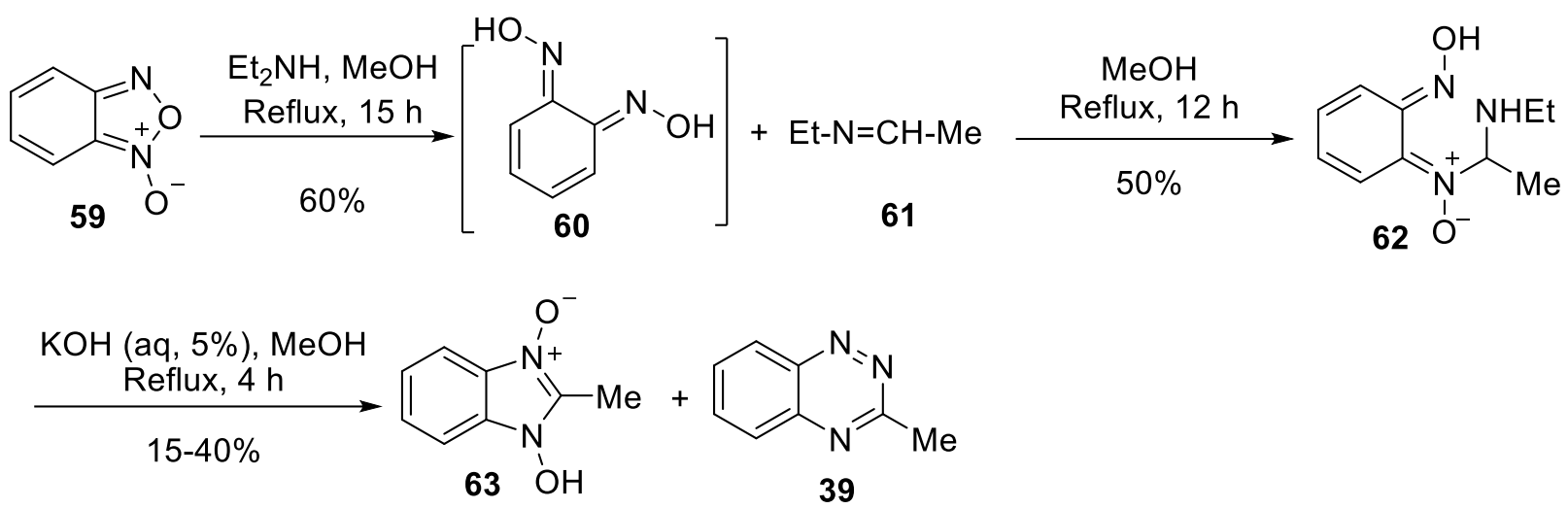

Scheme 8. Synthesis of 3-methyl-1,2,4-benzotriazine (39) from benzofuroxan (59).

$N$-Acyl-N'-(2-nitrophenyl)hydrazines (67) were prepared by two alternative routes: from the reaction of either 2-nitrofluorobenzene (64) and acylhydrazines (65), or by N-acylation of 2-nitrophenylhydrazine (40). The nitro group in compound (67) was reduced to the amino in (68) over a palladium catalyst. Ring closure was effected with ethanolic hydrochloric acid to give the dihydrotriazines (69). Finally, the oxidation of 1,4dihydro-1,2,4-benzotriazine (69) by activated $\mathrm{MnO}_{2}$ gave the 3-substituted-1,2,4-benzotriazines (39). Compounds (67) with various alkyl and aryl groups in the 3-position exhibited potential antifungal activity (Scheme 9). ${ }^{51,52}$
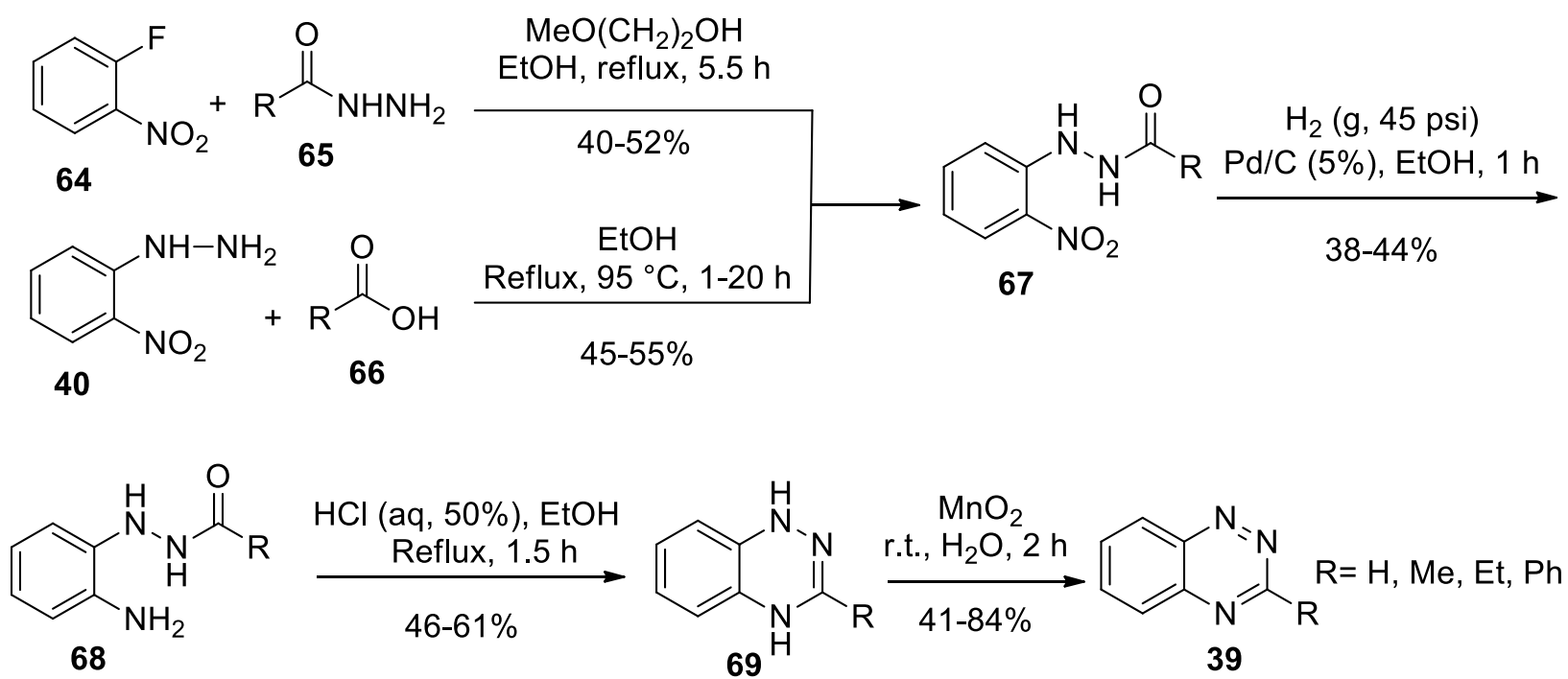

Scheme 9. Synthesis of 3-substituted-1,2,4-benzotriazines (39).

Bischler's method was used for the synthesis of 3-methyl-1,2,4-benzotriazines (39) starting with 2-chloro3-nitrobenzene (70) or the respective fluoro analogue and reacting it with acylhydrazines to give the hydrazides (67), which also resulted from acylation of 2-hydrazino-3-nitrobenzene (67). Catalytic reduction of 
the hydrazides (67) and cyclization of the resulting amino derivative (68) gave (72), the oxidation of which with potassium ferricyanide at pH 10 or with air gave (39). On the other hand, cyclization of the hydrazine (71) with acid gave (72). Compounds (72) and (39) showed antibacterial and anti-inflammatory activity (Scheme 10). ${ }^{53}$

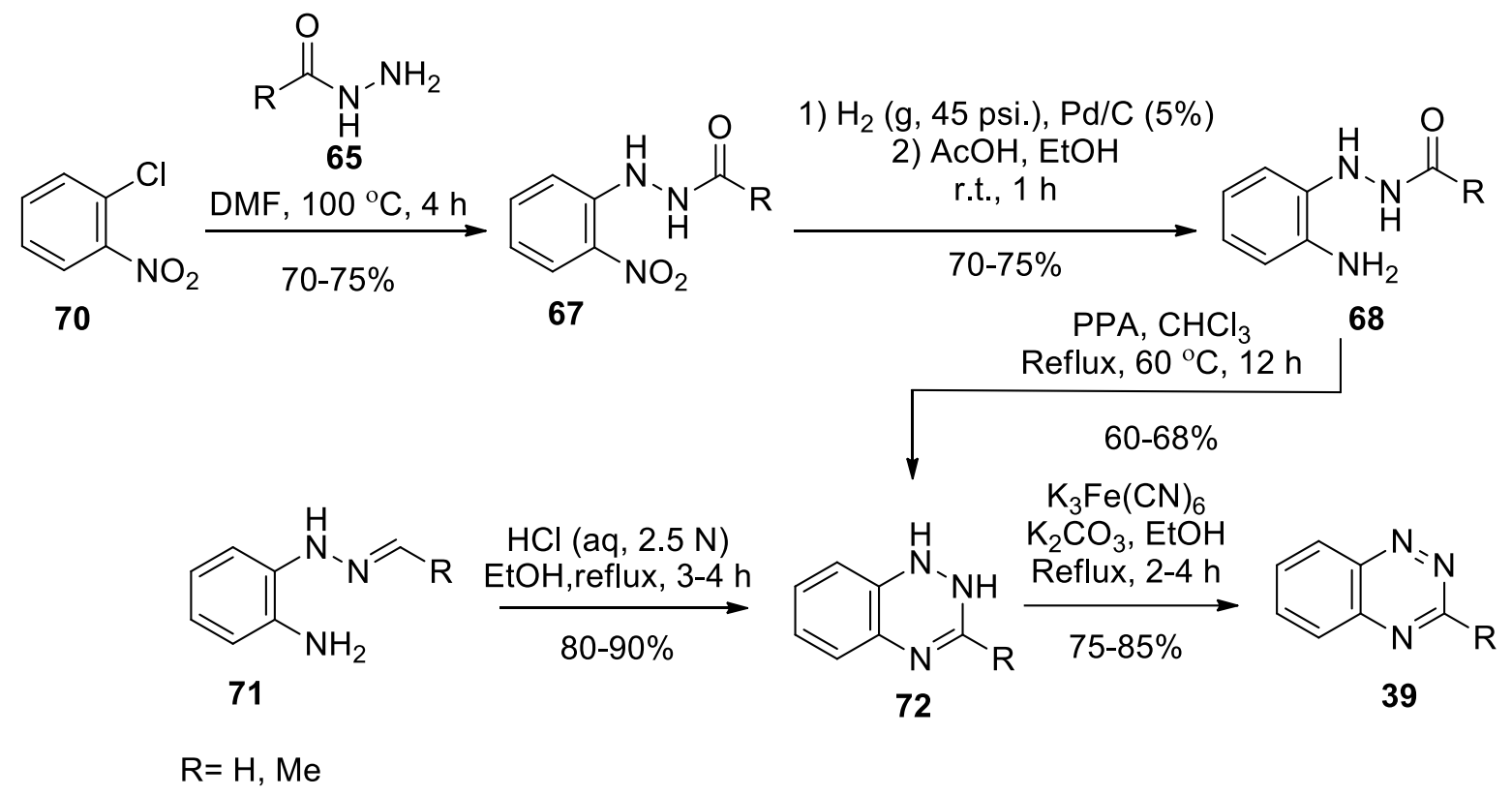

Scheme 10. Bischler's synthesis of 1,2,4-benzotriazines (39).

Gelvin and Turnbull reduced the 3-(2-nitrophenyl)sydnone (73) by hydrogenation over a palladium catalyst to form the aminophenyl sydnone (74). Acylation of the latter was performed using acetic anhydride, benzoyl chloride or trifluoroacetic anhydride (TFAA) in the presence of glacial acetic acid to afford the acylamino derivatives (75). On treatment of compounds (75) with concentrated hydrochloric acid and subsequent basic workup, the corresponding benzotriazines (39) (if $\mathrm{R}=\mathrm{Me}$ and $\mathrm{Ph}$ ) or 1,2-dihydrobenzotriazine (76) (if $\mathrm{R}=\mathrm{CF}_{3}$ ), were obtained, presumably via formation of a hydrazine derivative from the sydnone residue and nucleophilic attack on the acylamino group. 1-Aminobenzimidazole (77) was formed (if R = H) (Scheme 11). ${ }^{54}$
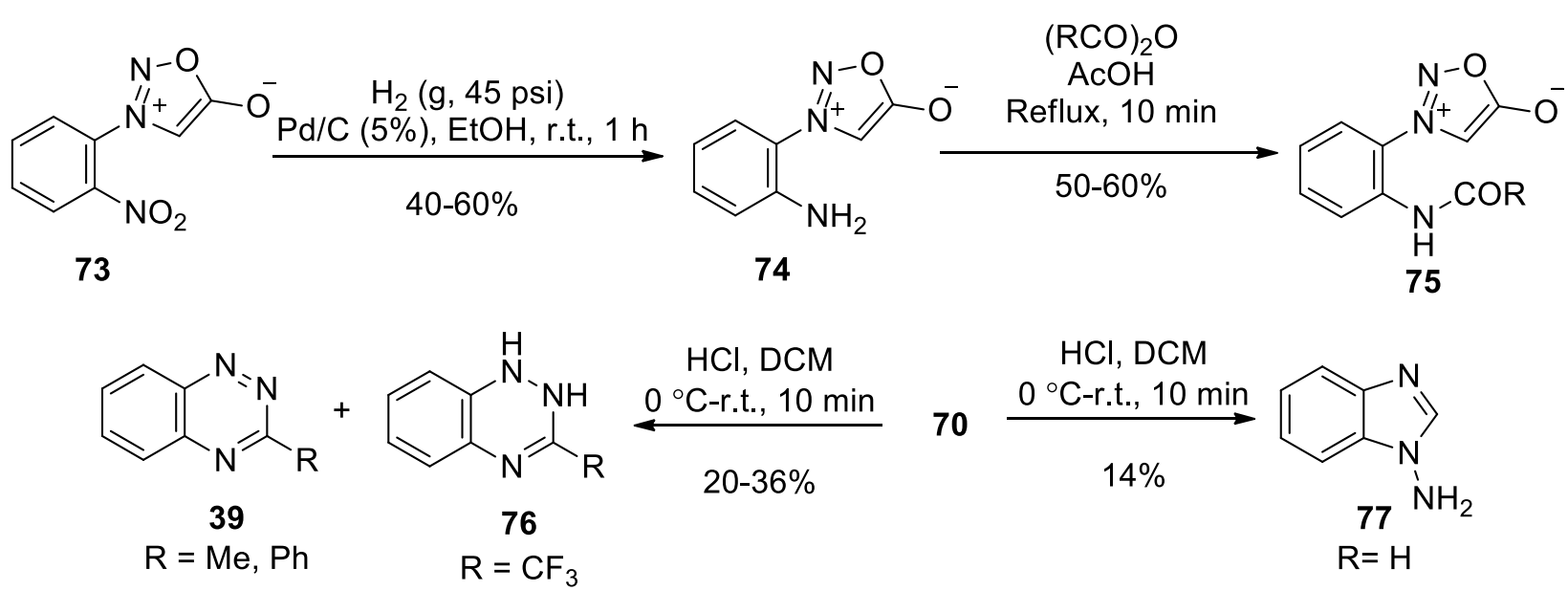

$\mathrm{HCl}, \mathrm{DCM}$

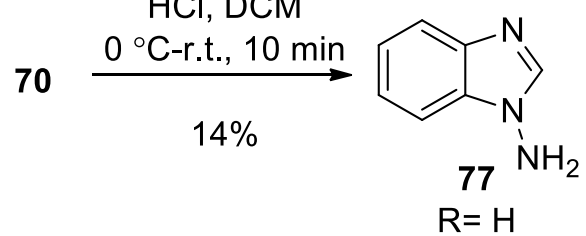

Scheme 11. A synthetic route for 3-substituted-1,2,4-benzotriazines (39) and 3-substituted 1,2dihydrobenzotriazine (76). 
1,2,4-Benzotriazines (80) were formed unexpectedly through an unusual [3,5]-sigmatropic rearrangement of an in situ-generated 2-benzoyloximic intermediate (79) produced in the reaction of oxime (78) and arylnitrile oxides. The carboxylic acid (81) as a minor product was produced (Scheme 12). ${ }^{55,56}$

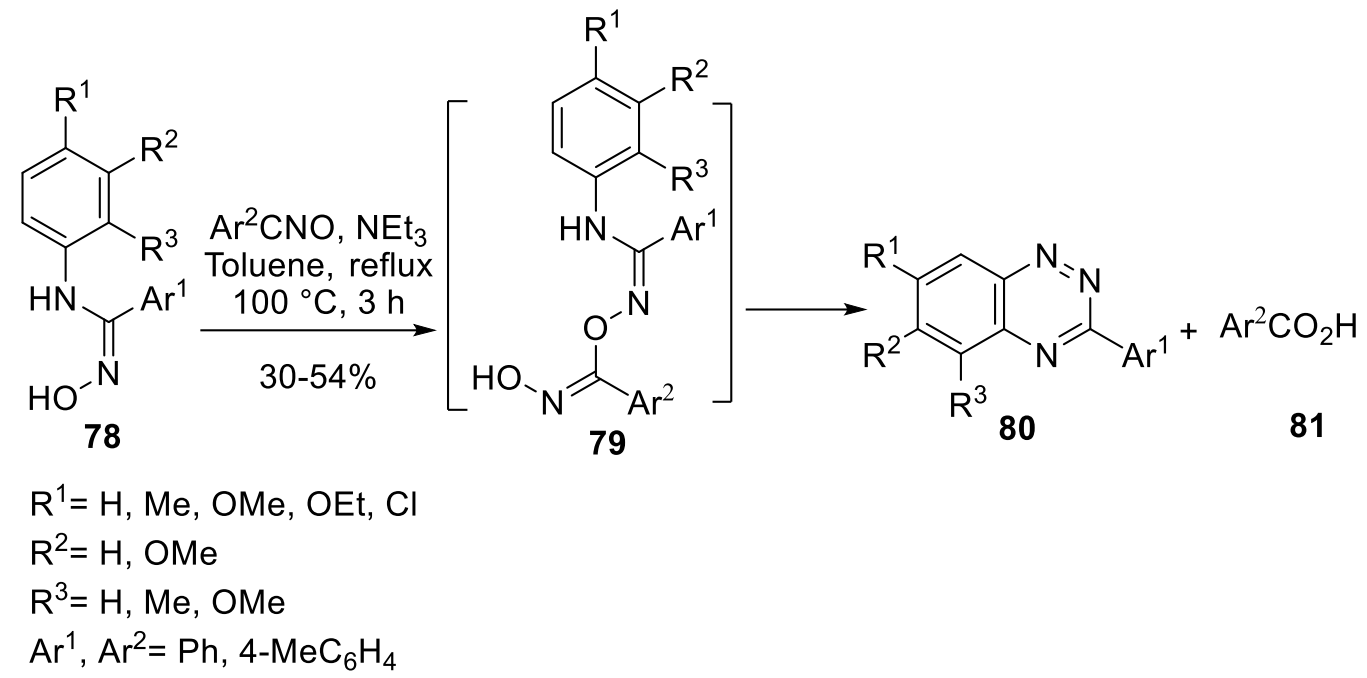

Scheme 12. Synthesis of 5,6,7-substituted-3-phenyl-1,2,4-benzotriazines (80).

Glidewell and coworkers found that the fluorine substituent of 4-fluoro-3-nitrobenzoate (82) was replaced by an aroylhydrazine group, to yield the 2-nitrohydrazides (83). Then, in a one-pot protocol, the nitro group was reduced to the amino group followed by an intramolecular cyclization in the presence of glacial acetic acid to afford the products (84) (Scheme 13)..$^{57}$
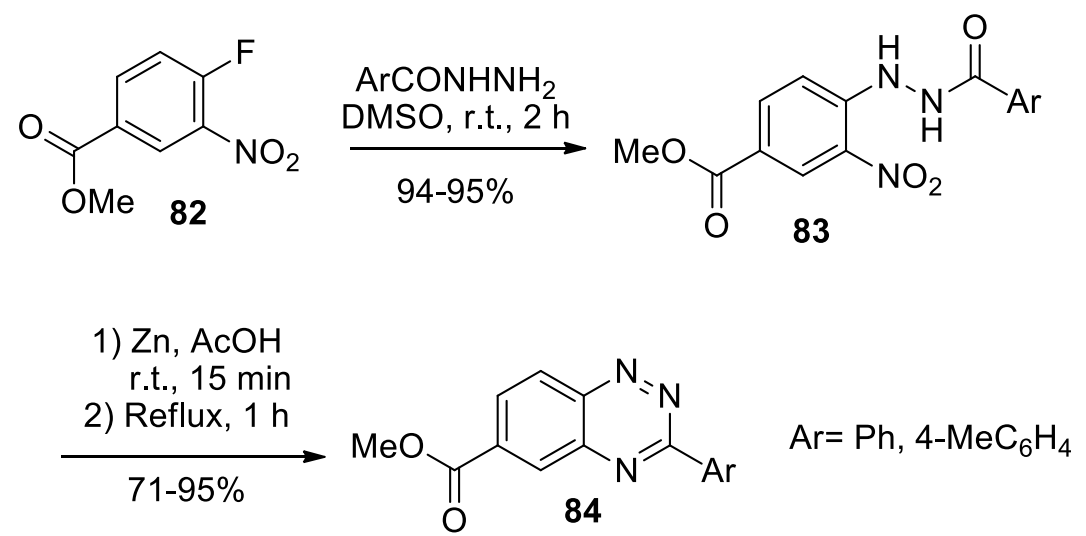

Scheme 13. Synthesis of 3-aryl-1,2,4-benzotriazine-6-carboxylates (84).

Mata's research team developed a strategy for the solid-phase-based synthesis of novel 1,2,4-benzotriazines (90) via the intramolecular cyclization of solid-supported 2-hydrazidoanilines (88). Initially, 4-fluoro-3nitrobenzoic acid (85) was linked to Wang's resin to afford the immobilized ester (86). Then, the fluorine atom was replaced by the benzoylhydrazides, producing the immobilized nitro derivatives (87). The nitro group in compound (87) was reduced by $\mathrm{SnCl}_{2}$ in refluxing DMF to produce compound (88) which was cyclized to the solid-supported benzotriazine (89) in hot acetic acid. This reaction was followed by detachment from the solid support to afford the desired 1,2,4-benzotriazines (90) in good yields. In addition, the synthesis of 1,2,4- 
benzotriazines derived from amino acids increased the versatility of the reaction sequence and opened the possibility of preparing large libraries of biologically promising compounds (Scheme 14). ${ }^{58}$
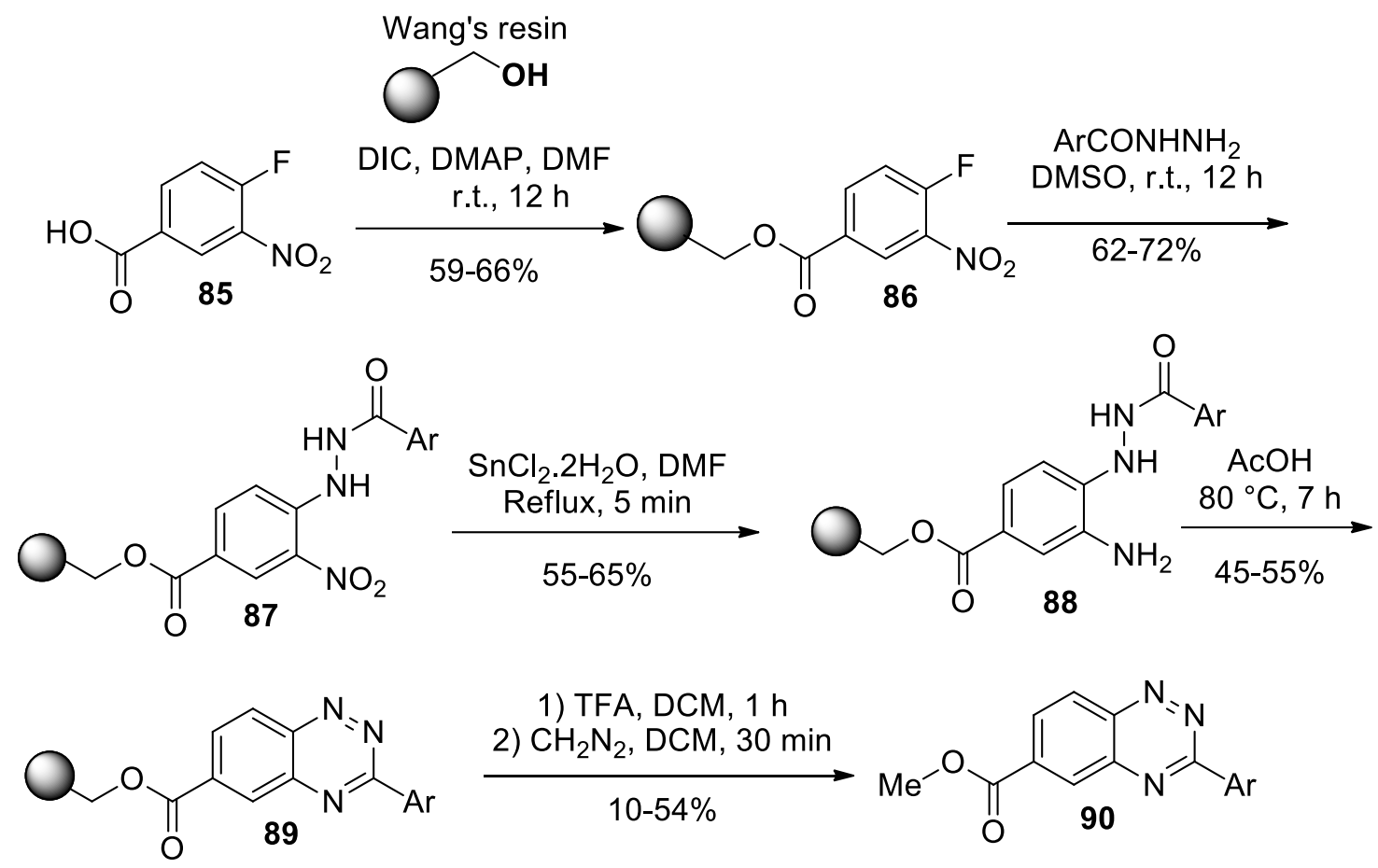

1) TFA, DCM, $1 \mathrm{~h}$ 2) $\mathrm{CH}_{2} \mathrm{~N}_{2}, \mathrm{DCM}, 30 \mathrm{~min}$ $10-54 \%$<smiles>COC(=O)c1ccc2nnc(Br)nc2c1</smiles>

$\mathrm{Ar}=4-\mathrm{ClC}_{6} \mathrm{H}_{4}, 2-\mathrm{FC}_{6} \mathrm{H}_{4}, 2-\mathrm{ClC}_{6} \mathrm{H}_{4}, 3-\mathrm{OMeC}_{6} \mathrm{H}_{4}, 4-\mathrm{FC}_{6} \mathrm{H}_{4}, 4-\mathrm{OMeC}_{6} \mathrm{H}_{4}, \mathrm{CH}_{2} \mathrm{C}_{6} \mathrm{H}_{5}, 4-\mathrm{NMe}_{2} \mathrm{C}_{6} \mathrm{H}_{4}, \mathrm{Py}-3-\mathrm{yl}$

Scheme 14. Solid-phase-based synthesis of 1,2,4-benzotriazines (90).

By treating cyclohexane-1,2-dione (91) with amidrazones (92), the 3-substituted 5,6,7,8-tetrahydro-1,2,4benzotriazines (93) were obtained. The latter were treated with sulfuryl chloride to give 5,5,8,8-tetrachloro5,6,7,8-tetrahydro-1,2,4-benzotriazines (94) which then were readily dehydrochlorinated, and 3-substituted5,8-dichloro-1,2,4-benzotriazines (95) were produced in fairly good yields. The reactions of 1,2,4benzotriazines (95) with dienophiles was examined under Diels-Alder conditions. When the compound (95) was heated with norbornadiene (96) in $p$-cymene as solvent under reflux, ethyl 5,8-dichloroquinoline-2carboxylate (97) was produced in 55\% yield. The presence of chloro substituents at the 5 and 8 position enhanced the efficiency of this intramolecular ring-transformation. For example, the ester group of (95) was hydrolyzed and the acid treated with propargyl bromide (98) and alkali to furnish the ester (99). The latter was heated in mesitylene to cyclize to form the lactone (100) (Scheme 15). ${ }^{59}$ 

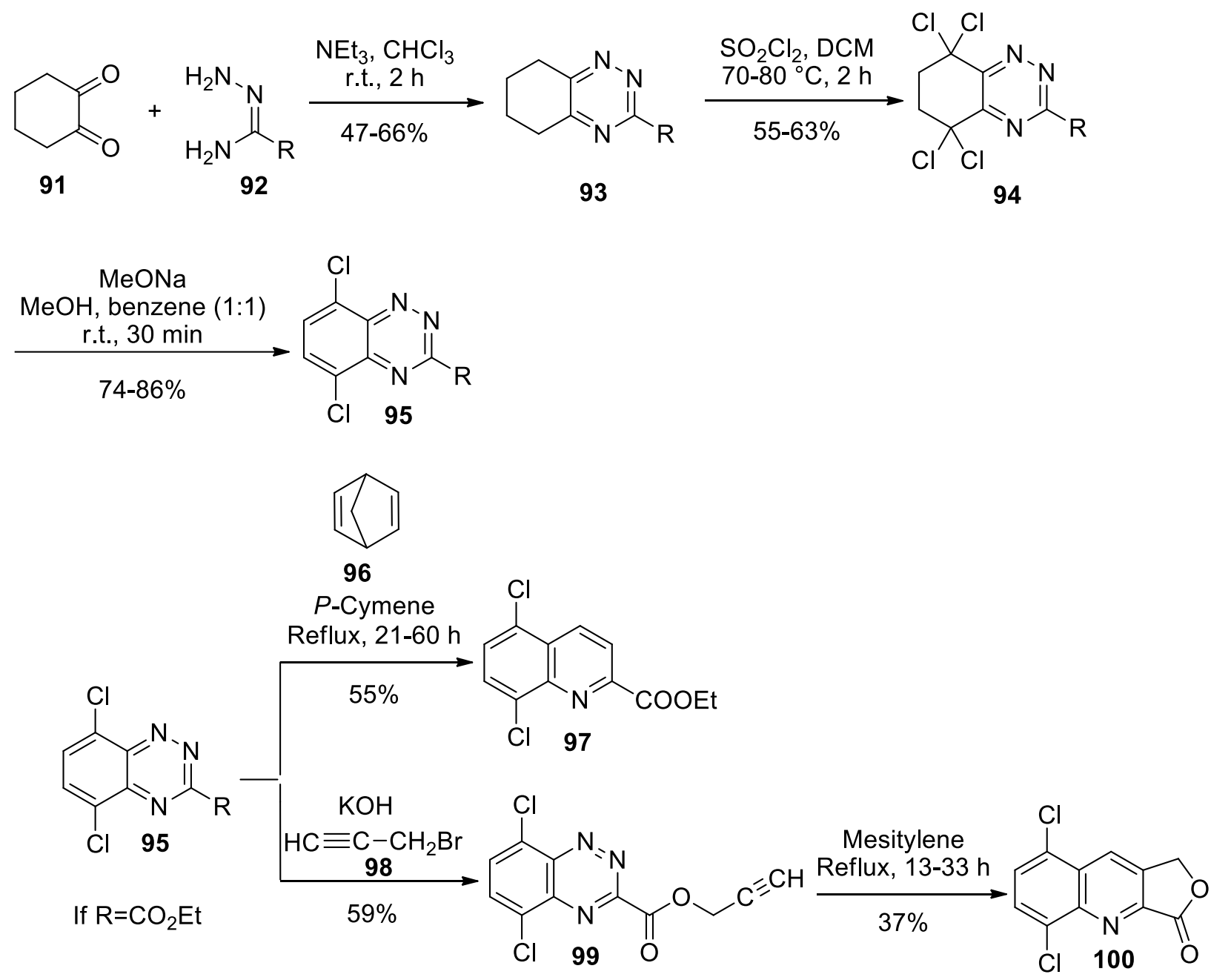

$\mathrm{R}=\mathrm{H}, \mathrm{Ph}, \mathrm{SMe}, \mathrm{SO}_{2} \mathrm{Me}, \mathrm{CO}_{2} \mathrm{Et}$

Scheme 15. Preparation of 5,8-dichloro-1,2,4-benzotriazines (95) and reaction with norbornadiene (96) and cyclization of the propargyl ester (99).

5,7-Di-t-butyl-3-(3-nitrophenyl)1,2,4-benzotriazine (103) was obtained in 59\% yield by treating 3,5-di-tbutylbenzoquinone (101) with the amidrazone (102) (Scheme 16). ${ }^{60}$

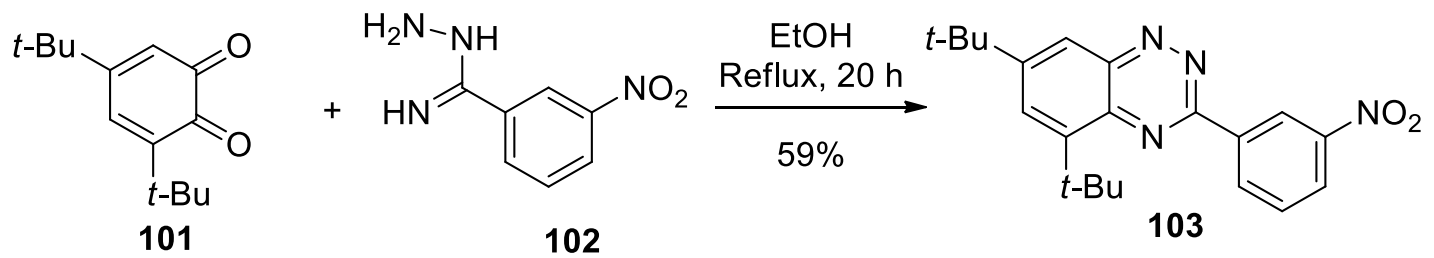

Scheme 16. Synthesis of 5,7-di-t-butyl-3-(3-nitrophenyl)1,2,4-benzotriazine (103).

\subsection{3-Aroyl-1,2,4-benzotriazines}

Abdelhamid and Al-Hamidi found that dihydrotriazines (106) were synthesized through the reaction of $N$ - 
hydroxyamidoyl chlorides (104) and 1,2-benzenediamine (105). These dihydrotriazines (106) were oxidized to the benzotriazines (107) using hydrogen peroxide in acetic acid (Scheme 17). ${ }^{61}$<smiles>Nc1ccccc1N</smiles>

Ar= 1-Naphthyl, 2-Naphthyl

Scheme 17. Synthesis of 3-naphthoyl-1,2,4-benzotriazines (107).

\subsection{1,2,4-Benzotriazine-3-thiones}

The 0 -(alkylazo)phenyldiazonium salt (109) was synthesized directly from the reaction of azoaniline (108) with nitrosonium tetrafluoroborate. The o-(alkylazo)phenyldiazonium salt (109) gave isothiocyanate (111) in acetonitrile in the presence of an excess of $\mathrm{NaSCN}$ under mild conditions. Interestingly, the formation of isothiocyanate (111) resulted from the attack of thiocyanate anion onto the carbon bridgehead of 2alkylbenzotetrazinium salts (110), followed by the elimination of dinitrogen. Next, isothiocyanates (111) was converted into the benzotriazinethiones (112) upon ring closure (Scheme 18). ${ }^{62}$
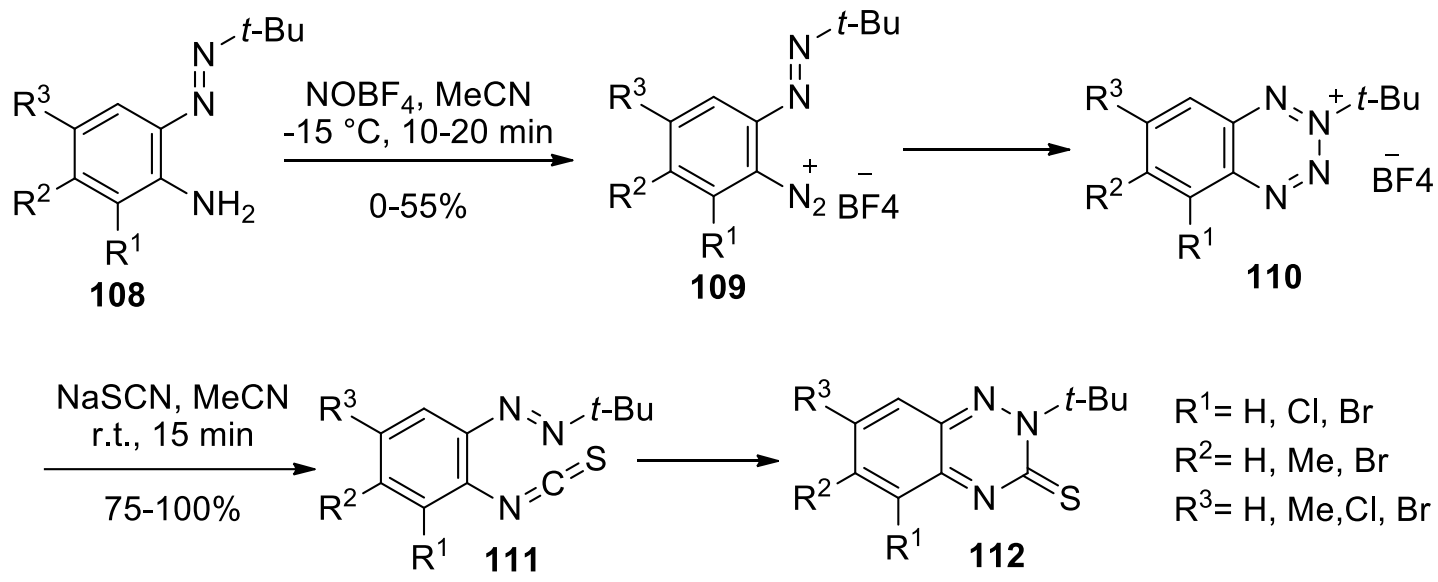

Scheme 18. Synthesis and tautomeric transformations of 2-(t-butyl)-1,2,4-benzotriazine-3(2H)-thiones (112).

It has been reported that 1,2-benzenediamines (113) react with thiosemicarbazide (114) under basic conditions to form dihydro-1,2,4-benzotriazine-3-thiones (116). ${ }^{63}$ However, this was refuted, both by Bakavoli et al. $^{64}$ and the El Ashry group experimentally, ${ }^{65}$ as well as by Siadati on theoretical grounds. The former groups identified the product as benzimidazoline-2-thione (115), a conclusion supported by the calculations of Siadati (Scheme 19). ${ }^{66}$ 
<smiles>[R]c1cc2c(cc1[R])NC(=S)NN2</smiles><smiles>[R]c1cc(N)c([NH3+])cc1[R]</smiles><smiles>NNC(N)=S</smiles><smiles>[R]c1cc2[nH]c(=S)[nH]c2cc1[R]</smiles>

$$
\mathrm{R}^{1}, \mathrm{R}^{2}=\mathrm{H}, \mathrm{Me}
$$

Scheme 19. Reaction of 1,2-benzenediamine (113) with thiosemicarbazide (114).

\subsection{3-(1-Iminoalkyl)-1,2,4-benzotriazines}

In research by Mann and coworkers, substituted 1,2,4-benzotriazine-3-acetates (121) were synthesized in three steps. First, the starting materials ethyl 3-amino-3-ethoxyacrylate (117) and 2-nitrophenylhydrazines (118) reacted to produce ethyl 3-[2-(2-nitrophenyl)hydrazono]propanoates (120) by elimination of ethanol or ammonia in the presence of triethylamine. The reaction proceeded through the intermediate ethyl 3-amino-3ethoxy-3-[2-(2-nitrophenyl)hydrazinyl]propanoates (119). Subsequently, compounds (120) were cyclized to compounds (121) in the presence of platinum oxide. The latter were reacted with aniline (122) to afford 1,2,4benzotriazine-3-yl acetanilides (123). Finally, the yellow 2-(1,2,4-benzotriazin-3-yl)-2-[4-(diethylamino)phenylimino]- $N$-phenylacetamides (125) were produced through the condensation reaction of 2-(1,2,4-benzotriazin3-yl)acetanilides (123) with N,N-diethyl-4-nitrosoaniline (124) (Scheme 20). ${ }^{67}$

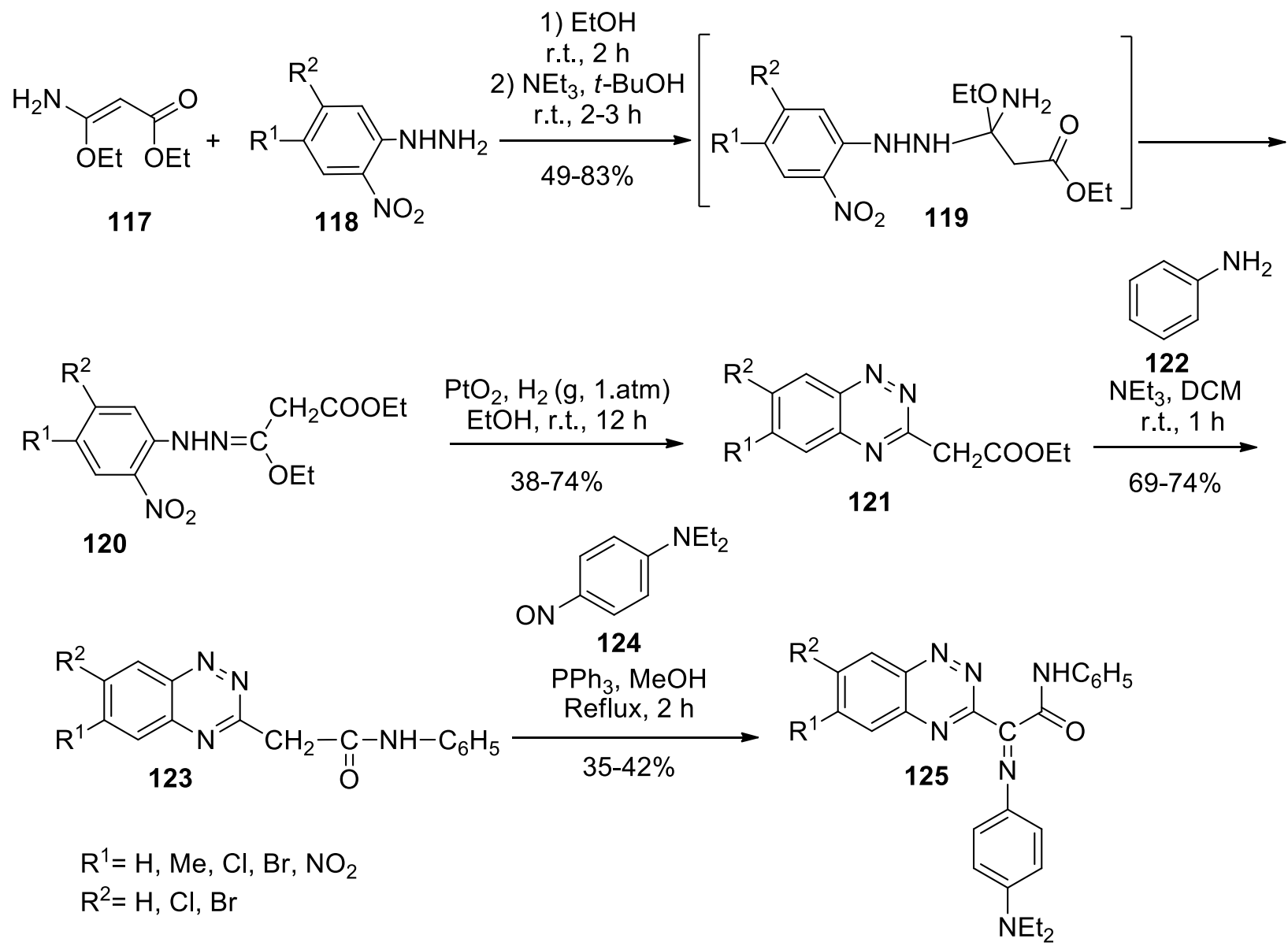

Scheme 20. Synthesis of 3-(1-iminoalkyl)-1,2,4-benzotriazines (125). 


\subsection{3-Spiro-1,2,4-benzotriazines}

Cyclohexane-3-spiro-3,4-dihydro-1,2,4-benzotriazine (129) was prepared directly by the reduction of 2nitrophenylhydrazone (126), intramolecular cyclization of compound (127), and subsequent oxidation of the intermediate tetrahydrobenzotriazine (128) (Scheme 21). ${ }^{68}$
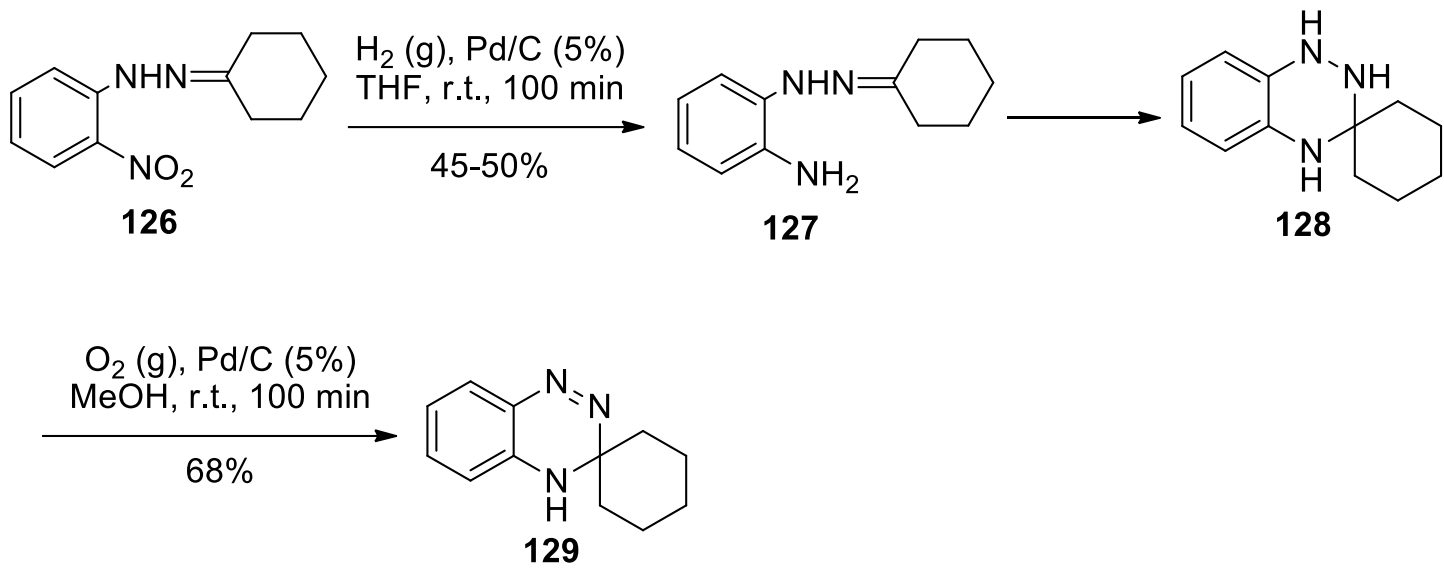

Scheme 21. The synthetic rout of 3-spiro-3,4-dihydro-1,2,4-benzotriazine (129).

Sparatore and Novelli synthesized spiro-(3,4-dihydro-1,2,4-benzotriazine-3,4'-(1'-substituted)piperidines) (134). The reaction of piperidine-4-ones (130) with 2-nitrophenylhydrazines (131) gave intermediates (132). Then, the nitro group of compound (132) was reduced in the presence of palladium on carbon to give the intermediate (133) which subsequently afforded the target compounds (134) by ring closure through the nucleophilic addition of the amino group to the double bond followed by oxidation of the intermediate tetrahydrobenzotriazine (Scheme 22). ${ }^{69}$<smiles>[R]c1ccc(NN)c([N+](=O)[O-])c1</smiles>

1) $\mathrm{H}_{2}(\mathrm{~g}), \mathrm{Pd} / \mathrm{C}(5 \%)$

2) Air (1 atm.)

$\underset{\text { THF, r.t., } 100 \mathrm{~min}}{\longrightarrow}$

$47-52 \%$

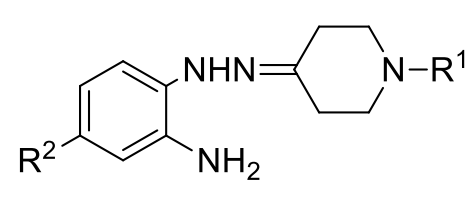

$\mathrm{O}_{2}(\mathrm{~g}), \mathrm{Pd} / \mathrm{C}(5 \%)$

133

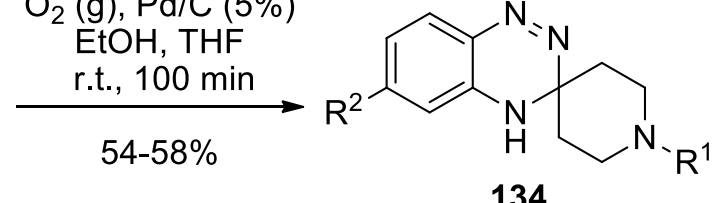

$\mathrm{R}^{1}=\left(\mathrm{CH}_{2}\right)_{2} \mathrm{C}_{6} \mathrm{H}_{4},\left(\mathrm{CH}_{2}\right)_{3} \mathrm{CO}-4-\mathrm{FC}_{6} \mathrm{H}_{4}$

$\mathrm{R}^{2}=\mathrm{H}, \mathrm{OMe} \mathrm{CF}_{3}, \mathrm{Cl}$

Scheme 22. Preparation of spiro-1,2,4-benzotriazine-substituted piperidines (134).

Spiro-1,2,4-benzotriazine-3(4H)-4'-(1'-substituted)-piperidines (135) were prepared through the oxidative cyclisation of 2-aminophenylhydrazones $\mathrm{N}$-substituted with piperidones and similar cyclic or open chain aminoketones (136) which in turn were commonly obtained by catalytic hydrogenation of the corresponding 2-nitrophenylhydrazones (135). Finally, the 1,2,3,4-tetrahydro-1,2,4-benzotriazine (137) was oxidized under air 
atmosphere to afford spiro-1,2,4-benzotriazine-3(4H),4'-(1'-substituted)-piperidines (138) (Scheme 23). Results of binding assays to sigma receptors showed that the derivatives of compound (138) exhibited good affinity for the $\sigma_{1}$ receptor subtype which is particularly concentrated in certain regions of the central nervous system, indicating an arylalkyl substituent on the basic nitrogen is necessary to have good affinity for the relevant subtype. ${ }^{70}$
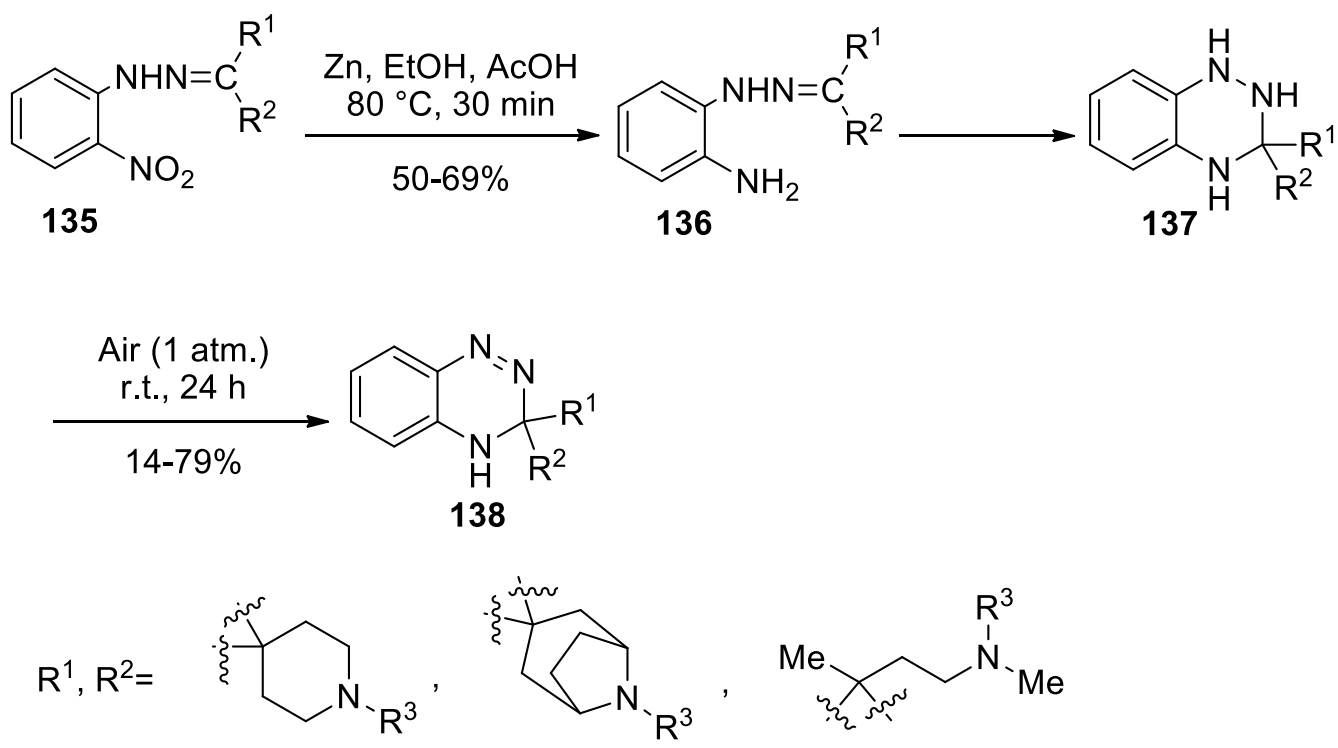

$\mathrm{R}^{3}=\mathrm{Me}, \mathrm{Bn}, \mathrm{CH}_{2} \mathrm{C}_{6} \mathrm{H}_{4} \mathrm{~F}, \mathrm{CH}_{2} \mathrm{C}_{6} \mathrm{H}_{4} \mathrm{Cl}, \mathrm{CH}_{2} \mathrm{C}_{6} \mathrm{H}_{4} \mathrm{Me}, \mathrm{CH}_{2} \mathrm{C}_{6} \mathrm{H}_{4} \mathrm{OMe},\left(\mathrm{CH}_{2}\right)_{2} \mathrm{Ph},\left(\mathrm{CH}_{2}\right)_{4} \mathrm{Ph},\left(\mathrm{CH}_{2}\right)_{5} \mathrm{Ph}$, $\left(\mathrm{CH}_{2}\right)_{3} \mathrm{COPh},\left(\mathrm{CH}_{2}\right)_{3} \mathrm{COC}_{6} \mathrm{H}_{4} \mathrm{~F}$

Scheme 23. The synthetic route for the preparation of spiro-1,2,4-benzotriazine-substituted piperidines (138).

\subsection{Bis-1,2,4-benzotriazines}

The reaction of 1,2-dianisidine (139) with $N$-arylhydrazono chloroacetate (140) in the presence of two equivalents of sodium ethoxide in refluxing ethanol afforded the symmetrical bis-adducts (144) passing from the intermediate (141). Bis-1,2,4-benzotriazines (144) have significant antibacterial activities. To account for the formation of (142) from reaction of (139) with (140), the mechanism suggested that the reaction proceeded through the initial formation of the respective intermediate (141) followed by in situ cyclization with concurrent elimination of water molecules to give the product (142). This is most likely a redox reaction through the $o$-quinone or $p$-quinoid oxidation stage, presumably oxidative ipso-attack on the carbon carrying the methoxy group, elimination of methanol and subsequent reduction to restore the initial oxidation stage. Consequently, the reaction of compound (142) with (140) led to the formation of intermediate (143), where hydrolysis of one of the methoxy groups occurred, followed by in situ cyclization under elimination of water to give the symmetrical bis-adducts (144) (Scheme 24). ${ }^{71}$ 

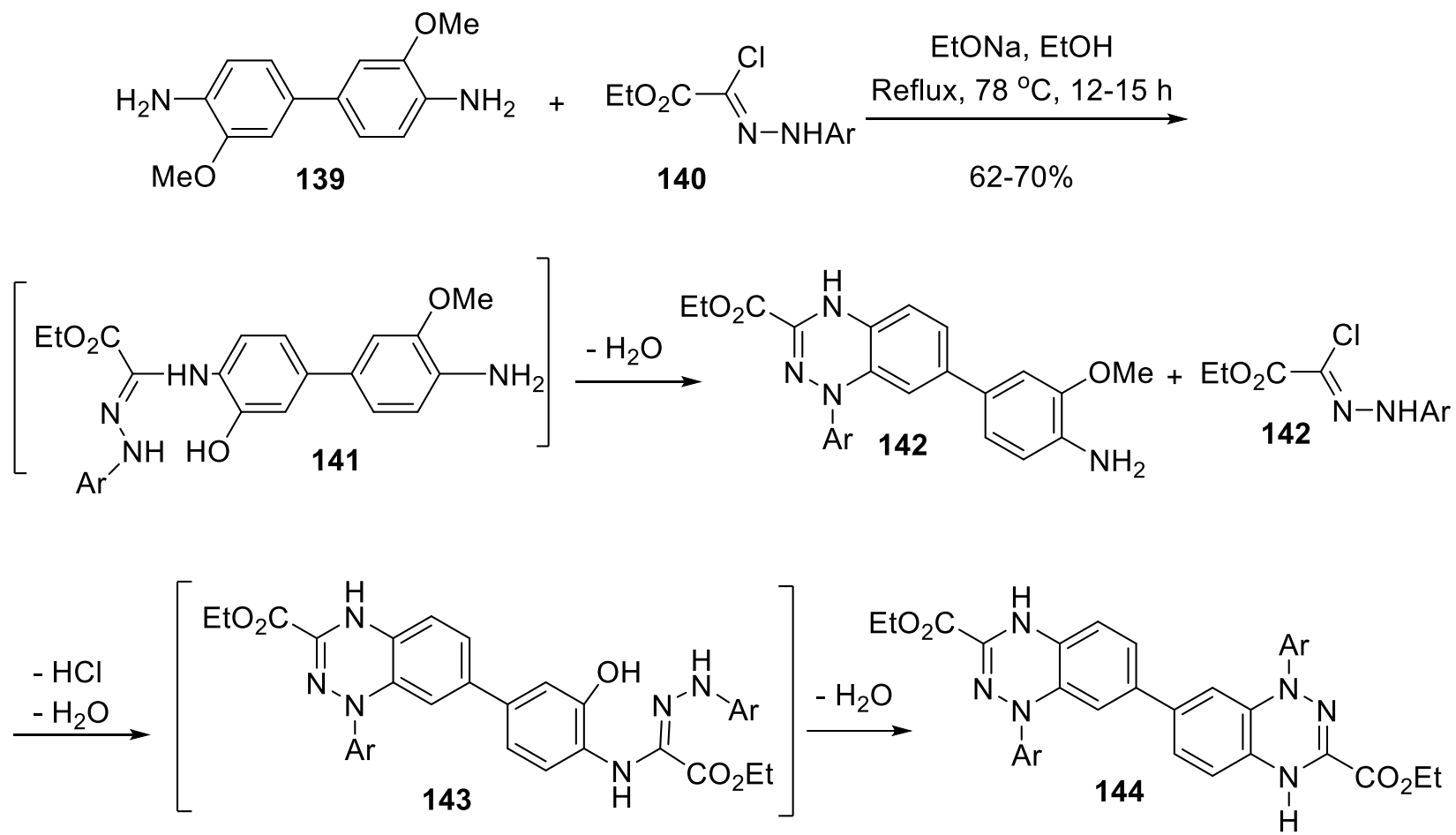

$\mathrm{Ar}=\mathrm{Ph}, 4-\mathrm{MeC}_{6} \mathrm{H}_{4}, 4-\mathrm{ClC}_{6} \mathrm{H}_{4}, 4-\mathrm{NO}_{2} \mathrm{C}_{6} \mathrm{H}_{4}$

Scheme 24. Reaction of o-dianisidine (139) with hydrazonoyl chlorides (140).

The effect of chloro and bromo substitutions at the 4-position of the pyridine ring of 6,6 '-bis $(5,5,8,8$ tetramethyl-5,6,7,8-tetrahydrobenzo[e][1,2,4]triazin-3-yl)-2,2'-bipyridine (CyMe4-BTBP) were studied with regard to the extraction of $\mathrm{Am}$ (III) from $\mathrm{Eu}(\mathrm{III})$ and $\mathrm{Cm}$ (III). The CyMe4-BTBP ligands (157) were synthesized through mono-oxidation of 2,2'-bipyridine (145) with $m$-chloroperbenzoic acid ( $m$-CPBA) in dichloromethane (DCM) which afforded 2,2'-bipyrdine 1-oxide. First, the product was nitrated to 4-nitro-2,2'-bipyridine 1-oxide (147) and further oxidation with $m$-CPBA gave the corresponding bis- $N$-oxide. In the case of BrCyMe4-BTBP (157), the nitro group was substituted by bromine using acetyl bromide in acetic acid followed by oxidation with $m$-CPBA to afford 4-bromo-2,2'-bipyridine 1,1'-dioxide. The bis- $N$-oxide (151) was converted into the biscarbonitrile by a Reissert-Henze reaction ${ }^{72}$ with trimethylsilyl cyanide and benzoyl bromide in DCM. When the same procedure was applied to 4-nitro-2,2'-bipyridine 1,1'-dioxide (150) using trimethylsilyl cyanide and benzoyl chloride in DCM, the dicarbonitrile (154) was obtained in addition to the nucleophilic substitution of the nitro group with the chloride ion. The dicarbonitriles (154) were then treated with hydrazine hydrate in DMF to generate the bis-amidrazones (155) in $91 \%$ and $74 \%$ yield, respectively. Finally, the condensation of compound (155) with tetramethylcyclohexane-1,2-dione (156) furnished the modified CyMe4-BTBP ligands (157) (Scheme 25). ${ }^{73}$ 

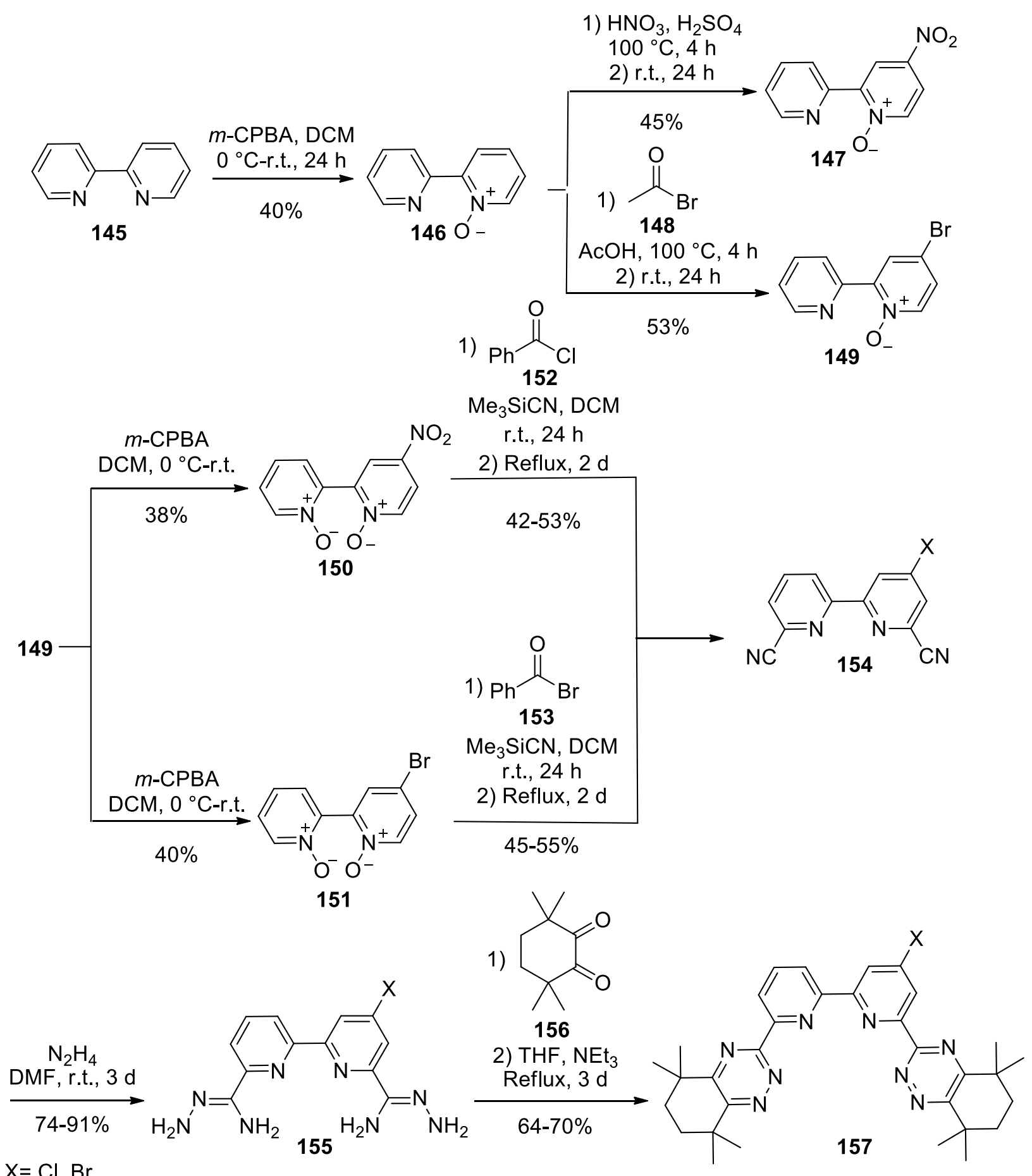

Scheme 25. Synthesis of Cl-CyMe4-BTBP and Br-CyMe4-BTBP (157).

Two 6,6-bis-(1,2,4-triazin-3-yl)-2,2-bipyridine (BTBP) ligands, which contain additional alkyl groups on the pyridine rings, were synthesized. Then, the effects of additional alkyl substitution in the 4- and 4'-positions of the pyridine rings on their extraction properties with $\operatorname{Ln}(\mathrm{III})$ and $\mathrm{An}$ (III) cations in simulated nuclear waste solutions were studied. The 4,4-disubstituted BTBP ligands (159) were synthesized through oxidation of the 2,2-bipyridines (158) with hydrogen peroxide in acetic acid which afforded the bis- $N$-oxides (159). They were then converted into the dicarbonitriles $(\mathbf{1 6 0})$ by a Reissert-Henze reaction with trimethylsilyl cyanide and benzoyl chloride in DCM. The dicarbonitriles $(\mathbf{1 6 0})$ were treated with hydrazine hydrate in ethanol to generate 
the bis-amidrazones (161) in 81 and 79\% yield, respectively. Finally, the condensation of (161) with 3,3,6,6tetramethylcyclohexane-1,2-dione (156) furnished the 4,4-disubstituted BTBP ligands (162) (Scheme 26). ${ }^{74}$

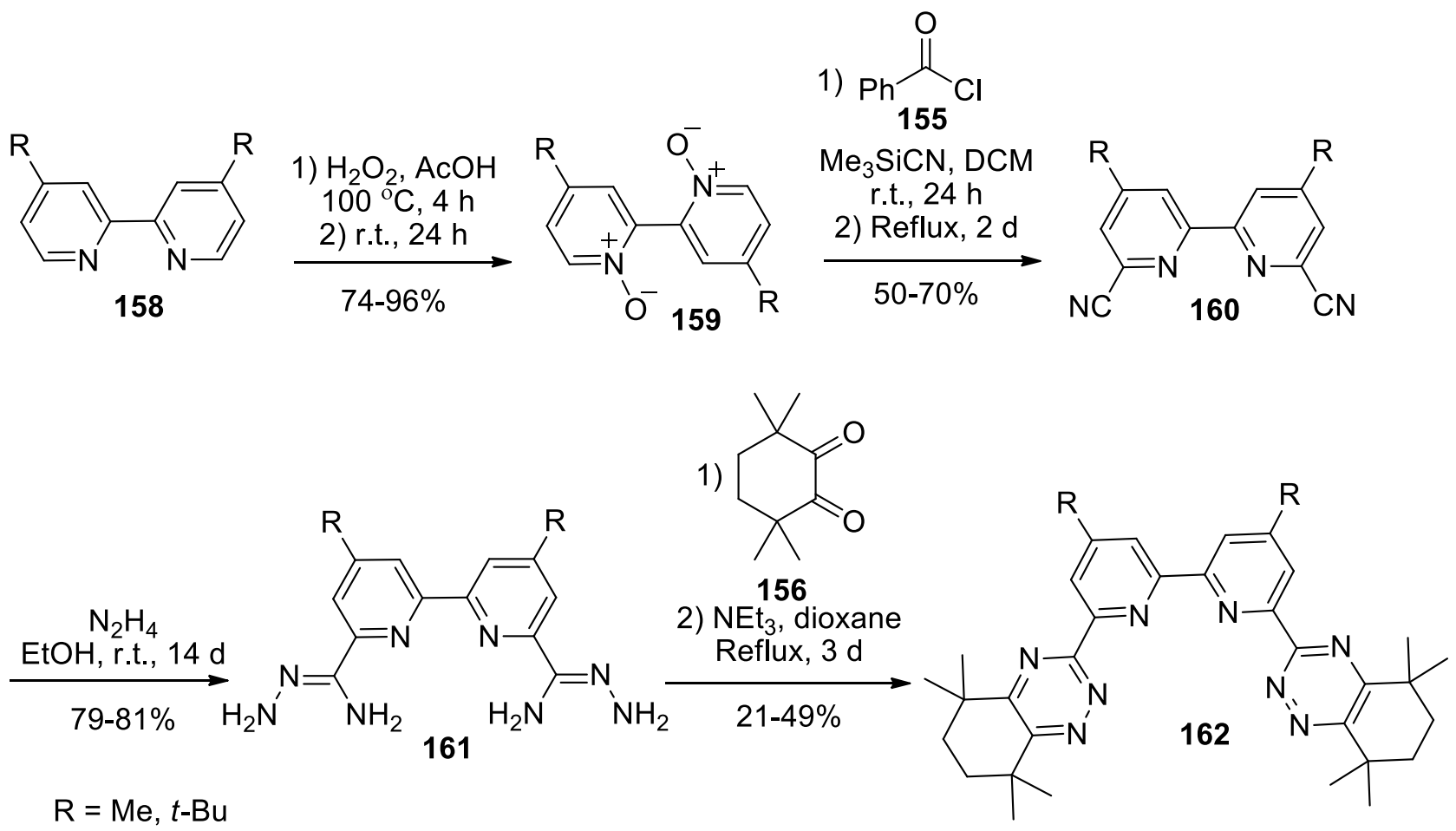

Scheme 26. Synthesis of 6,6'-bis-(5,5,8,8-tetramethyl-5,6,7,8-tetrahydrobenzo[e][1,2,4]triazin-3-yl)-2,2'bipyridines (162).

\section{1,2,4-Benzotriazine Fused to Five Membered Rings}

\subsection{Cyclopenta[f][1,2,4]benzotriazines}

The photodegradation of morpholine-substituted benzotriazine di- $N$-oxide (14) was explained as proceeding via the formation of an oxaziridine intermediate. The major product from the photolysis of compound (14) was 4-[3-(1-oxido-7,8-dihydro-6H-cyclopenta[f][1,2,4]benzotriazin-3-yl)propyl]morpholine 4-oxide (156) and the minor product was (158), without the $N$-oxide group on the morpholine residue. These can be formed via the oxaziridine intermediate (156) through oxygen transfer. The major product (157) can be obtained by intramolecular oxygen transfer from the oxaziridine (156) to the morpholine nitrogen through a six-membered cyclic transition state. A third product (159) was formed from the intermediate (156) by rearrangement with migration of the morpholinopropyl group from $\mathrm{C}$ to $\mathrm{N}$ (Scheme 27 ). ${ }^{75}$ 
<smiles>CC1(C)Cc2cc3c(cc2C1)[N+]([O-])=NC1(CCCN2CCOCC2)ON31</smiles>
14

163

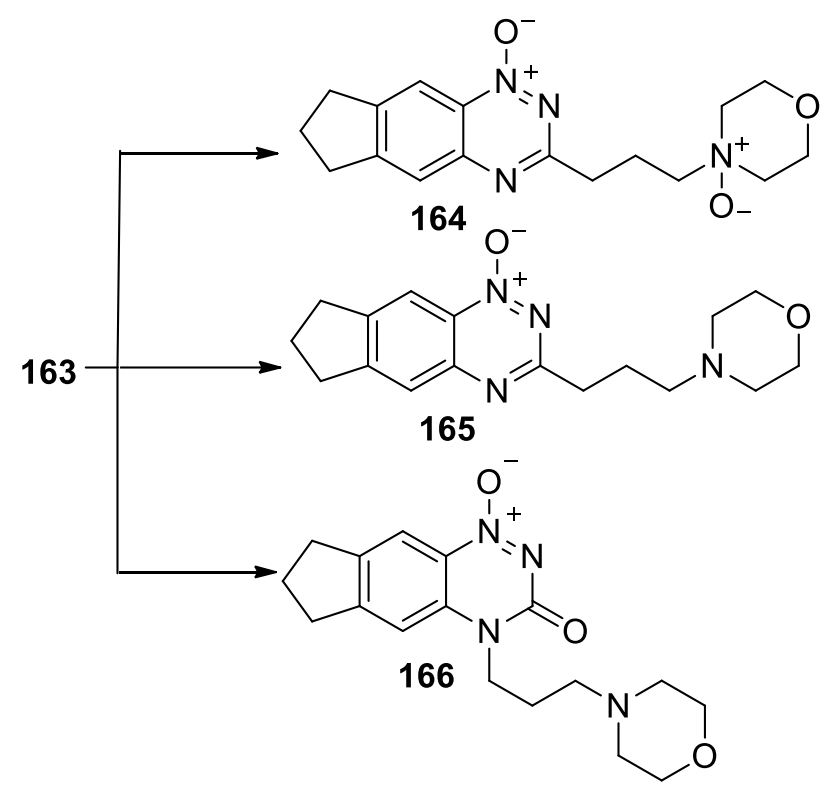

Scheme 27. Photodegradation of the morpholine substituted 1,2,4-benzotriazine di- $N$-oxides (14).

\subsection{Pyrrolo[2,1-c] $[1,2,4]$-benzotriazines}

Diazotization of $\mathrm{N}$-(2-aminophenyl)pyrrole (167) in an aqueous acidic medium was followed by intramolecular coupling; pyrrolo[2,1-c][1,2,4]benzotriazine (168) was produced. Heating compound (168) in aqueous permanganate solution formed the 1,2,4-triazine-3,5,6-tricarboxylic acid (169) which produced the furo[3,4-e]$[1,2,4]$ triazine-5,7-dione (170) upon dehydration and decarboxylation (Scheme 28). ${ }^{76}$

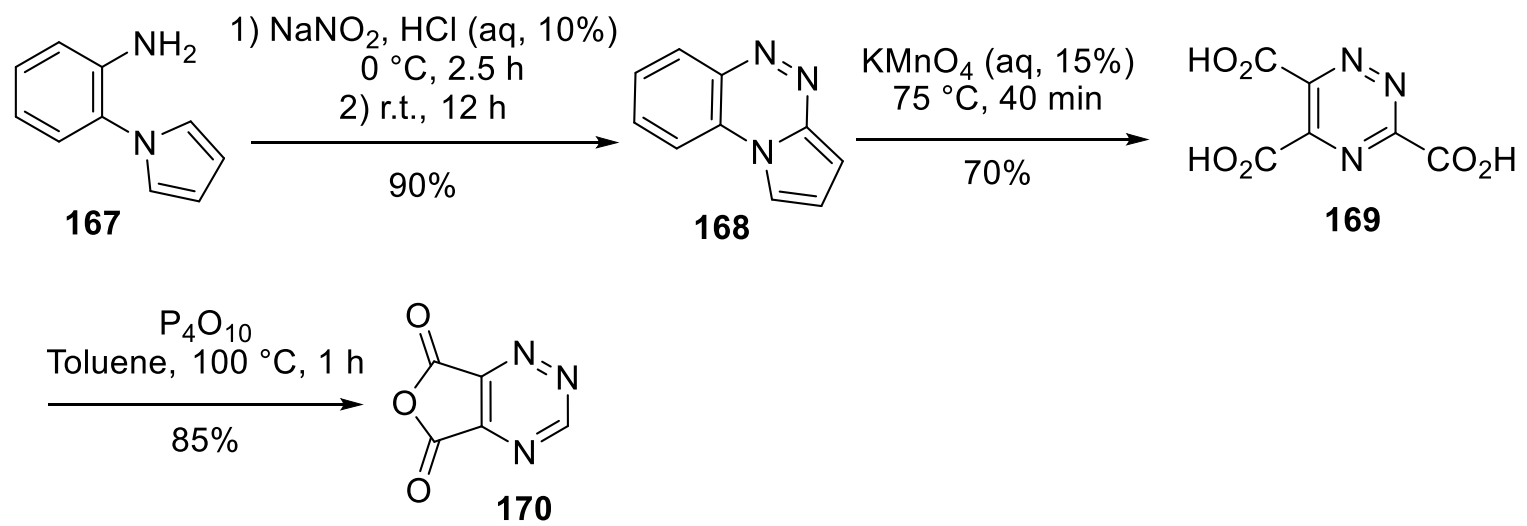

Scheme 28. Synthesis of the furo[3,4-e][1,2,4]triazine-5,7-dione (170).

Hajra and coworkers obtained a series of pyrrolo[2,1-c][1,2,4]benzotriazines (172) in 60-78\% yields through the intramolecular azo coupling of 2-(1-pyrrolyl)aniline (171) (Scheme 29). ${ }^{77}$ 
<smiles>NC1=C(n2cccc2)C=C[R]C=C1</smiles>

171

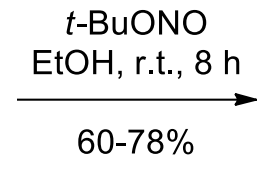<smiles>[R]1ccc2nnc3cccn3c2c1</smiles>

172

$\mathrm{R}=7-\mathrm{OMe}, 7-\mathrm{Cl}, 7-\mathrm{F}, 7-\mathrm{CO}_{2} \mathrm{Et}, 8-\mathrm{OMe}, 8-\mathrm{Cl}, 8-\mathrm{F}$

Scheme 29. Synthesis of pyrrolo[2,1-c][1,2,4]benzotriazines (172).

Cheeseman's research group investigated electrophilic substitution reactions in pyrrolo[2,1-c][1,2,4]benzotriazine (168). The 3-nitro derivative (173) was obtained using potassium nitrate in concentrated sulfuric acid. With concentrated sulfuric acid it afforded the 3-sulfonic acid (174). lodination of pyrrolobenzotriazine with bispyridineiodonium nitrate (175) in chloroform gave the 1-iodo derivative (176), and bromination with NBS in aqueous sulfuric acid produced mainly the 1-bromopyrrolobenzotriazine (177), but this (partially) rearranged to the 3-bromo-derivative (178) on refluxing with aqueous $\mathrm{HBr}$ (Scheme 30). ${ }^{78}$

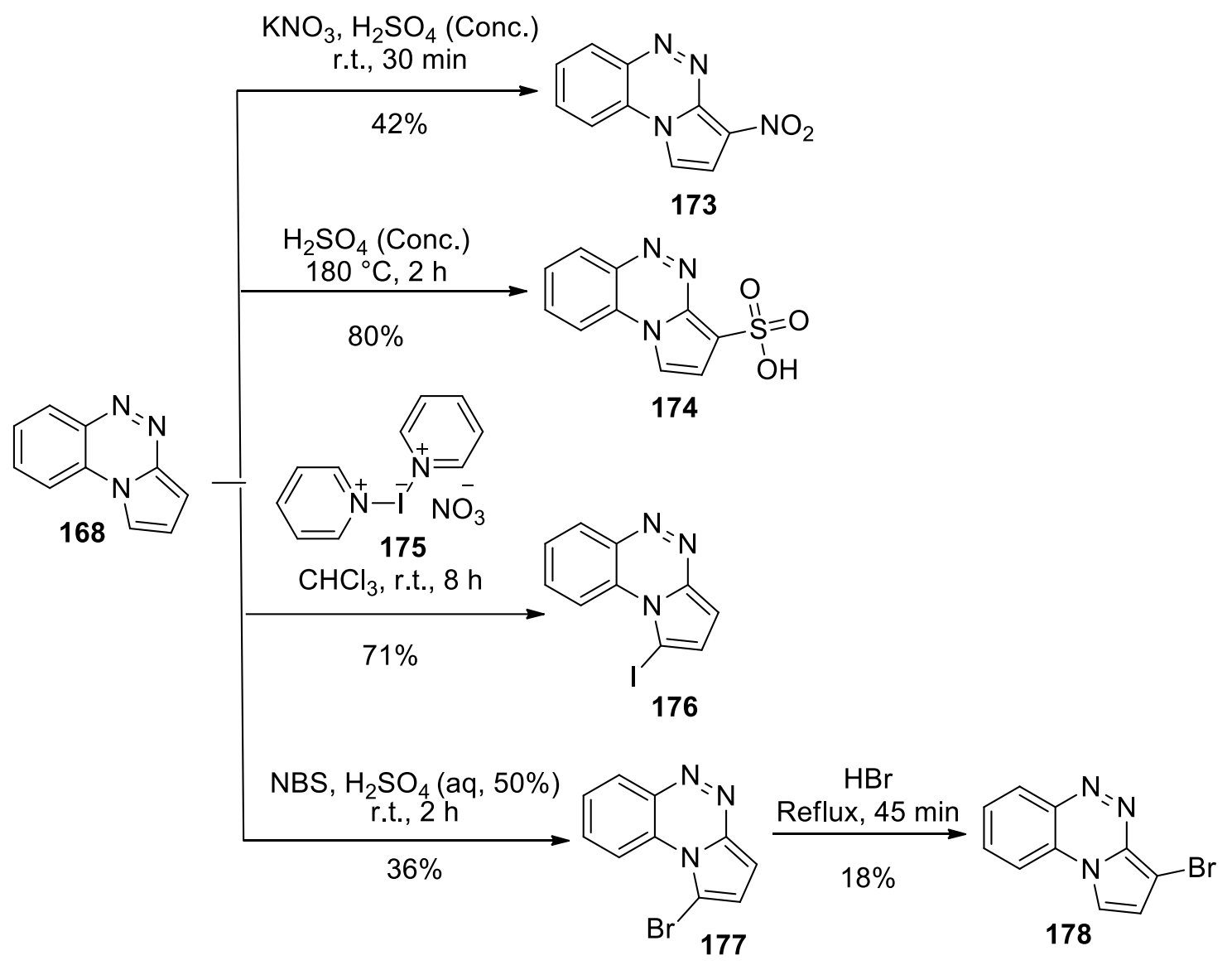

Scheme 30. Substitution reactions of pyrrolo[2,1-c][1,2,4]benzotriazine (168).

\subsection{Imidazo[l,2-c][1,2,4]benzotriazines}

Condensation of 3-amino-I,2,4-benzotriazine 1-oxide (179) with ethyl bromopyruvate (180) in THF at reflux in the presence of ethanol furnished the imidazo[l,2-c][l,2,4]benzotriazine-2-carboxylate 5-oxide (181), which can be reduced to the 5-deoxygenated analogue (Scheme 31). ${ }^{79}$ 
<smiles>Nc1nc2ccccc2[n+]([O-])n1</smiles>

179
1)<smiles></smiles>

2) $\mathrm{EtOH}$, reflux, 6-8 h

$60-70 \%$<smiles>CCOC(=O)c1cn2c(n1)n[n+]([O-])c1ccccc12</smiles>

Scheme 31. Synthesis of imidazo[I,2-c][1,2,4]benzotriazine-2-carboxylate 5-oxide (181).

\subsection{Pyrazolo[1,2-a][1,2,4]benzotriazines}

The chemical reactivity of the antiphlogistic azapropazones (182) was examined. These compounds comprise a 1,2,4-benzotriazine condensed to a 3,5-dioxopyrazolidine ring, which is readily attacked by many chemical reagents such as lithium aluminium hydride and hydrogen peroxide to form pyrazolobenzotriazin-3-ones (183) and 3-oxopropanoic acid derivatives (184), respectively. The reactions were carried out mostly on the 3,5dioxo-pyrazolidine ring and on the dimethylamino group $\left(\mathrm{R}^{2}=\mathrm{NMe}\right)$. The compounds $(\mathbf{1 8 4})$ were converted into compounds (185) in the presence of phosphorus pentoxide by loss of carbon dioxide (Scheme 32). ${ }^{80}$

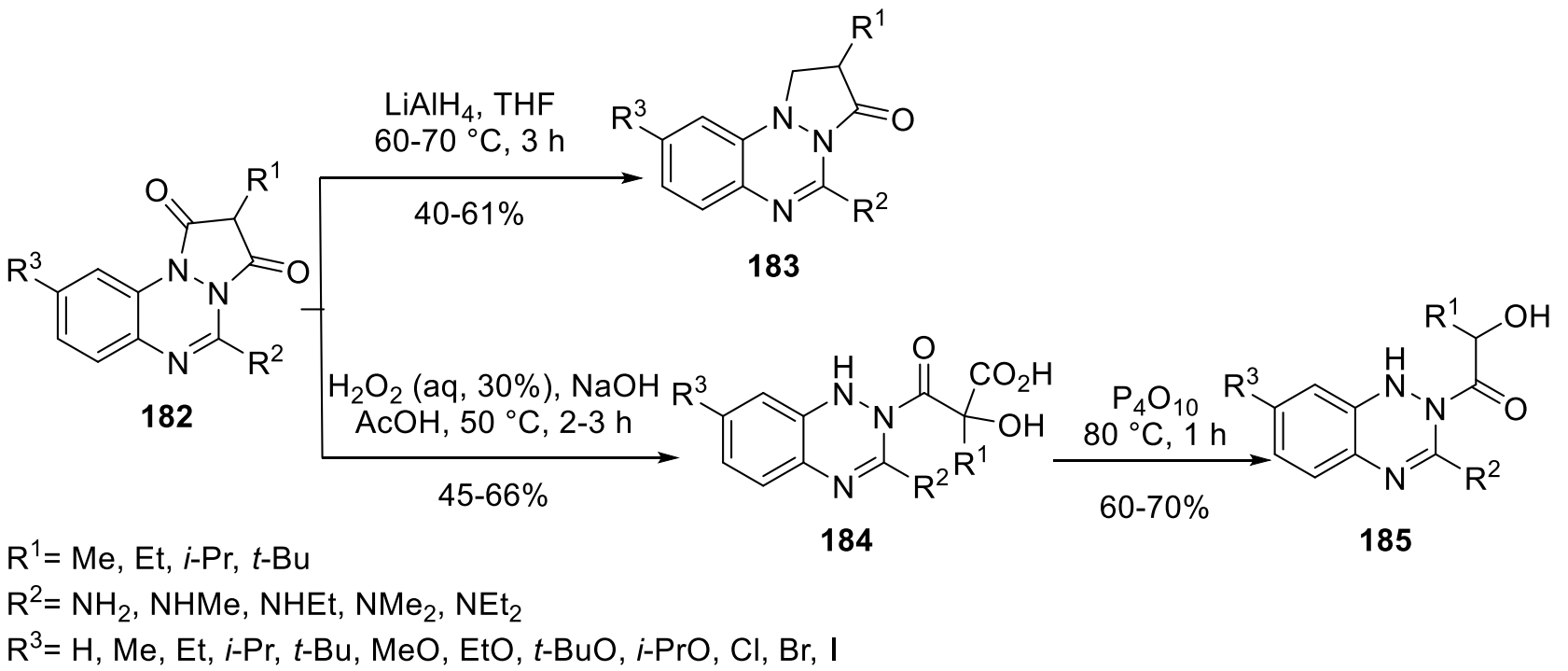

Scheme 32. Reactions of pyrazolo[1,2-a][1,2,4]benzotriazine-1,3-diones (182).

\subsection{Oxazolo $[2,3-c][1,2,4]$ benzotriazines}

$5 H$-2-Phenyloxazolo[2,3-c][1,2,4] benzotriazine (188) was prepared through the double alkylation of 1,2,4benzotriazine-2-thione (116) by methyl iodide and bromoacetophenone (186). The cyclization of 2-[3(methylthio)-1,2,4-benzotriazin-4(1H)-yl]-1-phenylethan-1-one (187) was carried out in refluxing isopropanol to produce the title compound (188) in $60 \%$ yield (Scheme 33$).{ }^{81}$ 


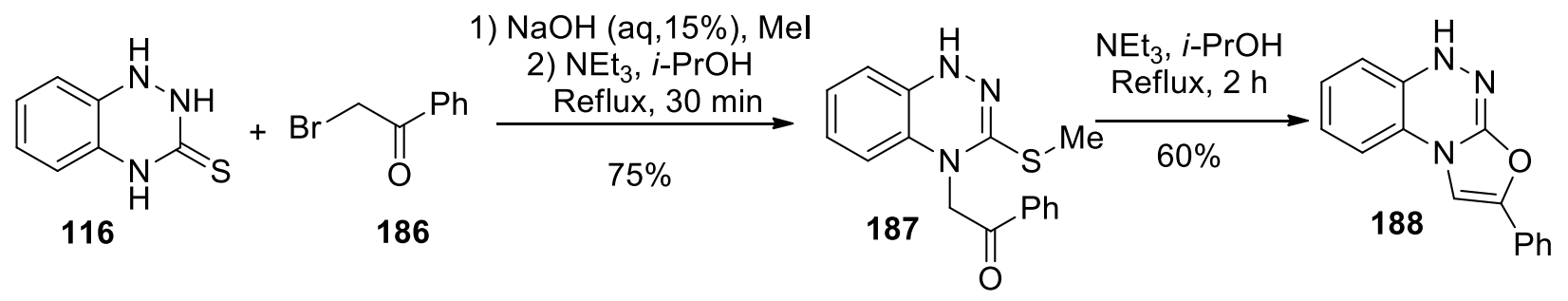

Scheme 33. Synthesis of oxazolo[2,3-c][1,2,4]benzotriazine (188).

\subsection{Thiazolo[1,2,4]benzotriazines}

Dihydro-1,2,4-benzotriazine-3-thione (116) reacted with propargyl bromide (98) in the presence of sodium methoxide to form the propargylthio-1,2,4-benzotriazine (189). Then the latter was refluxed with a catalytic amount of $\mathrm{Pd}\left[\mathrm{Cl}_{2}(\mathrm{PhCN})_{2}\right]$ in a mixture of acetonitrile and methanol to form 1-methylene-1,2-dihydro-5Hthiazolo[2,3-c][1,2,4]benzotriazine (190) through a hydroamination process (Scheme 34$).{ }^{82}$

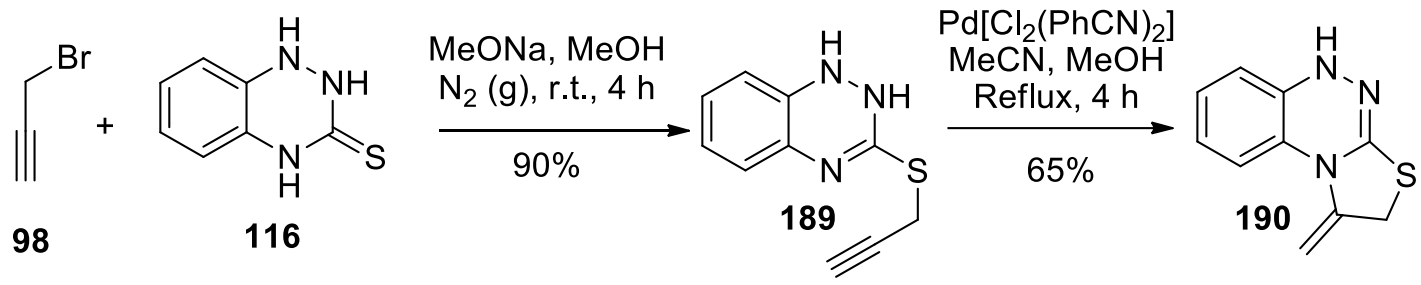

Scheme 34. Synthetic route to thiazolo[2,3-c][1,2,4]benzotriazines (190).

\subsection{Triazolo $[5,1-c][1,2,4]$ benzotriazines}

Compound (191) was reacted with an aryldiazonium salt which obtained from anilines (192) to form an intermediate which was promptly reacted with acetic anhydride in pyridine to give the triazolium hydroxide
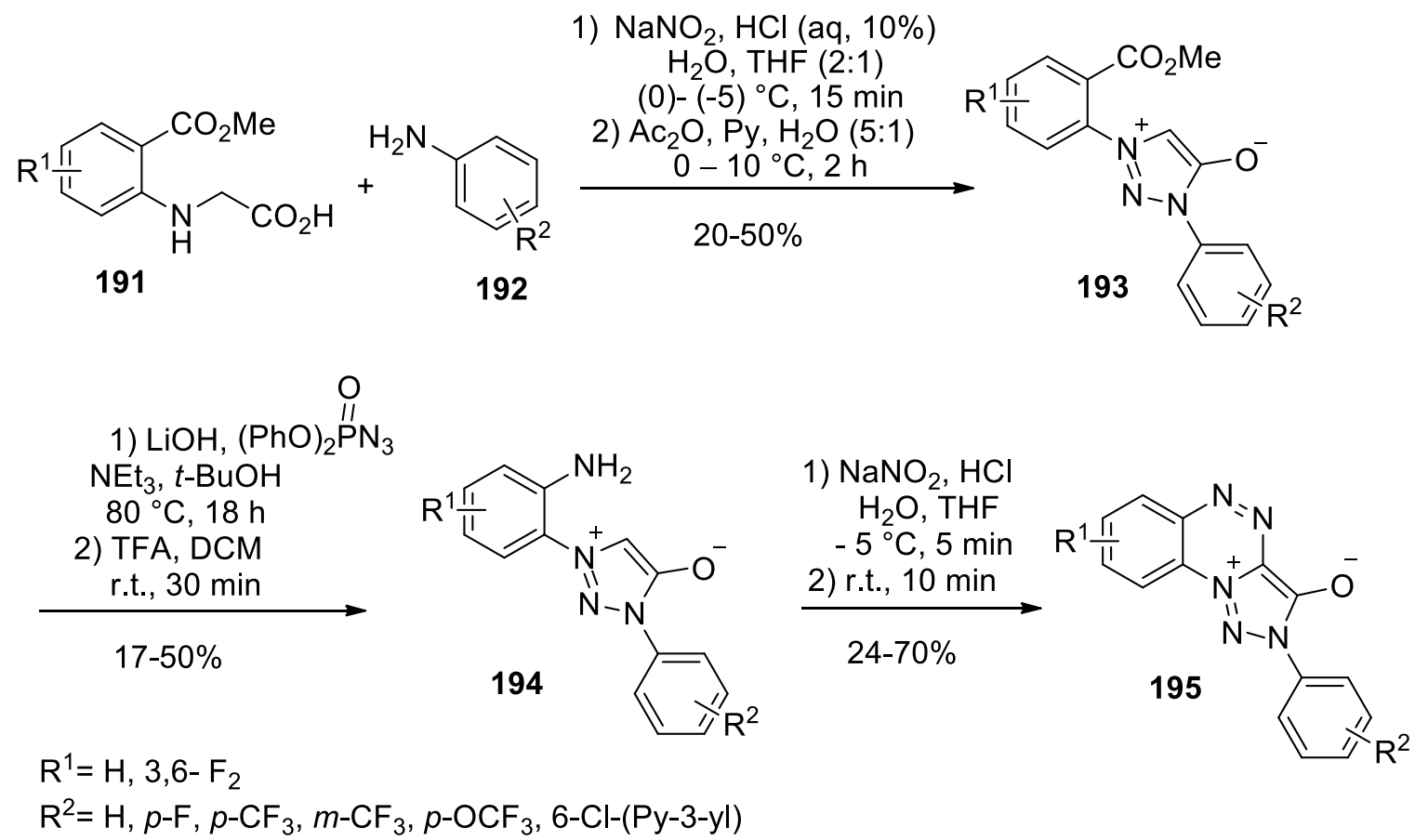

Scheme 35. Formation of the 1,2,3-triazolo[5,1-c][1,2,4]benzotriazinium system (195). 
betaines (193). By a Curtius rearrangement, ${ }^{83}$ the ester group of the latter was replaced by an amine in triazolium hydroxide (194). Diazotization of the amine resulted in cyclization to afford the 1,2,3-triazolo[5,1c]benzotriazinium hydroxide (195) (Scheme 35). ${ }^{84}$

A report by Hassan and coworkers demonstrated that $[1,2,4]$ triazolo[4,3-b][1,2,4]benzotriazines (198) could be prepared by cyclocondensation of triazoles (196) with 2-aminothiophenol (197) at reflux temperature in absolute ethanol (Scheme 36). ${ }^{85}$

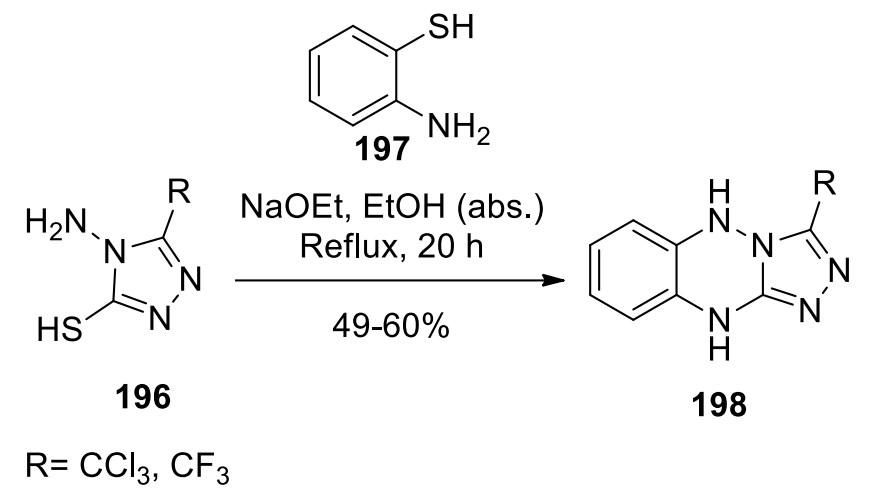

Scheme 36. Synthesis of 5,10-dihydro-[1,2,4]triazolo[4,3-b][1,2,4]benzotriazines (198).

In 1967, Tennant reported that the 1,2,4-benzotriazines (200) were produced upon treatment of 1,2,3triazolo[5,1-c][1,2,4]benzotriazine-5-oxides (199) with sodium dithionite in acetic acid. The oxides (199) were converted into the ketones (201) in the presence of chromic acid in acetic acid. A suggested intermediate in these reactions is the carbenium ion derived from the oxides (199) by cleavage of the triazole ring and loss of nitrogen from the diazonium cation (Scheme 37$).{ }^{86}$

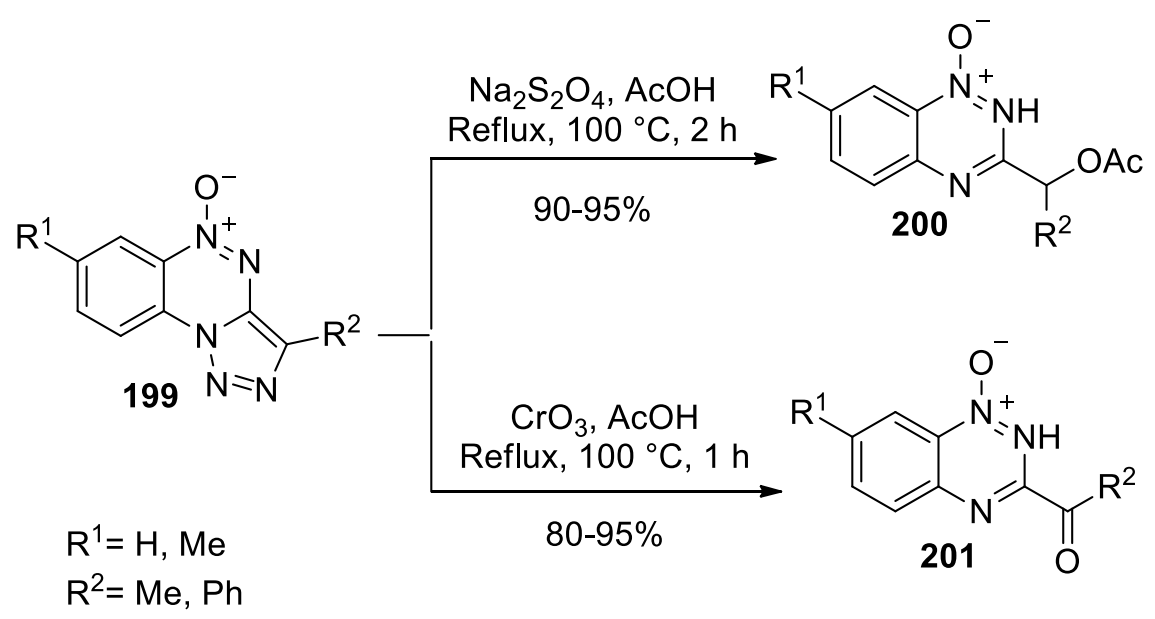

Scheme 37. Preparation of 1,2,4-benzotriazine 1-oxides (200) and conversion of 1,2,3-triazolo[5,1-c][1,2,4]benzotriazine 1-oxide (199).

\subsection{Indolo[2,1-c][1,2,4]benzotriazines}

$\mathrm{N}$-Arylindoles (204) were produced upon reaction of indoles (202) with 2-nitrophenyl halides (203) using cesium carbonate as the catalyst. The nitro group of 1-(2-nitrophenyl)- $1 H$-indoles (204) was then reduced to 
the amino group using stannous chloride. Finally, the corresponding indolo[2,1-c][1,2,4]benzotriazines (206) were obtained from (205) via an intramolecular cyclization in the presence of $t$-butyl nitrite (Scheme 38). ${ }^{87}$
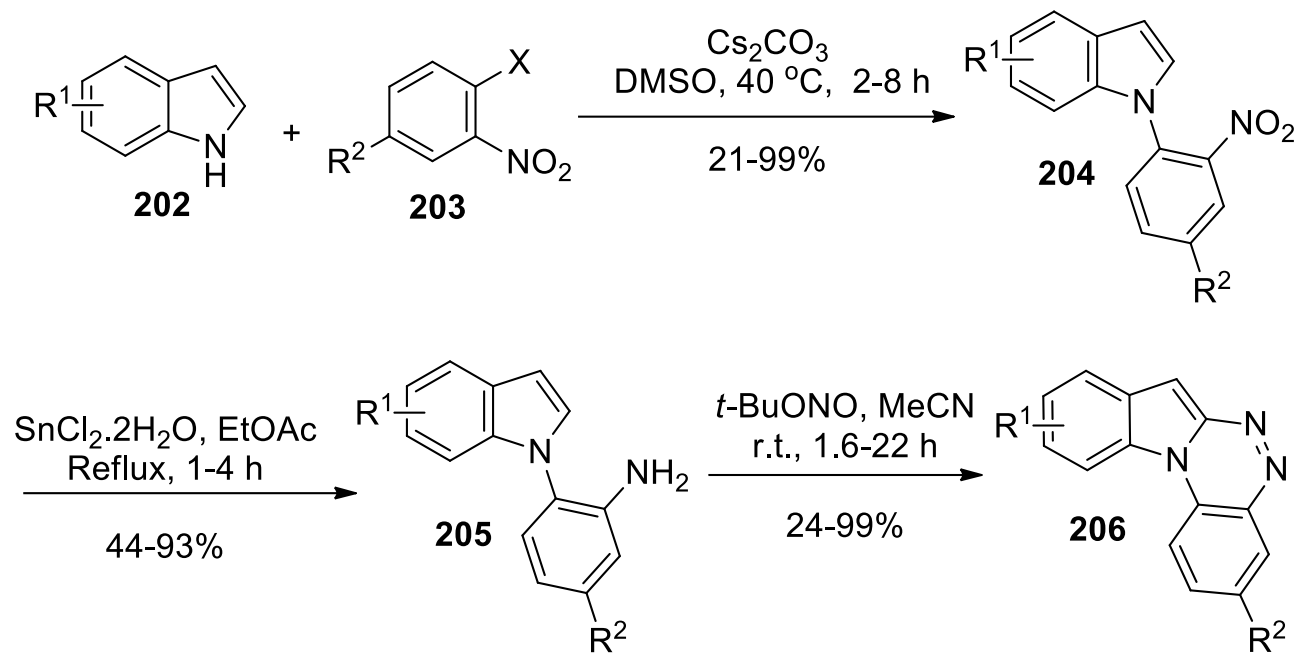

$\mathrm{R}^{1}=\mathrm{H}, 5-\mathrm{Br}, 5-\mathrm{OMe}$, 3-Me, 3-Br, 4-Me, 6-Me, 7-Me

$\mathrm{R}^{2}=\mathrm{H}, \quad \mathrm{C}-\mathrm{NHPh}$

$\mathrm{X}=\mathrm{F}, \mathrm{ClO}$

Scheme 38. The synthetic route for the preparation of indolo[2,1-c][1,2,4]benzotriazines (206).

Diana et al. found that a series of isoindolobenzotriazines of type (210) was obtained by diazotization of 2(2-aminoaryl)-1-cyanoisoindoles (209). 2-(2-Aminoaryl)-1-cyanoisoindoles (209) appeared valuable and versatile intermediates for the synthesis of the new ring system isoindolo[2,1-c]benzo[1,2,4]triazines (210). Derivatives (209) were prepared in good yield by a Strecker-type synthesis between substituted 0 phenylendiamines (207) and phthaloyldicarboxaldehyde (208) in the presence of potassium cyanide and sodium hydrogensulfite (Scheme 39). ${ }^{88}$<smiles>[R]c1c([R])c(N)c([R])c(N)c1[R]</smiles>

207

208

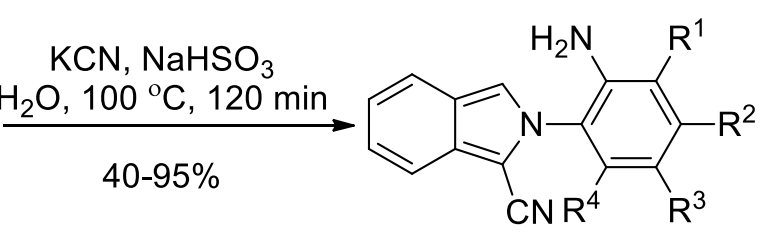

209<smiles>[R]c1c([R])c([R])c2c(nnc3c4ccc(CC(C(=O)O)C(=O)O)cc4c(C)n32)c1[R]</smiles>

$\mathrm{R}^{1}=\mathrm{H}, \mathrm{Me}, \mathrm{OMe}$

$\mathrm{R}^{2}=\mathrm{H}, \mathrm{Me}, \mathrm{OMe}, \mathrm{Cl}, \mathrm{CF}_{3}$

$\mathrm{R}^{3}=\mathrm{H}, \mathrm{Cl}, \mathrm{CF}_{3}$

$\mathrm{R}^{4}=\mathrm{H}, \mathrm{Me}$

Scheme 39. Synthesis of isoindolo[2,1-c]benzo[1,2,4]triazines (210). 


\section{9. $[1,2,4]$ Triazino $[5,6,1-j k]$ carbazol-6-one}

6-[(8-Bromooctyl)(methyl)amino]-8-iodo-1,3-diphenyl-1,2,4-benzotriazin-7(1H)-one (213) was prepared through the reaction of readily available 8-iodo-1,3-diphenyl-1,2,4-benzotriazin-7(1H)-one $(211)$, with aqueous methylamine and oxidation by air to give 8-iodo-6-(methylamino)-1,3-diphenyl-1,2,4-benzotriazin-7(1H)-one (212) followed by reaction with 1,8-dibromooctane. Afterwards, the desired 6-(\{[benzyl(methyl)amino]alkyl\}(methyl)amino)-1,3-diphenyl-1,2,4-benzotriazin-7(1H)-ones (214) were prepared via benzylmethylamination of bromoalkyl derivatives 6-[(bromoalkyl)(methyl)amino]-1,3-diphenyl-1,2,4-benzotriazin-7(1H)ones (213). Finally, to avoid protodeiodination during benzylmethylamination, the non oxidative Pd and $\mathrm{AgF}$ mediated cyclization was carried out to give 5-[N-(8-bromooctyl)- $N$-methylamino]-2-phenyl-6H-[1,2,4]triazino[5,6,1-jk]carbazol-6-one (215) in moderate yield. The triazafluoranthenone (215) readily underwent benzylmethylamination to give 5 - $\{N$-[8-( $N$-benzyl- $N$-methylamino)octyl]- $N$-methylamino $\}-2-$ phenyl- $6 H$ $[1,2,4]$ triazino[5,6,1-jk]carbazol-6-one (216) in 90\% yield (Scheme 40). The heterocyclic scaffolds 1,3-diphenyl1,2,4-benzotriazin-7(1H)-ones (214) and 2-phenyl-6H-[1,2,4]triazino[5,6,1-jk]carbazol-6-ones (216), were explored for their multitarget-directed inhibition of beta-amyloid $(A \beta)$ fibrillization and acetyl- $(A C h E)$ and/or butyryl- $(B C h E)$ cholinesterase, three valuable targets for $A D$ therapy. In particular, the mentioned compounds displayed an interesting multiple activity and considerable $I C_{50}$ values on $A \beta$ aggregation, $A C h E$ and $B C h E$ inhibition. ${ }^{89}$


Scheme 40. Sytnhesis of triazafluoranthenones (216). 
Silver(I) fluoride (AgF)-mediated intramolecular nonoxidative and oxidative coupling palladium-catalyzed cyclizations of 1,3-diphenylbenzo[e][1,2,4]triazin-7(1H)-ones (208) and 8-iodo-1,3-diphenylbenzo[e][1,2,4]triazin-7(1H)-ones (207) afforded a new alkaloid like ring system, triazafluoranthenone, as present in the 2phenyl-6H-[1,2,4]triazino[5,6,1-jk]carbazol-6-ones (209). Furthermore, these cyclization protocols were used to prepare triazafluoranthenone analogues (210) bearing dialkylamino, methoxy, and phenylsulfanyl substituents at C-5, which were also independently synthesized from triazafluoranthenone (209) by regioselective nucleophilic addition. 8-Iodobenzotriazinones (207) underwent palladium-catalyzed nonoxidative intramolecular coupling in the presence of AgF to give the 2-phenyl-6H-[1,2,4]triazino[5,6,1-jk]carbazol-6-ones (209) in moderate to excellent yields while palladium-catalyzed oxidative intramolecular cyclization of benzotriazinones (208) required a combination of co-oxidants such as $\mathrm{AgF}$ and $\mathrm{Cu}(\mathrm{OTf})_{2}$ in an oxygen atmosphere (Scheme 41). ${ }^{90}$
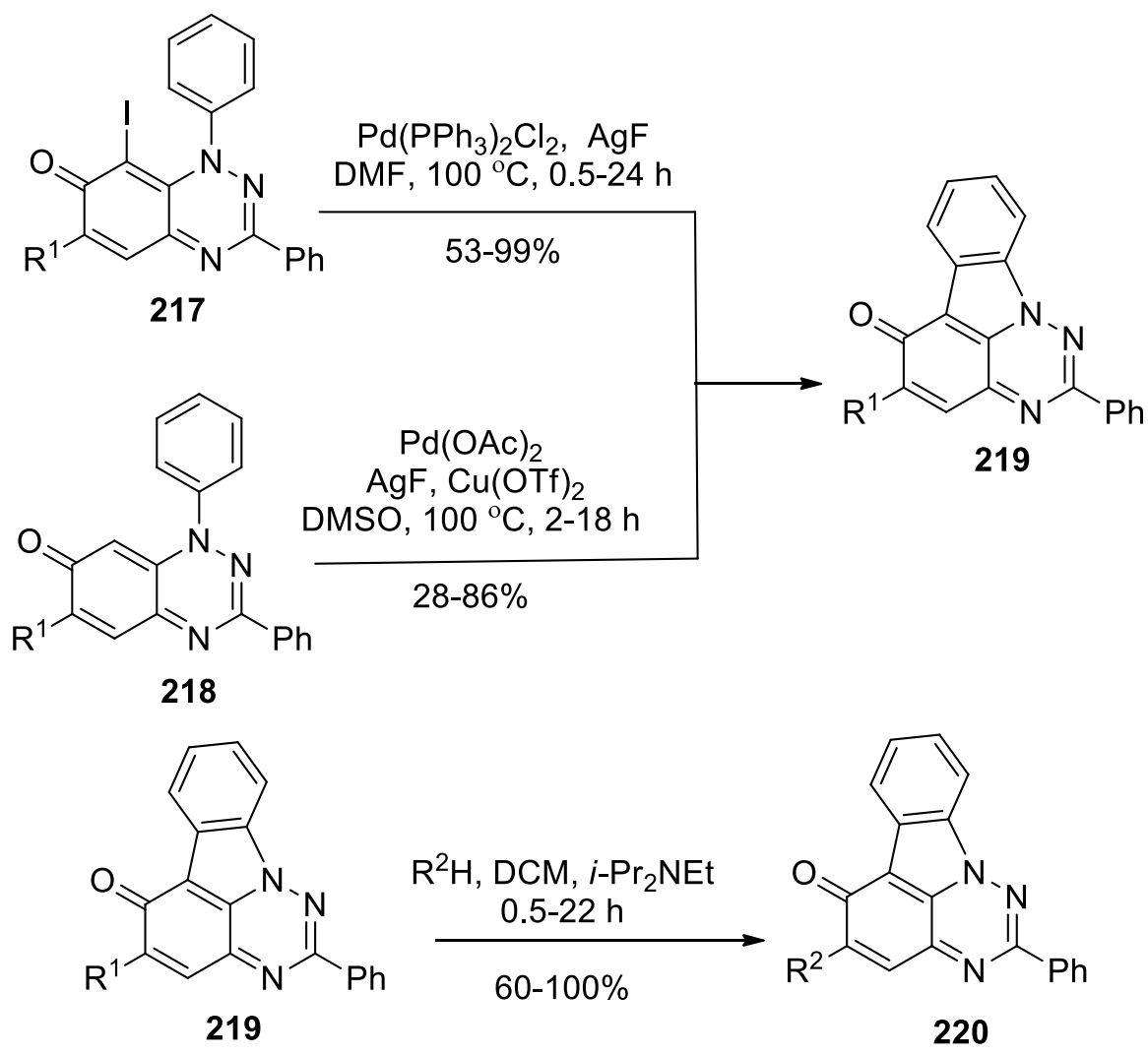

$$
\text { If } \mathrm{R}^{1}=\mathrm{H}
$$

$\mathrm{R}^{1}=\mathrm{H}, \mathrm{NEt}_{2}, \mathrm{~N}\left(\mathrm{CH}_{2}\right)_{4}, \mathrm{OMe}, \mathrm{SPh}$

$\mathrm{R}^{2}=\mathrm{NEt}_{2}, \mathrm{~N}\left(\mathrm{CH}_{2}\right)_{4}, \mathrm{OMe}, \mathrm{SPh}$

Scheme 41. Conversion of benzotriazinones (218) and 8-iodobenzotriazinones (217) into triazafluoranthenones (219) and regioselective nucleophilic addition to triazafluoranthenone (219)

\subsection{0. $[1,2,5]$ Thiadiazolo[3,4-b][1,2,4]triazino[1,6,5-Im]carbazol-7-one}

Treatment of 6-amino-1,3-diphenyl-1,2,4-benzotriazin-7(1H)-one and 6-amino-1-phenyl-3-(trifluoromethyl)1,2,4-benzotriazin-7(1H)-one (221) with $\mathrm{S}_{4} \mathrm{~N}_{4}$ in $\mathrm{DMF}$ gave the desired thiadiazolobenzotriazinone and 6phenyl-8-(trifluoromethyl)-[1,2,5]thiadiazolo[ $\left[3^{\prime}, 4^{\prime}: 5,6\right]$ benzo[1,2-e][1,2,4]triazin-4(6H)-one (222). Afterwards, treating the available thiadiazolobenzotriazinones (222) with tetracyanoethylene oxide (TCNEO) in toluene gave the desired final thiadiazolo-fused ylidenemalononitriles (223). Separately, thermolysis of the 1,4- 
thiazino-fused systems 2-phenyl and 2-(trifluoromethyl)-7H-[1,2,5]thiadiazolo[3,4- $b][1,2,4]$ triazino[1,6,5-mn]phenothiazin-7-one (224) led to ring contraction on thermolysis to give the triazafluoranthenones 2-phenyl and 2-(trifluoromethyl)-7H-[1,2,5]thiadiazolo[3,4-b][1,2,4]triazino[1,6,5-Im]carbazol-7-one (226). Finally, the thiadiazolo-fused triazafluoranthenone (226) was also prepared by reacting $\mathrm{S}_{4} \mathrm{~N}_{4}$ with triazafluoranthenone (225) (Scheme 42). ${ }^{91}$

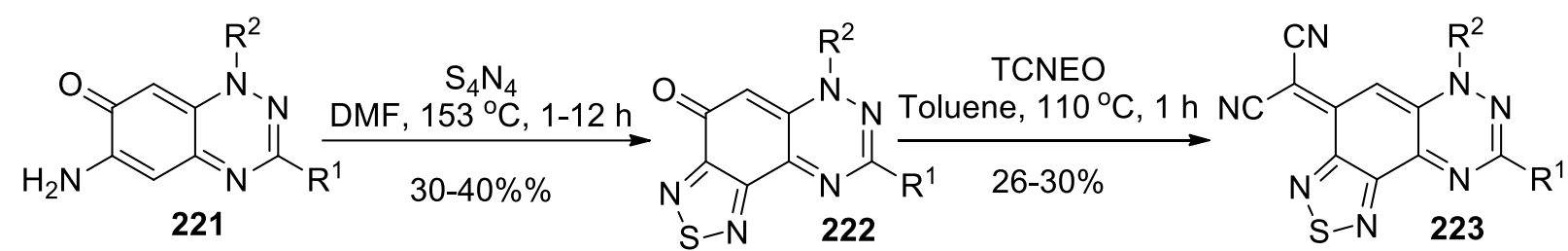

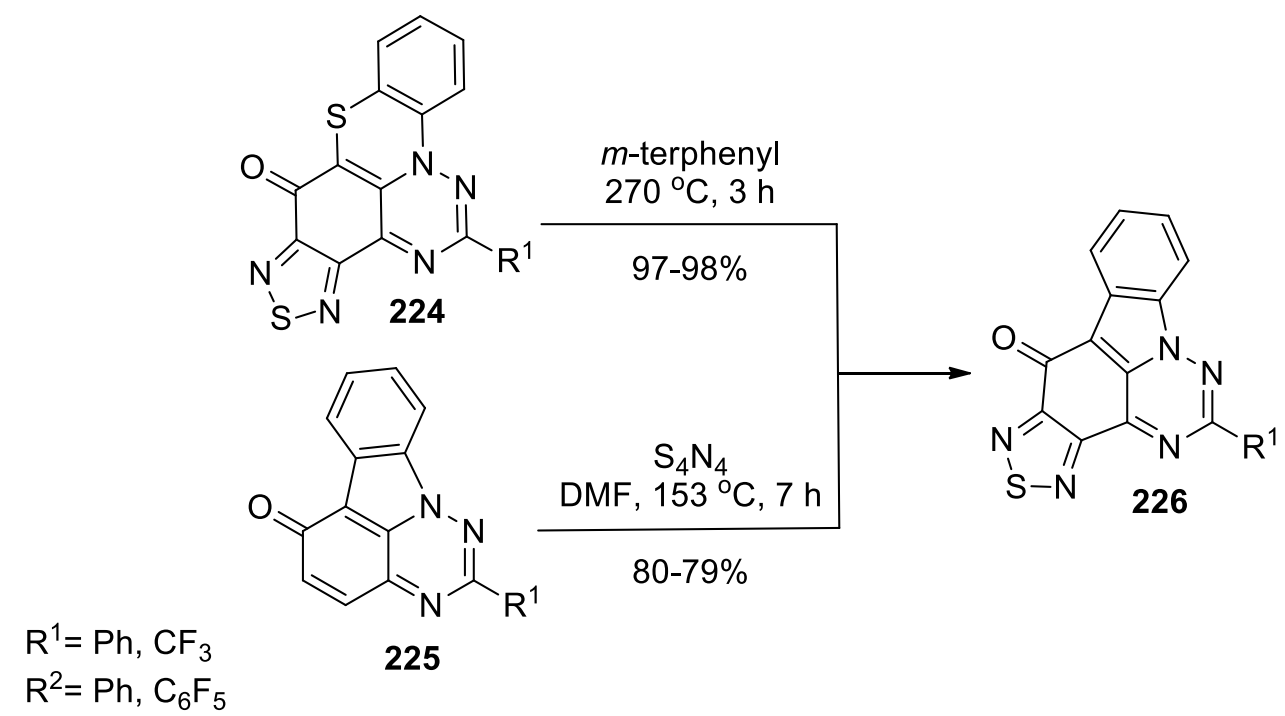

Scheme 42. Preparation of thiadiazolo-fused triazafluoranthenones (223) and (226).

\section{1,2,4-Benzotriazine Fused to Six Membered Rings}

\section{1. $[1,2,4]$ Triazino[3,4-c][1,2,4]benzotriazines}

The sulfur atom of dihydro-1,2,4-benzotriazine-3-thione (116) was methylated by methyl iodide in basic medium to afford 1,2-dihydro-3-methylthio-1,2,4-benzotriazine (227). Reaction with hydrazine hydrate produced 3-hydrazino-1,2-dihydro-1,2,4-benzotriazine (228) which upon reaction with phenacyl bromide (186) gave (3-phenacylhydrazyl) 1,2,4-benzotriazine (229). Finally, the ketone (229) produced 4,6-dihydro-1-phenyl$3 H$-triazino[3,4-c][1,2,4]benzotriazine (230) via cyclocondensation with polyphosphoric acid (PPA) (Scheme 43). ${ }^{92}$ 

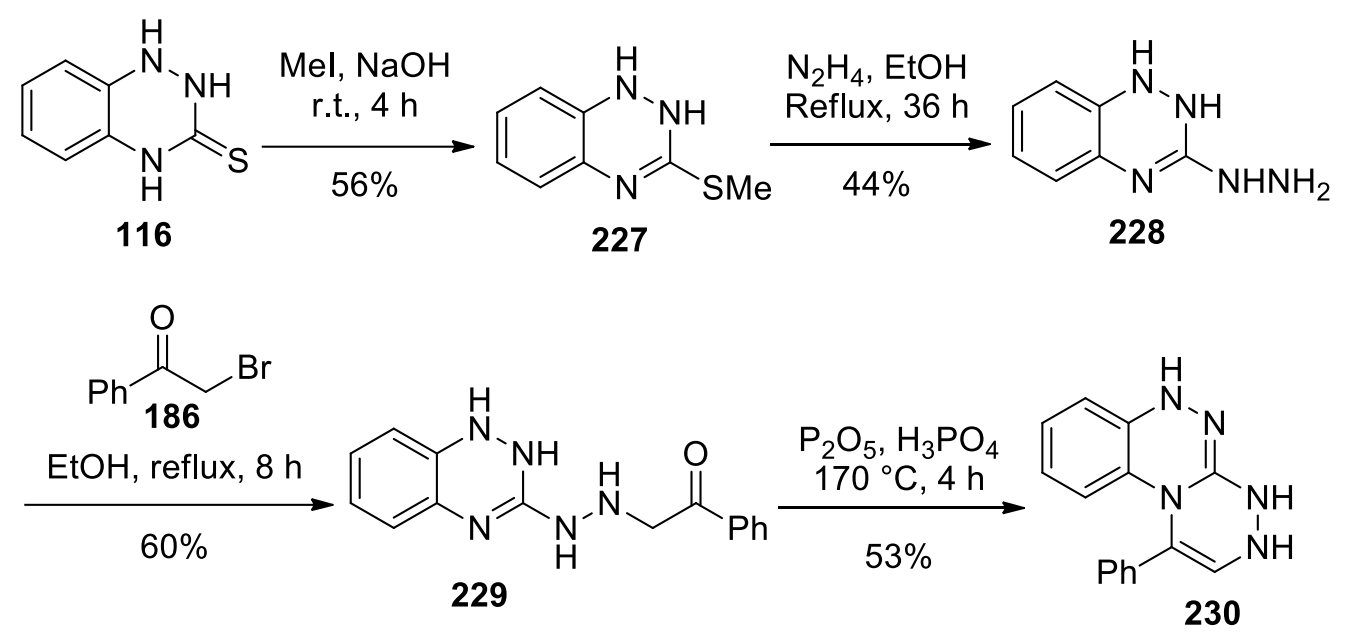

Scheme 43. Synthesis of 4,6-dihydro-1-phenyl-3H-triazino[3,4-c][1,2,4]benzotriazine (230).

\section{2. $[1,3]$ Thiazino $[1,2,4]$ benzotriazines}

Michael type addition of 1,4-dihydro-1,2,4-benzotriazine-3(2H)-thione (116) to propiolic acid (231) in refluxing ethanol give the $S$-acrylic acid derivative (232) which was regioselectively cyclized to a [1,3]thiazino[2,3-c]$[1,2,4]$ benzotriazin-1-one (233). The spectral data showed that upon cyclization, the tricyclic $1 H, 6 H$ $[1,3]$ thiazino[2,3-c] $[1,2,4]$ benzotriazin-1-one (233) was produced in $74 \%$ yield (Scheme 44$).{ }^{93}$

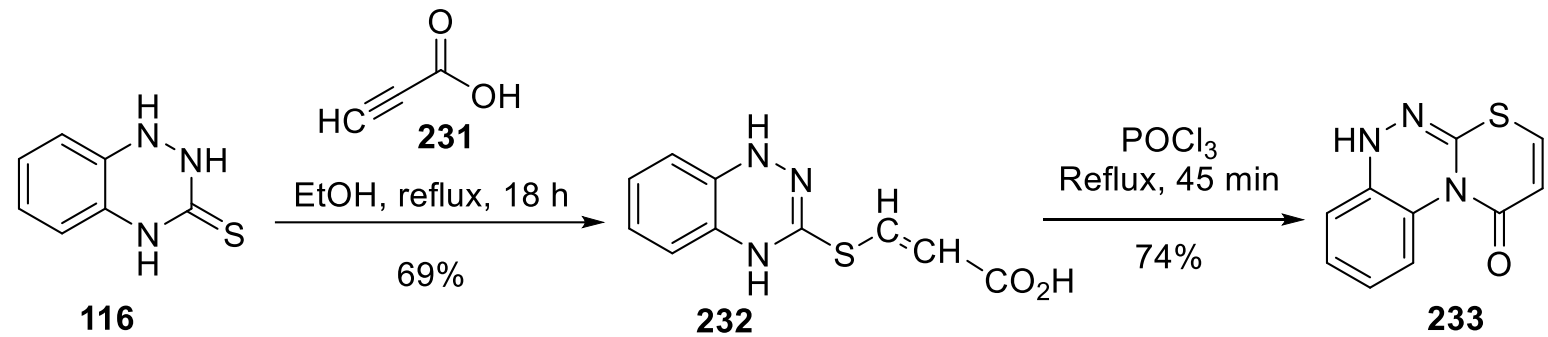

Scheme 44. Synthesis of thiazino[2,3-c][1,2,4]benzotriazine (233).

\section{3. $[1,2,4]$ Triazino $[5,6-b]$ phenazin-11-ium}

1,3-Diphenyl-1,2,4-benzotriazin-7(1H)-one (211) was treated with bisnucleophiles (234) including 1,2benzenediamine, 2-aminobenzenethiol and $N$-phenyl-1,2-benzenediamine. In the first three cases, the expected C-6-substituted benzotriazinones (235) were obtained as intensely colored compounds. Subsequent treatment of substituted benzotriazinones (235) with $\mathrm{TsOH} \cdot \mathrm{H}_{2} \mathrm{O}$ in $\mathrm{EtOH}$ gave the expected cyclization products either as the tosylates or, when treated with alkali, as the free bases. The reaction of benzotriazinone (235) with $\mathrm{TsOH} \cdot \mathrm{H}_{2} \mathrm{O}$ gave 1,3-diphenyl-1,6-dihydro-[1,2,4]triazino[5,6-b]phenazin-4-ium 4-methylbenzenesulfonate (236). On the other hand, the reaction of 1,3-diphenyl-6-[2-(phenylamino)phenylamino]-1,2,4benzotriazin-7(1H)-one (235) in EtOH gave 1,3,11-triphenyl-1,6-dihydro-[1,2,4]triazino[5,6-b]phenazin-11-ium 4-methylbenzenesulfonate (237) in 99\% yield. Finally, by treating the reaction mixture with $\mathrm{KOH}$, the free base 1,3,11-triphenyl- $1 H$-[1,2,4] triazino[5,6- $b]$ phenazin-11-ium-6-ide (238) was isolated in 87\% yield (Scheme 45). ${ }^{94}$ 
<smiles>[R]Nc1ccccc1[Y1]([R4])([H])[H]</smiles>

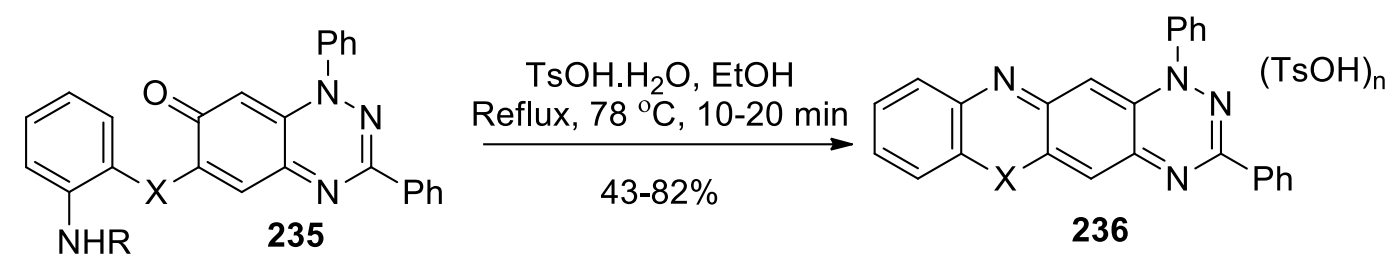

If $\mathrm{R}=\mathrm{H}$

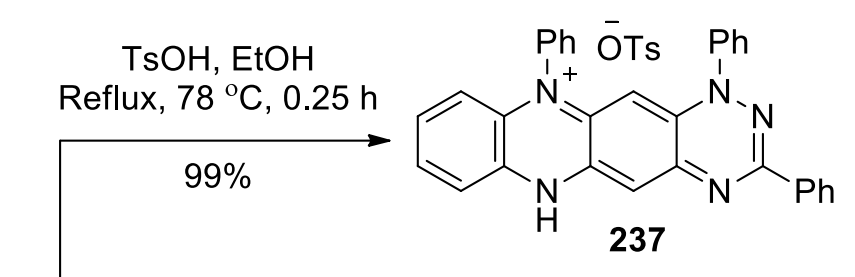<smiles>[R]Nc1ccccc1Nc1cc2nc(-c3ccccc3)nn(-c3ccccc3)c-2cc1=O</smiles>

1) $\mathrm{TsOH}, \mathrm{EtOH}$ Reflux, $78^{\circ} \mathrm{C}, 0.3 \mathrm{~h}$

2) $\mathrm{KOH}, 15 \mathrm{~min}$

$$
\text { If } \mathrm{R}=\mathrm{Ph}
$$

$\mathrm{R}=\mathrm{H}, \mathrm{Ph}$

$\mathrm{X}=\mathrm{NH}, \mathrm{S}$

$87 \%$<smiles></smiles>
$\mathrm{n}=0,1$

Scheme 45. Reaction of 1,2,4-benzotriazinone (211) with bisnucleophiles (234) and cyclization reactions of 1,3-diphenyl-1,2,4-benzotriazin-7(1H)-ones (235).

\subsection{Tetraphenylhexaazaanthracene}

$\mathrm{N}$-Nitroarylation of $N^{\prime}$-phenylbenzohydrazide (240) via nucleophilic aromatic substitution of 1,5-difluoro-2,4dinitrobenzene (239) afforded the bishydrazide (241). Mild reduction with $\mathrm{H}_{2}$ over $\mathrm{Pd} / \mathrm{C}$ in EtOH and further thermal oxidative cyclization under acid catalysis affords only tetraphenylhexaazaanthracene (TPHA) (242) in an overall $63 \%$ yield (Scheme 46$).{ }^{95}$

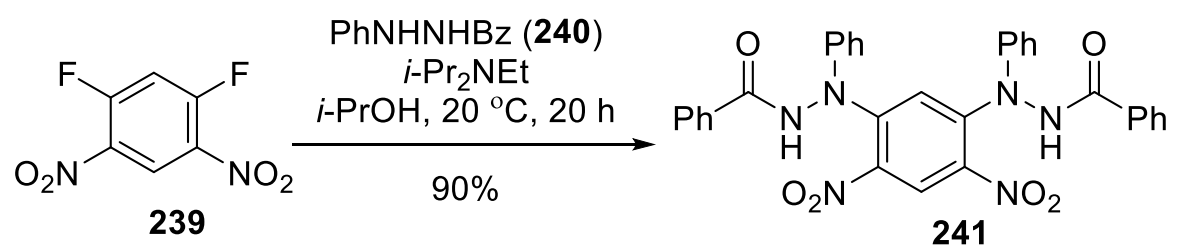

1) $\mathrm{H}_{2}, \mathrm{Pd} / \mathrm{C}, \mathrm{EtOH}$, r.t.

2) Air, $\mathrm{EtOH}, 78^{\circ} \mathrm{C}$

$70 \%$<smiles></smiles>

Scheme 46. Unambiguous route to TPHA (242). 
TPHA (242), a fluorescent zwitterionic biscyanine, on treatment with manganese dioxide or (phenyliodine bis(trifluoroacetate)) (PIFA), underwent oxidative dimerization to give a near-zero dipole scissor 5,5'-dimer DITPHA (246). The synthesis of TPHA (242) was investigated, which involved the oxidation of the bisamidrazone (243) and $\mathrm{Ag}_{2} \mathrm{O}$ was identified as a superior oxidant that gave TPHA (242) in near-quantitative yield. Another synthesis of TPHA (242) involved the reaction of $N, N^{\prime}-(m$-phenylene)dibenzimidoyl dichloride (243) with phenylhydrazine to give the unstable bisamidrazone (245) which then oxidatively cyclized in the presence of DBU to afford TPHA (242) in an overall yield of 17\%. DI-TPHA (246) was prepared in high yield by treating TPHA (242) with either excess $\mathrm{MnO}_{2}$ or PIFA in DCM (Scheme 47). ${ }^{96}$

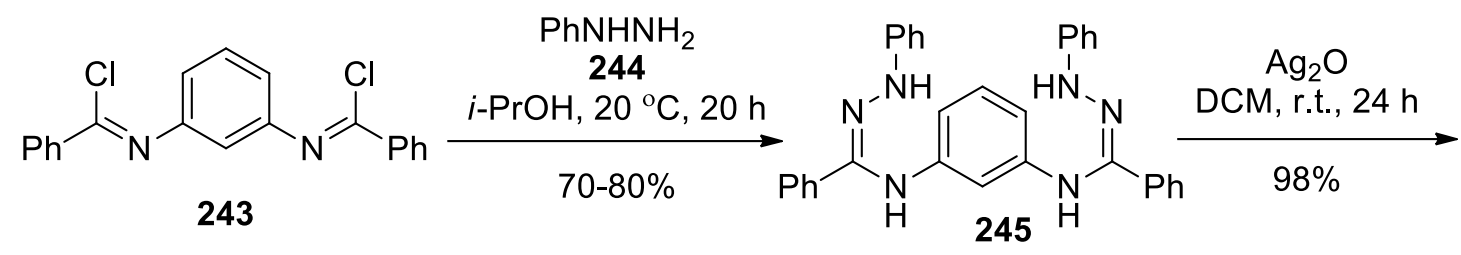<smiles></smiles>

242
$\mathrm{MnO}_{2}$ or PIFA $\stackrel{\mathrm{DCM}, 20^{\circ} \mathrm{C}, 10 \mathrm{~min}}{\longrightarrow}$

$88-100 \%$

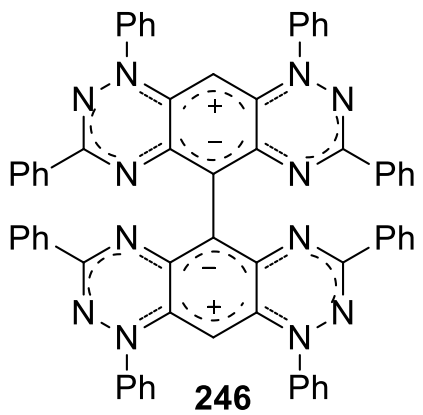

Scheme 47. Improved route to TPHA (242) and conversion of TPHA (242) to DI-TPHA (246).

\section{1,2,4-Benzotriazinyl Radicals}

1,3-Bis(pyrid-2-yl) and 1,3-bisphenyl-1,2,4-benzotriazin-7-one (8) were prepared by the $\mathrm{MnO}_{2}$-mediated oxidation of 1,3-bis(pyrid-2-yl) and 1,3-bisphenyl-1,4-dihydro-1,2,4-benzotriazine (7) with manganese dioxide in DCM at room temperature in 90 and $46 \%$ yield, respectively. All these stable free radicals (7) were significantly more cytotoxic towards the cancer cell line DU-145 than their oxidation products, 1,2,4benzotriazin-7-ones (8). (Scheme 48). ${ }^{97}$
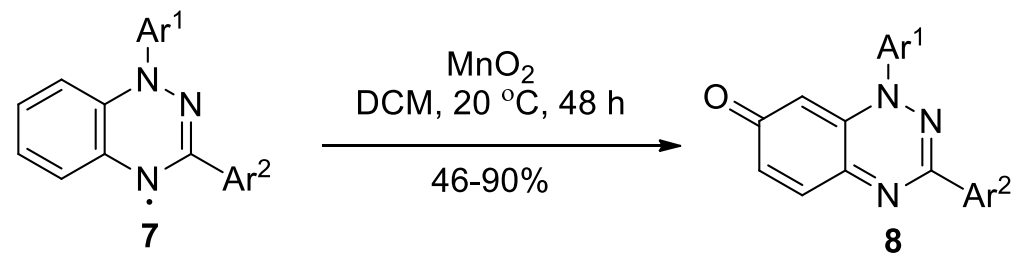

$$
\begin{aligned}
& A r^{1}=P h, P y-2-y l \\
& A r^{2}=P h, P y-2-y l
\end{aligned}
$$

Scheme 48. $\mathrm{MnO}_{2}-$ Mediated oxidation of benzotriazinyls (7) to benzotriazinones (8). 
Koutentis and coworkers developed a synthesis of radicals (249) based on an aza-Wittig reaction. The treatment of $\mathrm{N}$-aryliminophosphorane (247) with 1-aroyl-2-aryldiazenes (248) in preheated diphenyl ether at 150-250 ${ }^{\circ} \mathrm{C}$ afforded the 1,3-diaryl-1,4-dihydro-1,2,4-benzotriazinyls (249) as the main products in moderate to good yields (Scheme 49). ${ }^{98}$

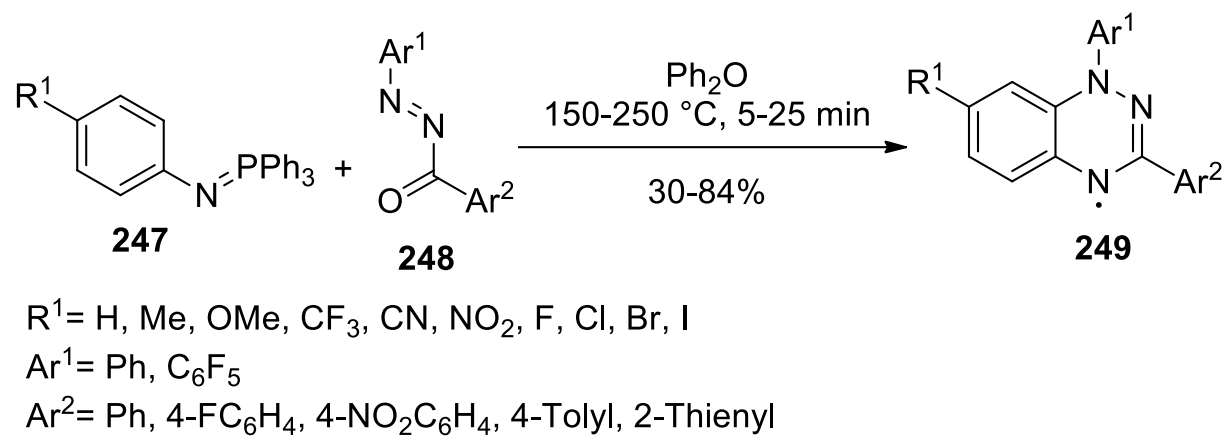

Scheme 49. Preparation of radicals (249) via the aza-Wittig reaction.

A route to benzo- and pyrido-fused triazinyl radicals was developed that avoids the formation of reactive intermediates, such as amidrazones or imidoyl chlorides. A two-step route to 1,3-disubstituted benzo- and pyrido-fused 1,2,4-triazinyl radicals (253) was presented. The route involved the $N^{\prime}$-(2-nitroarylation) of easily prepared $N^{\prime}$-(het)arylhydrazides (251) via nucleophilic aromatic substitution of 1-halo-2-nitroarenes (250), bearing a range of substituents at $\mathrm{N}-1, \mathrm{C}-3$, and $\mathrm{C}-7$, which gave $N^{\prime}$-(het)aryl- $N^{\prime}$-[2-nitro(het)aryl]hydrazides (252) in good yields. Subsequent reduction of the nitro group using a mild reducing agent, e.g. In or Sn powder, followed by in situ acid-catalyzed cyclodehydration finally afforded the desired radicals (253) (Scheme 50). ${ }^{99}$

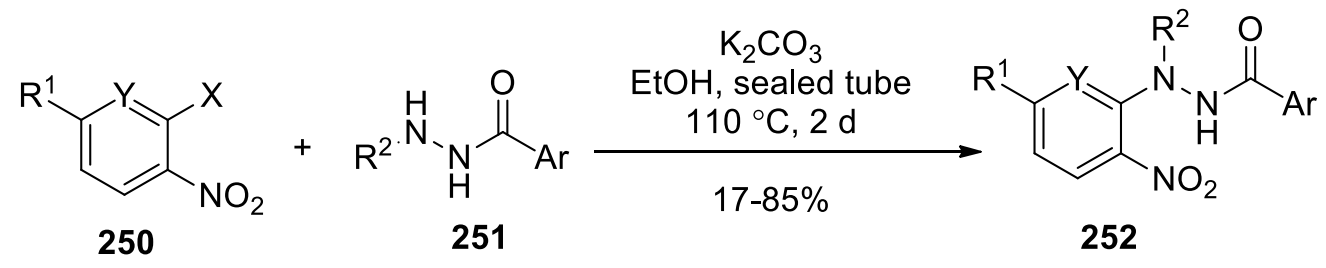

1) $\mathrm{Sn}, \mathrm{AcOH}, 0.5 \mathrm{~h}, 20^{\circ} \mathrm{C}$

2) Reflux, $118^{\circ} \mathrm{C}, 10-180 \mathrm{~min}$ 3) $\mathrm{NaOH}(\mathrm{aq}, 2 \mathrm{M}), 3 \mathrm{~h}-3 \mathrm{~d}, 20^{\circ} \mathrm{C}$

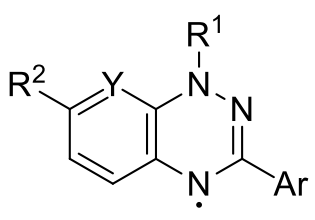
$63-98 \%$

253

$$
\begin{aligned}
& \mathrm{X}=\mathrm{F}, \mathrm{Cl} \\
& \mathrm{Y}=\mathrm{CH}, \mathrm{N} \\
& \mathrm{R}^{1}=\mathrm{Ph}, 4-\mathrm{FC}_{6} \mathrm{H}_{4}, \text { Thien-2-yl, Py-2-yl, Me, } \mathrm{CF}_{3} \\
& \mathrm{R}^{2}=\mathrm{H}, \mathrm{CF}_{3} \\
& \mathrm{Ar}=\mathrm{Ph}, 4-\mathrm{CNC}_{6} \mathrm{H}_{4}, \mathrm{Py}-2-\mathrm{yl}
\end{aligned}
$$

Scheme 50. Reaction of 1-halo-2-nitroarenes (250) with hydrazides (251) and in situ cyclodehydration to benzotriazinyls (253). 
Tuononen et al. prepared the stable benzotriazinyl radicals (258) in good to excellent yields. The pyridylthioamides (256) were prepared via the Willgerodt-Kindler reaction of 2-picoline (254), sodium sulfide, and anilines (255). Treatment of compound (256) with phenylhydrazine (244) afforded the pyridyl amidrazones (257). Finally, ring closure and catalytic oxidation of the amidrazones (257) were carried out in the presence of palladium-on-carbon and 1,8-diazabicyclo[5.4.0]undec-7-ene (DBU) under air to produce the 7-substituted 1,3-diphenyl-1,4-dihydro-1,2,4-benzotriazin-4-yls (258) (Scheme 51). ${ }^{100,101}$
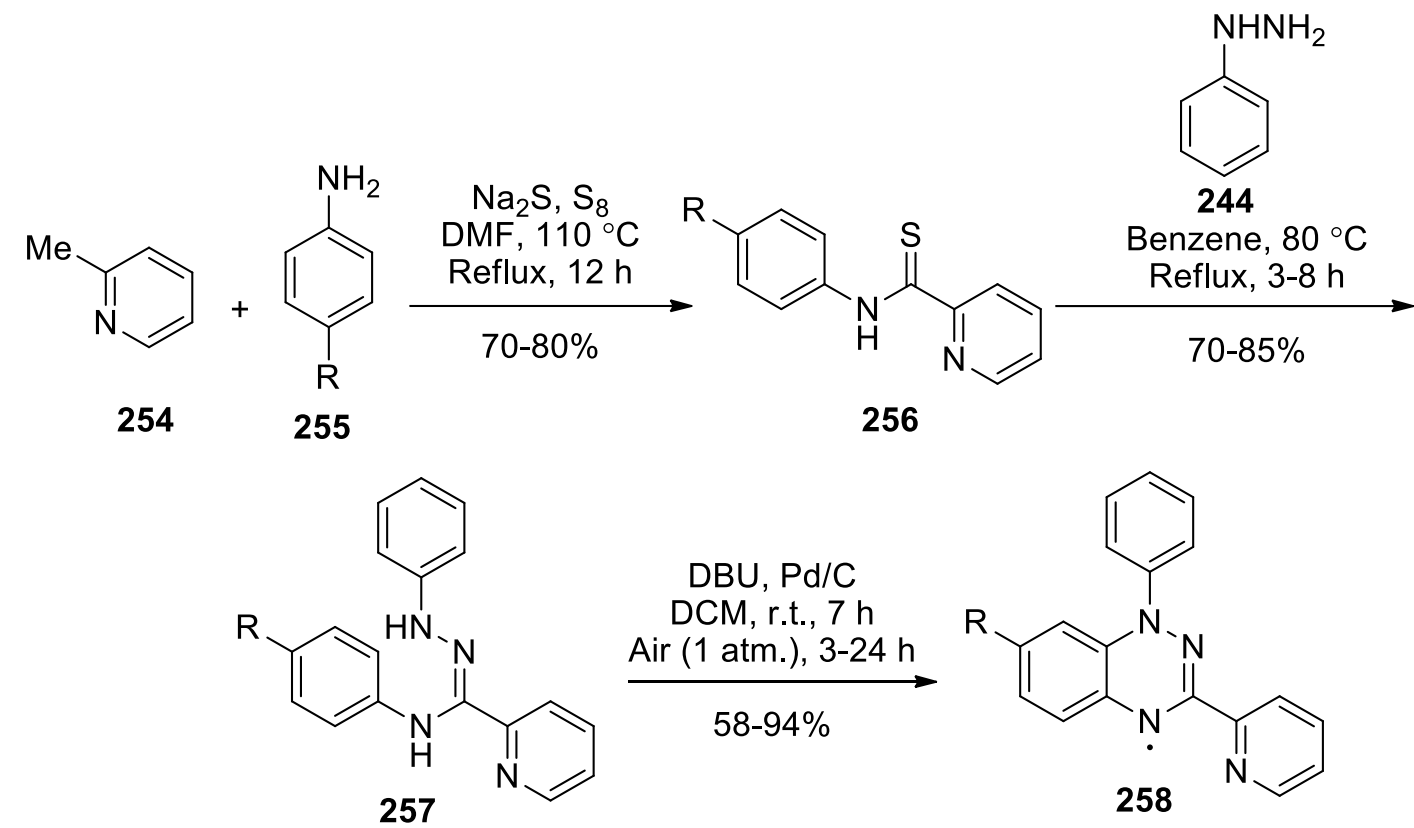

$\mathrm{R}=\mathrm{H}, \mathrm{Me}, \mathrm{OMe}, \mathrm{CF}_{3}, \mathrm{Cl}, \mathrm{Br}, \mathrm{I}$

Scheme 51. Synthesis of 1-phenyl-3-pyridyl-1,2,4-benzotriazinyl radicals (258).

Stille and Suzuki-Miyaura reactions of 7-iodo-1,3-diphenyl-1,4-dihydro-1,2,4-benzotriazin-4-yl (249) were presented as rare examples of cross-coupling reactions with stable organic radicals. A mild and high-yielding method was developed for converting $N$-phenylamidrazones (259) into stable radicals of 1,3-diphenyl-1,2,4benzotriazin-7(H)-one (249) using DBU in an atmosphere of air. The Suzuki-Miyaura reaction of the 7iodobenzotriazinyl (249) was cleaner and only traces of the benzotriazinone (8) were observed, however, longer reaction times were required. When $\mathrm{Pd}(\mathrm{OAc})_{2}$ as a catalyst and $\mathrm{K}_{2} \mathrm{CO}_{3}$ as a base in toluene were used, the major product 7-arylbenzotriazinyl (260) was formed. Furthermore, the reactivity of 7-chloro, bromo-, iodobenzotriazinyls (249) was established in a typical Stille reaction using a three-fold excess of tributylphenylstannane with $\mathrm{Pd}(\mathrm{OAc})_{2}$ as catalyst in DMF. Consequently, the desired 7-arylbenzotriazinyl (260) along with traces of the 1,2,4-benzotriazin-7-one (8) were obtained (Scheme 52). ${ }^{102}$

The stable free radical polymerization (SFRP) process based on 1,3-diphenyl-1,4-dihydro-1,2,4benzotriazin-4-yl and several C-7 substituted derivatives (249) was introduced for the polymerization of styrene. Styrene polymerization was performed in the presence of different benzotriazinyl radicals (249) and the amount of over-oxidized benzotriazinone (8) was analyzed aiming to correlate the structural characteristics of the radicals with their efficacy in controlling the radical polymerization process. 1,3Diphenyl-1,4-dihydro-1,2,4-benzotriazin-4-yl and several of its C-7 substituted analogues (249) were prepared via the catalytic oxidation of the corresponding amidrazones (259) by using DBU in air. 7-Aryl-1,3-diphenyl-1,4- 
dihydro-1,2,4-benzotriazin-4-yls (261) were prepared from 7-iodo-1,3-diphenyl-1,4-dihydro-1,2,4-benzotriazin4-yl (249), by the Suzuki-Miyaura reaction while oxidation of radical (249) with $\mathrm{MnO}_{2}$ afforded the 1,3diphenyl-1,2,4-benzotriazin-7(H)-one (8) (Scheme 53). ${ }^{103}$<smiles>[R]c1ccc(N/C(=N/Nc2ccccc2)c2ccccc2)cc1</smiles>

259

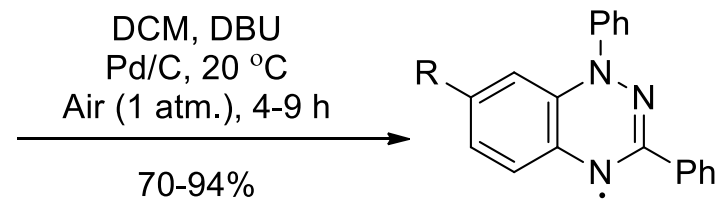

249

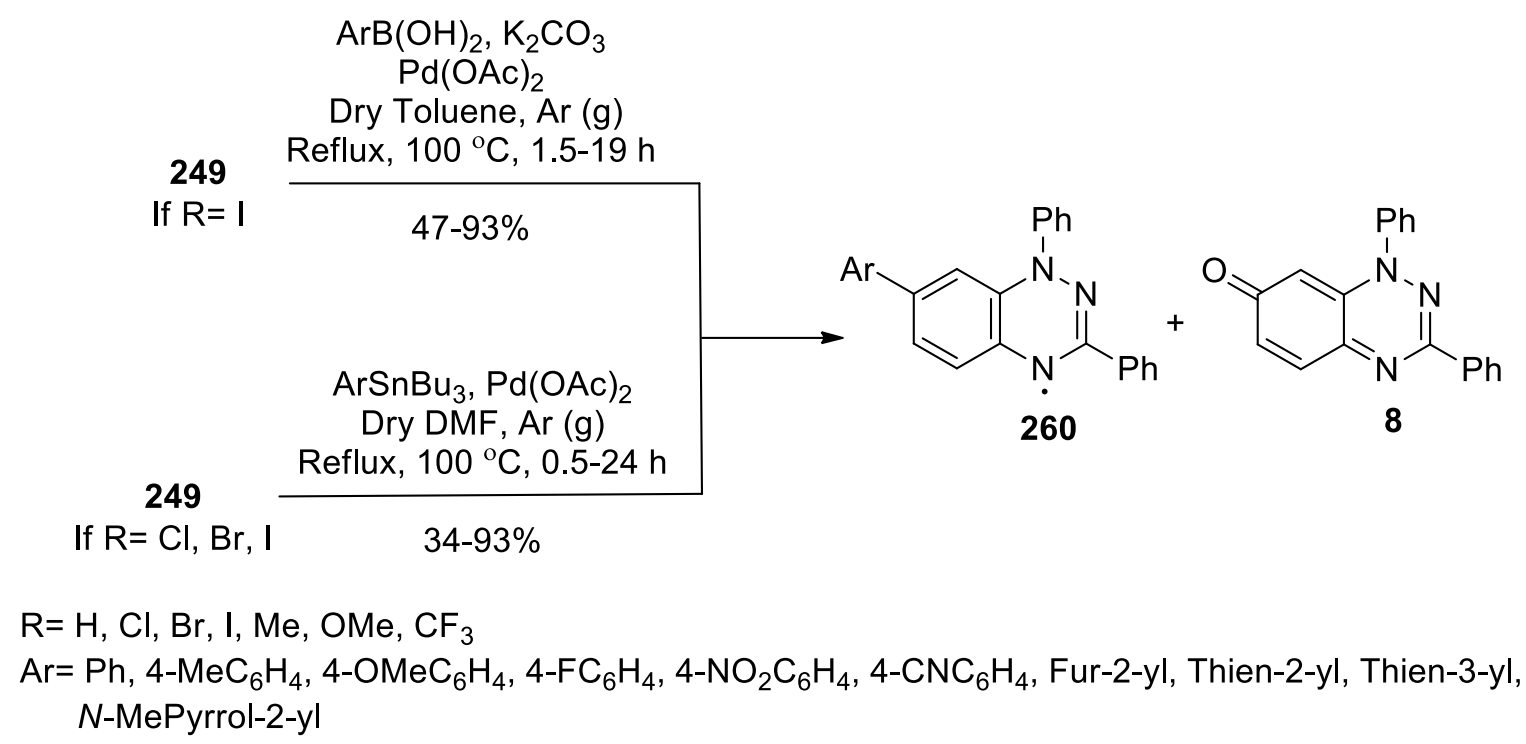

Scheme 52. Synthesis of various 1,3-diphenyl-1,2,4-benzotriazinyls (249) from $N$-phenylamidrazones (259), Stille and Suzuki cross-coupling reactions of 7-halo-1,3-diphenyl-1,2, 4-benzotriazinyls (249).

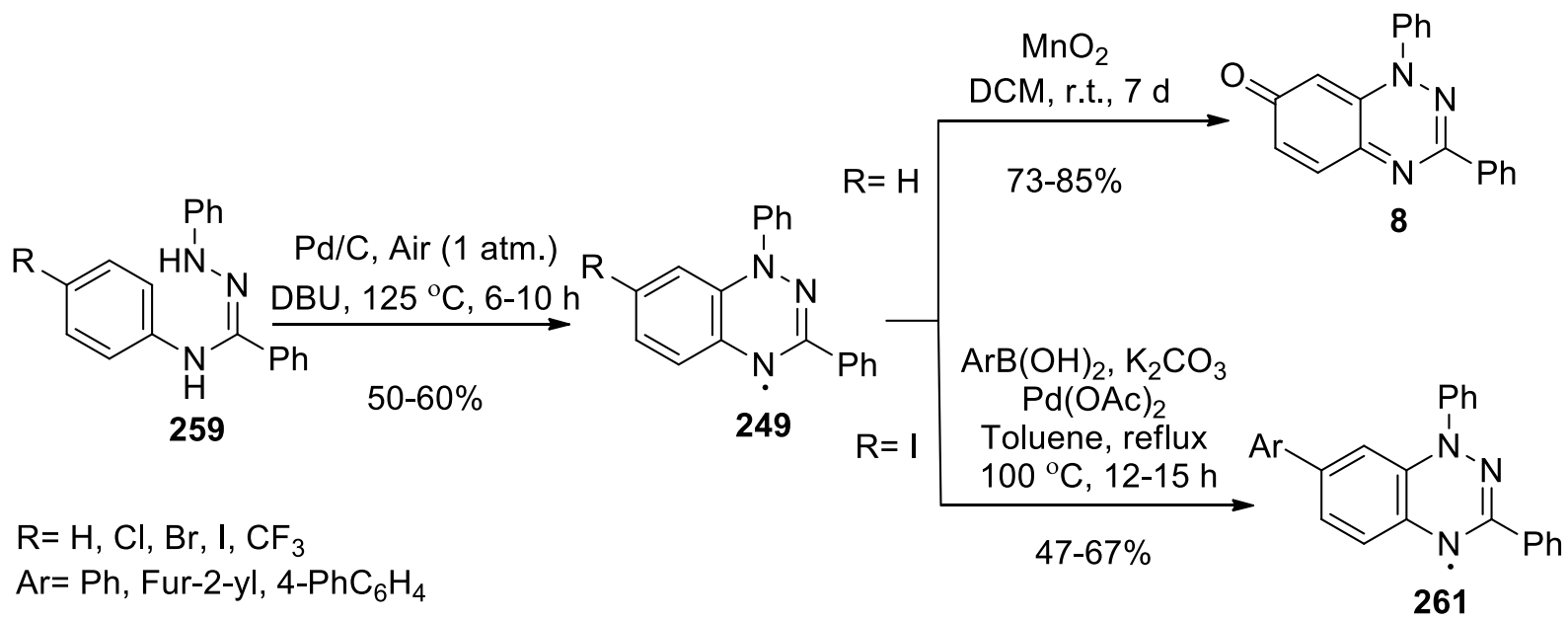

Scheme 53. The 1,2,4-benzotriazinyl radicals (249) and the over-oxidized benzotriazinone (8) used for polystyrene synthesis. 
Neugebauer and Umminger described the dehydrogenation of amidrazone (262) using mercuric oxide to produce the diazene (263). Upon thermal ring closure of compound (263) at $150{ }^{\circ} \mathrm{C}, 1,4-$ dihydro-1,2,4benzotriazine (264) was produced. The compound (264) formed the 1,4-dihydro-1,2,4-benzotriazinyl (265) using silver oxide (Scheme 54). ${ }^{104-106}$

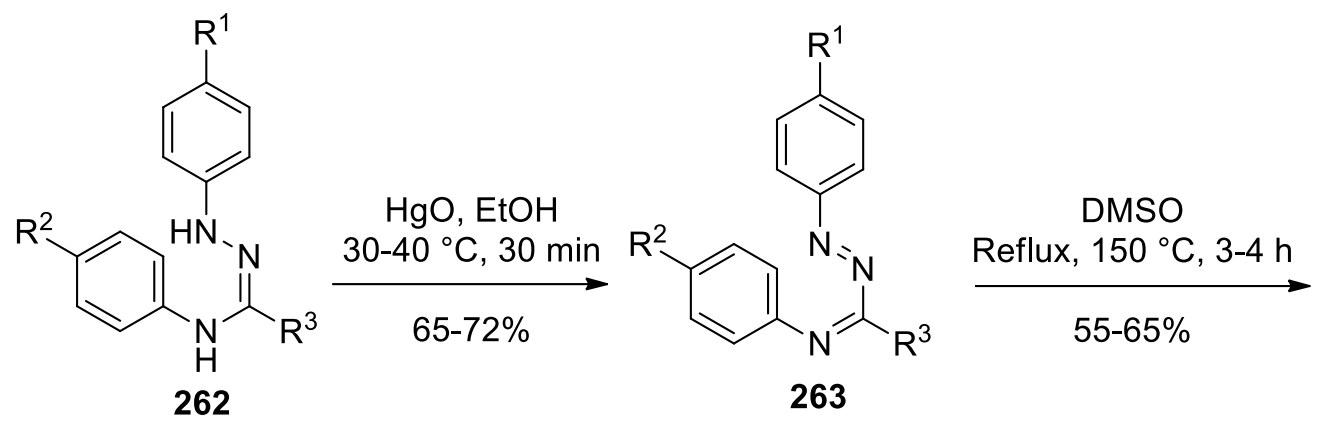<smiles>[R]C1=NN(c2ccc([R])cc2)c2cc([R])ccc2N1</smiles>

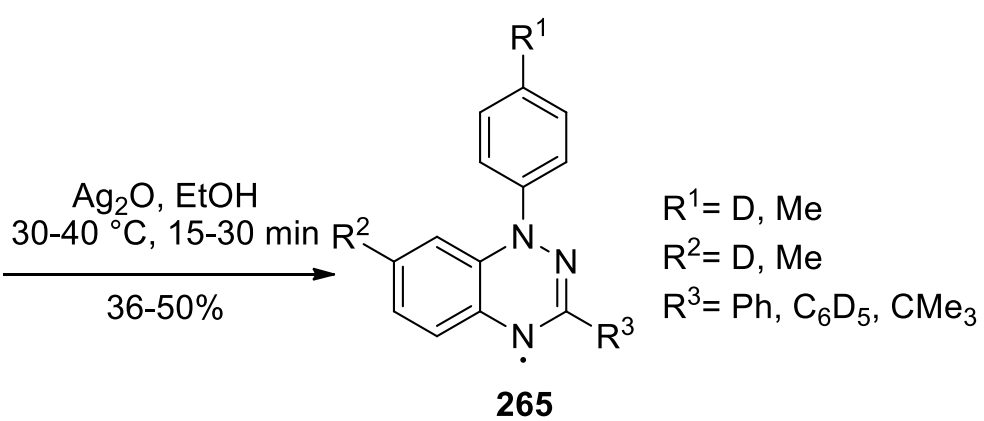

Scheme 54. Formation of 1-aryl-1,2,4-benzotriazinyl (265).

Tuononen and coworkers carried out a two-step route to the synthesis of 1,3-disubstituted 1,2,4-benzotriazinyl (269). The route involves the $N^{\prime}-2$-nitroarylation of easily prepared hydrazides $N^{\prime}$-aryl- $N^{\prime}$-[2nitro(het)aryl]hydrazides (268) via nucleophilic aromatic substitution of 1-halo-2-nitroarenes (266) with hydrazides (267). Mild reduction of the nitro group followed by an acid-mediated cyclodehydration led to the 1,2,4-benzotriazinyls (269) in the presence of $\mathrm{Ag}_{2} \mathrm{O}$ as oxidant. (Scheme 55). ${ }^{107}$<smiles>[R]C(=O)NN([R])c1cc(Br)ccc1[N+](=O)[O-]</smiles>

$$
\begin{aligned}
& \text { 1) } \mathrm{Sn}, \mathrm{AcOH} \\
& 30 \mathrm{~min}, 2{ }^{\circ} \mathrm{C} \\
& \text { 2) } \mathrm{Ag} 2 \mathrm{O}, \mathrm{DCM} \\
& \text { r.t., } 15-30 \mathrm{~min}
\end{aligned}
$$

Scheme 55. A flexible route to the synthesis of benzotriazinyls (269). 
Koutentis and coworkers developed a modified synthetic route for the preparation of 1,2,4-benzotriazinyls (279). The arylation of hydrazones (272) with 1-fluoro-2-nitro-4-(trifluoromethyl)benzenes (273) in DMSO containing potassium carbonate gave the corresponding products (274). By treating the hydrazones (274) with an excess of hydroxylamine hydrochloride in hot pyridine, the benzylidene group was removed and hydrazines (275) were obtained. ${ }^{99} \mathrm{~A}$ subsequent reaction of compounds (275) with acid chlorides (276) gave the desired hydrazides (277). The latter were converted into the 1,3-diphenyl-1,4-dihydro-1,2,4-benzotriazines (278) by reduction of the nitro group with tin powder in acetic acid. The radicals (279) could also be prepared by oxidation of compounds (278) with $\mathrm{NaIO}_{4}$ in nearly quantitative yields (Scheme 56). ${ }^{108,109}$

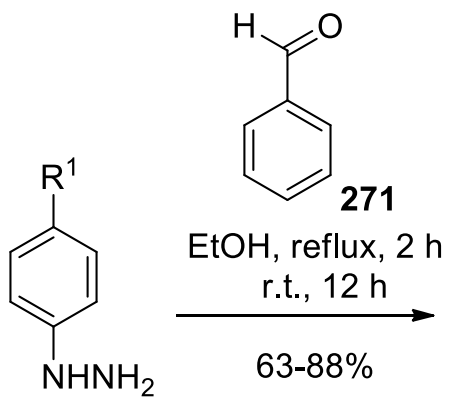

270

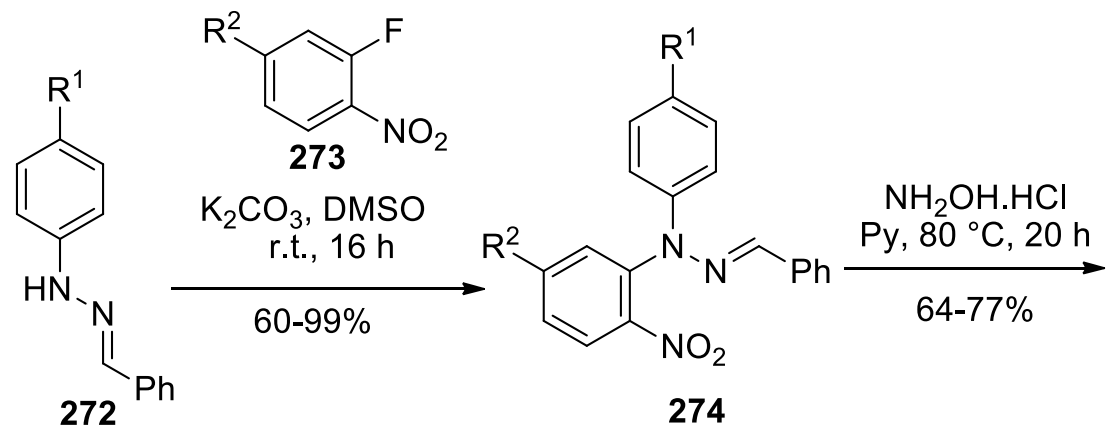

274<smiles>[R]c1ccc(N(N)c2cc([R])ccc2[N+](=O)[O-])cc1</smiles>

275<smiles>[R]c1ccc(C(=O)Cl)cc1</smiles>

$\mathrm{NEt}_{3}, 10 \mathrm{~min}-10 \mathrm{~h}$

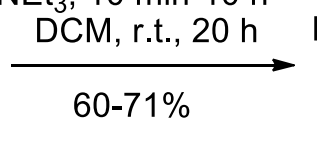

$60-71 \%$

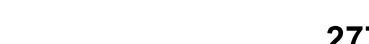<smiles>[R]c1ccc(N2N=C(c3ccc(F)cc3)Nc3ccc([R])cc32)cc1</smiles>

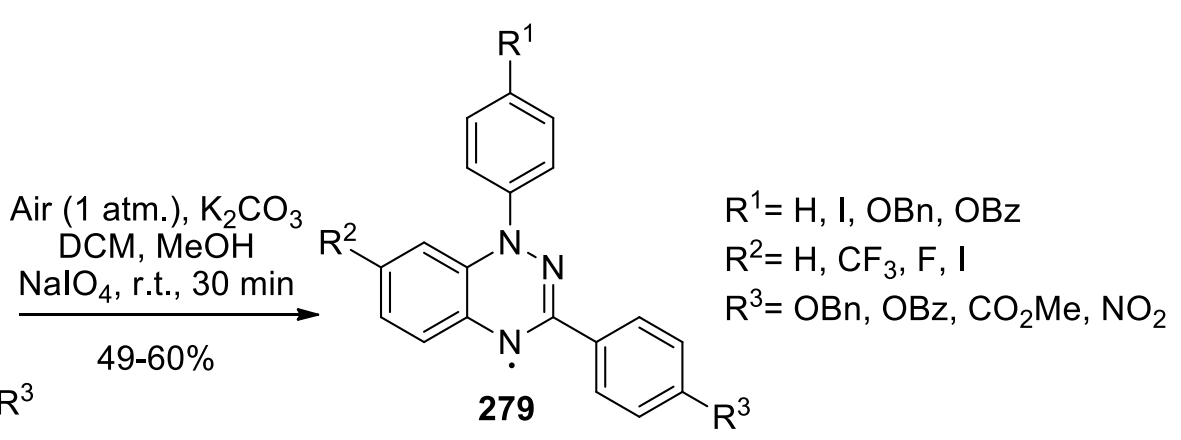

Scheme 56. Synthesis of 1,2,4-benzotriazinyl radicals (279).

The 8-fluoro-3-phenyl-1,2,4-benzotriazine (282) was prepared in three steps and 76\% overall yield from benzhydrazide, which was $\mathrm{N}$-arylated with 2,3-difluoronitrobenzene (280) with phenylhydrazine (281) to form the hydrazide (281) with subsequent cyclization to compound (282) under reductive conditions. The 8substituted-1,2,4-benzotriazines (285) were conveniently prepared by nucleophilic aromatic substitution of fluorine in 8-fluoro-1,2,4-benzotriazine (282) with either 2-bromothiophenolate (283) or 2-bromophenolate 
(284) under phase-transfer catalysis conditions. Finally, by reacting the 1,2,4-benzotriazine (285), with $t$-BuLi which followed by aerial oxidation of the intermediate anion gave the final radicals (286) (Scheme 57). ${ }^{110}$
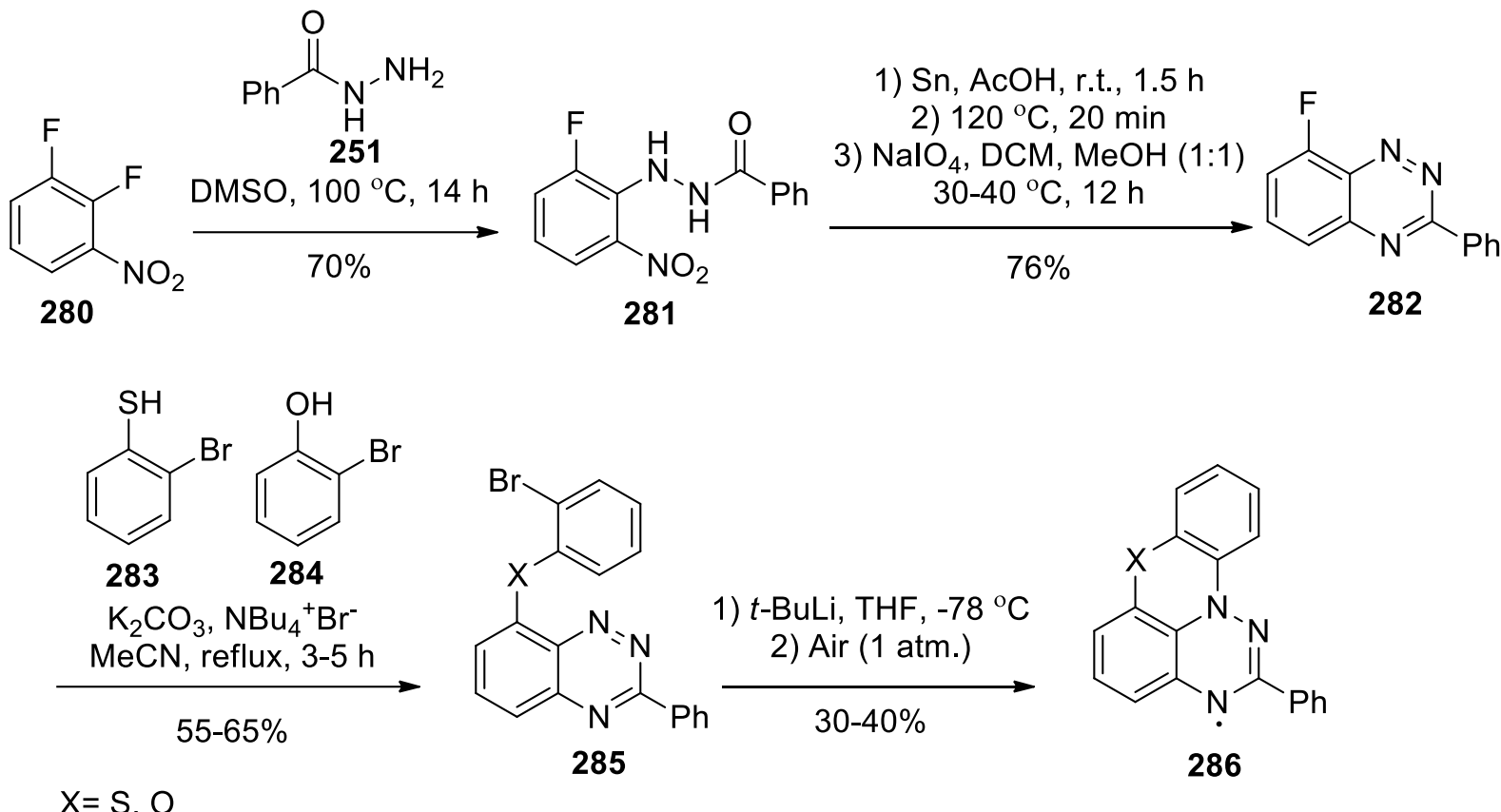

Scheme 57. Synthesis of 1,2,4-benzotriazin-4-yls (286).

In further work by Kaszynski and coworkers, 1,2,4-benzotriazinyls (293) with long-chain alkoxy substitutents were prepared in typical yields of 40-70\%. By reaction of 4-bromo-1-fluoro-2-nitrobenzene (287) with 3,4,5-tris(dodecyloxy)benzhydrazide (288), the $N^{\prime}$-(4-bromo-2-nitrophenyl)-3,4,5-tris(dodecyloxy)benzohydrazide (289) was produced. The hydrazide (289) was cyclized to 6-bromo-3-[3,4,5-tris(dodecyloxy)phenyl]1,2,4-benzotriazine (290) in 63\% overall yield. Suzuki coupling was employed in the presence of 3,4,5tris(dodecyloxy)phenylboronic acid (291) to introduce another 3,4,5-tris(dodecyloxy)phenyl group into the benzotriazine structure affording 3,6-bis(3,4,5-tris(dodecyloxy)phenyl)-1,2,4-benzotriazine (292). Finally, by addition of aryllithium to the compound (292) and aerial oxidation, the 1,2,4-benzotriazinyls (293) were produced (Scheme 58). ${ }^{111}$

1,4-Dihydro-1,2,4-benzotriazin-4-yls (300) were prepared by adding organometallic reagents to 1,2,4benzotriazines (34) followed by aerial oxidation of the resulting anions (294). Initially, the formation of the radicals (300) was investigated by addition of PhLi to 1,2,4-benzotriazine (34) in THF solution. Afterwards, the treatment of anion (294) with $\mathrm{BnBr}$ gave 4-benzyl derivative (296). Unfortunately, (296) showed limited stability on solid support, and reductive removal of the benzyl group using standard conditions failed. Thus, treatment of the anion (294) with $\mathrm{BnOCOCl}(\mathrm{CbzCl})$ (297) gave two isomers (298) and (299). Removal of the $\mathrm{Cbz}$ protecting group was accomplished quantitatively under standard conditions interestingly, the reaction was faster for the 2-isomer (299). Finally, the resulting solution was exposed to air, and the resulting radical (300), formed as the only product, was isolated. The Cbz protective group was also removed by treatment of (299) with MeLi in THF and exposure of the solution to air upon which radical (300) was formed (Scheme 59)..$^{112}$ 
<smiles>O=[N+]([O-])c1cc(Br)ccc1F</smiles>

287

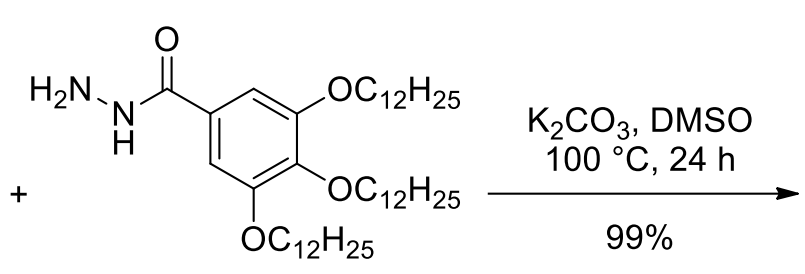

288<smiles>CCCCOc1cc(C(=O)NNc2ccc(Br)cc2[N+](=O)[O-])cc(OCC)c1OCCC</smiles>

1) $\mathrm{Sn}, \mathrm{AcOH}$, r.t., $2 \mathrm{~h}$

Reflux, 25 min

2) $\mathrm{NaIO}_{4}, \mathrm{MeOH}, \mathrm{DCM}$

$\stackrel{\text { r.t., } 2 \mathrm{~h}}{63 \%}$<smiles>CCCOc1c(OCC)cc(-c2nnc3ccc(Br)cc3n2)cc1OCC</smiles>

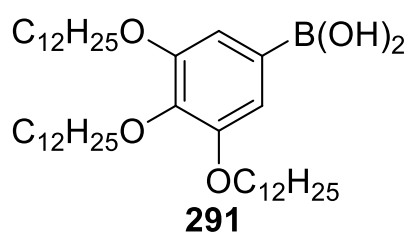

$\mathrm{Pd}\left(\mathrm{PPh}_{3}\right)_{4}, \mathrm{~K}_{2} \mathrm{CO}_{3}$

THF, $\mathrm{H}_{2} \mathrm{O}$, reflux, $4 \mathrm{~h}$

$93 \%$

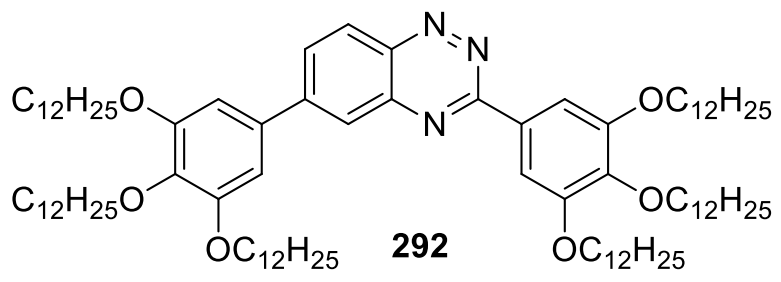

1) $\operatorname{ArLi}, \mathrm{THF},-5^{\circ} \mathrm{C}, 1 \mathrm{~h}$ 2) Air (1 atm.), 3-24 h $40-70 \%$

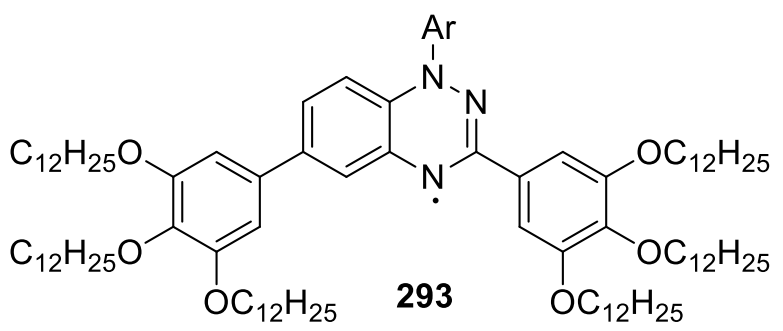

Ar= Ph, 3- $\mathrm{FC}_{6} \mathrm{H}_{4}, 3,4,5-\left(\mathrm{C}_{12} \mathrm{H}_{25} \mathrm{O}\right) \mathrm{C}_{6} \mathrm{H}_{2}, 3,4,5-\left(\mathrm{C}_{12} \mathrm{H}_{25} \mathrm{~S}\right) \mathrm{C}_{6} \mathrm{H}_{2}$

Scheme 58. Synthesis of 1,2,4-benzotriazinyls (293).

1,3-Diphenyl-1,2,4-benzotriazin-7(1H)-one (8) was prepared from radical (249) or directly from an amidrazone precursor using either $\mathrm{MnO}_{2}$ or $\mathrm{KMnO}_{4}$ as an oxidant in 68 and $82 \%$ yields, respectively. Furthermore, benzotriazinone (8) readily underwent high yielding and regioselective nucleophilic substitution at C-6 and electrophilic halogenations at C-8. 1,3-Diphenyl-1,2,4-benzotriazin-7(1H)-one (8) was treated with tetracyanoethylene (TCNE) or TCNEO to give 2-[1,3-diphenyl-1,2,4-benzotriazin-7(1H)-ylidene]propanedinitrile (303) in low yield. Then, treating benzotriazinone (8) with Hünig's base in EtOH gave 6-ethoxybenzotriazinone (302) in moderate yield (44\%). In addition, treating benzotriazinone (8) with $\mathrm{KOH}$ in $\mathrm{THF} / \mathrm{H}_{2} \mathrm{O}$ and $\mathrm{O}_{2}$ as oxidant gave 6-hydroxy-1,3-diphenyl-1,2,4-benzotriazin-7(1H)-one (301) in good yield (92\%). Finally, O-ethylation using Etl and Hünig's base in MeCN gave the identical 6-ethoxybenzotriazinone (302) in 71\% yield (Scheme 60). ${ }^{113}$ 


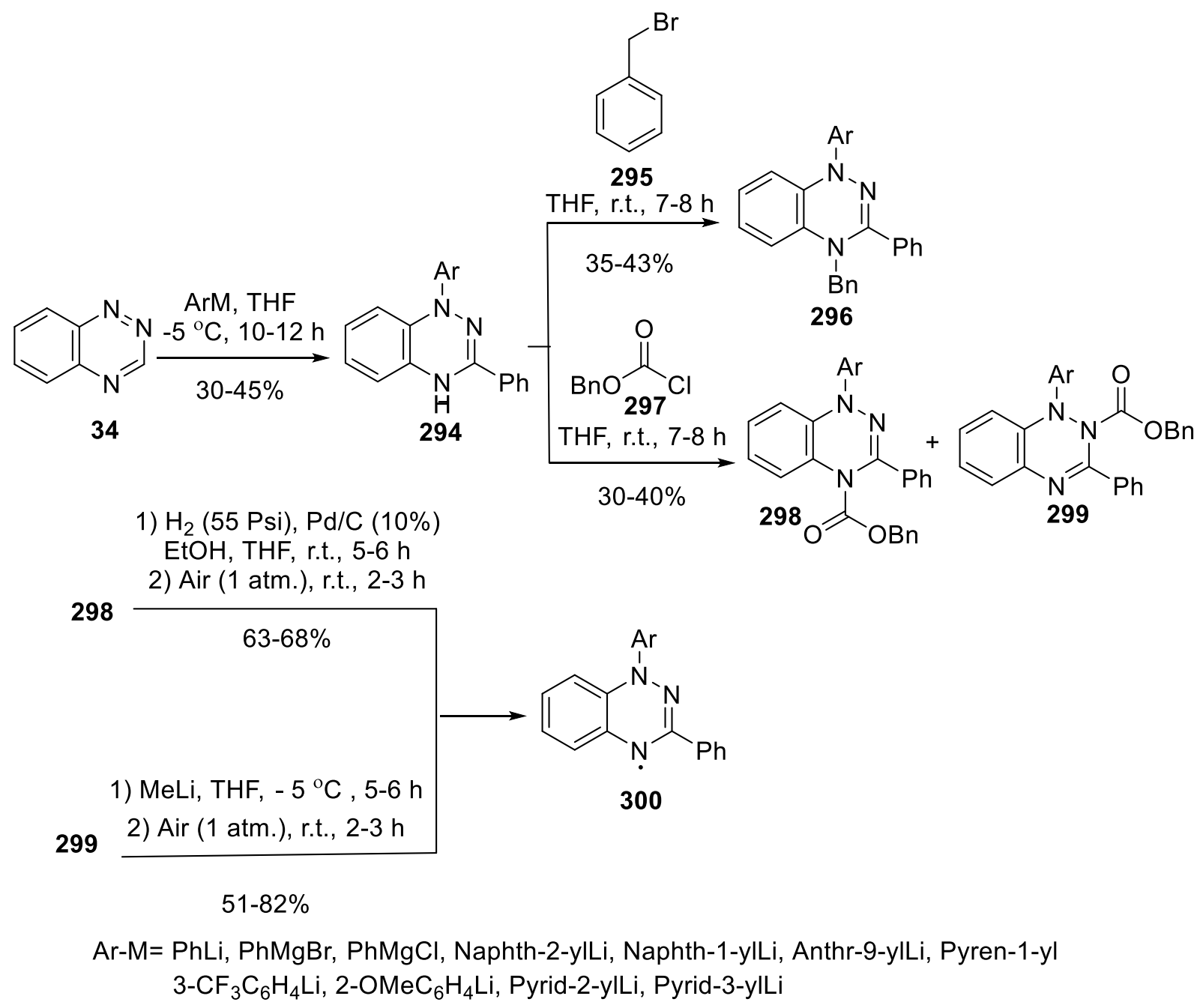

Scheme 59. Preparation of 1-aryl-3-phenyl-1,4-dihydro-1,2,4-benzotriazin-4-yls (300) from 1,2,4-benzotriazine (34) and preparation of radical (300) from 1,2,4-benzotriazine (34) via the protection/deprotection route.

In further work by the Koutentis group, the radicals (307) were prepared in three steps starting from benzotriazin-7(1H)-one (304) which was directly aminated using $O$-benzylhydroxylamine hydrochloride and Hünig's base in refluxing ethanol to give the 6-aminobenzotriazinone (305) in $79 \%$ yield. Reaction of compound (305) with acyl chlorides and sodium hydride in DMF gave the $N$-(benzotriazin-6-yl)carboxamides (306). Finally, the oxazolo- or thiazolo-fused benzotriazinyls (307) were produced in good yields by the treatment of the carboxamides (306) with phosphorus pentasulfide or phosphorus pentoxide (Scheme 61). ${ }^{114}$ 


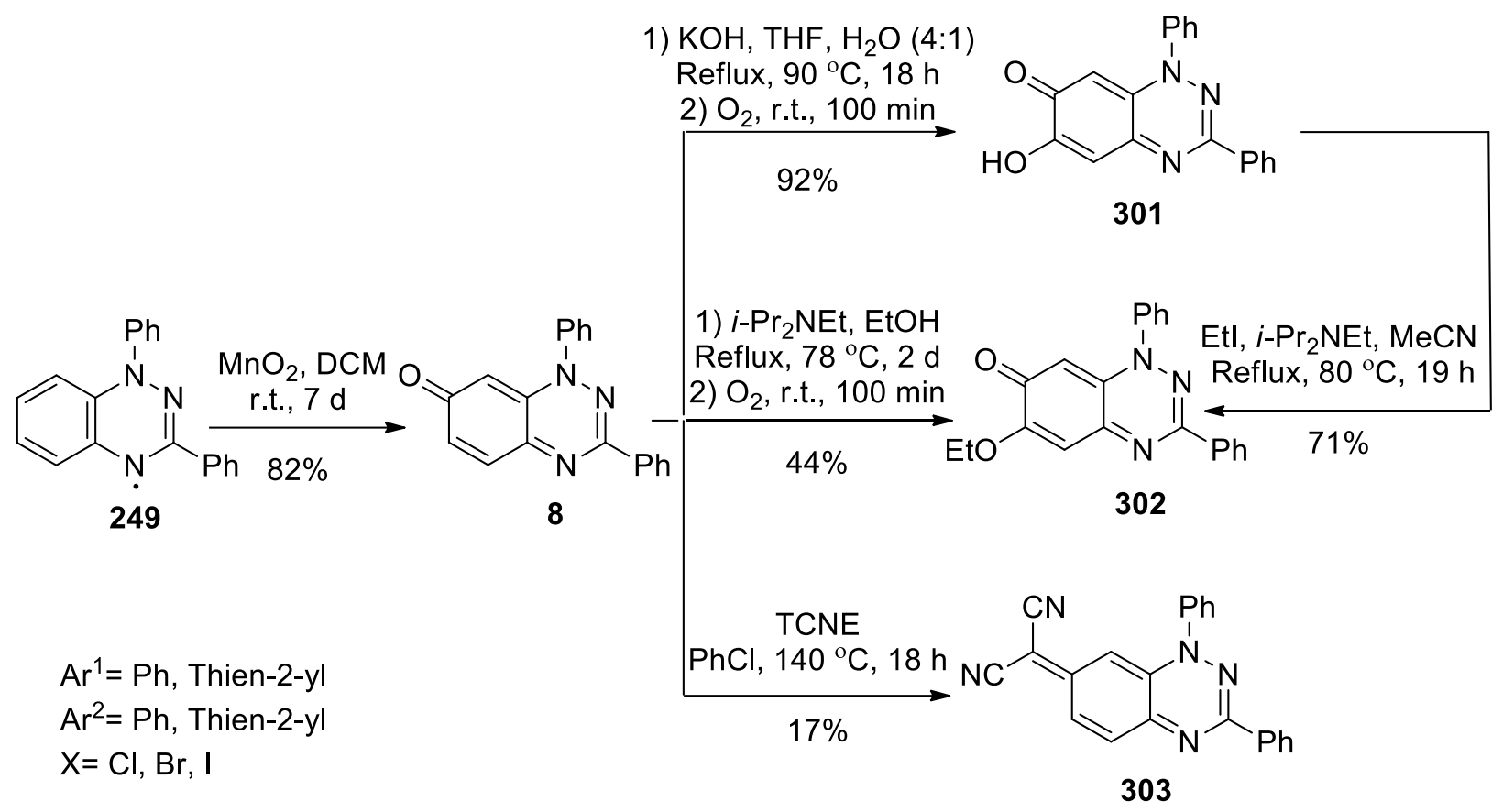

Scheme 60. Preparation of 6-ethoxy-1,2,4-benzotriazinone (302).

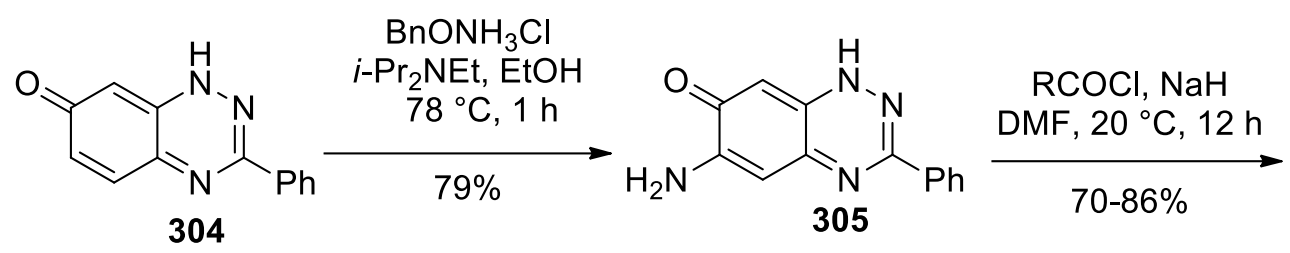<smiles>[R]C(=O)Nc1cc2nc(-c3ccccc3)n[nH]c-2cc1=O</smiles>

$\mathrm{R}=\mathrm{Me}, \mathrm{Ph}, 2-\mathrm{Naphthyl}, \mathrm{Py}-2-\mathrm{yl}, 2-\mathrm{Thienyl}$ $\mathrm{X}=\mathrm{O}, \mathrm{S}$

Scheme 61. Synthetic route for the preparation of oxazolo and thiazolo-fused benzotriazinyl radicals (307).

Reductive ring contraction of 1,3-diphenyl-1,4-dihydro-1,2,4-benzotriazin-4-yls (308) using zinc powder (2 equiv.) in hot acetic acid gave 1,2-diphenylbenzimidazoles (310) in high yield. Treating a pure sample of 6iodo-1,2-diphenylbenzimidazole (309) with $\mathrm{Zn}$ (3 equiv.) in AcOH gave the diphenylbenzimidazole (310) in 97\% yield. Interestingly, the reductive ring contraction also worked with 1,3-diphenyl-1,2,4-benzotriazin-7(1H)-one (8) but required at least 3 equivalents of $\mathrm{Zn}$ powder to drive the reaction to completion, affording 1,2diphenylbenzimidaz-6-ol (311) in 74\% yield. 1,3-Diphenyl-1,2,4-benzotriazin-7(1H)-one (8) and the zwitterionic TPHA (242) also underwent reductive ring contractions to give 1,2-diphenylbenzimidaz-6-ole (311). Furthermore, the zwitterionic TPHA (242), when treated with $\mathrm{Zn}$ in $\mathrm{AcOH}$, gave the anticipated 1,2,6,7tetraphenyl-1,7-dihydrobenzo[1,2-d:4,5- $\left.d^{\prime}\right]$ diimidazole (312) in 95\% yield. However, when only 2 equivalents 
of zinc were used the reaction could not be driven to completion and the diimidazole (312) was obtained in only $22 \%$ yield together with the unusual imidazole-fused radical (313) in $45 \%$ yield. By using less zinc, the incomplete reduction of TPHA (242) gave the stable organic radical 1,3,7,8-tetraphenyl-4,8-dihydro- $1 \mathrm{H}$ imidazo[4,5-g][1,2,4]benzotriazin-1-yl (313). Imidazolo-, oxazolo- and thiazolo-fused 1,2,4-benzotriazinyls (307) all underwent zinc-mediated ring contractions to give imidazolo-, oxazolo- and thiazolo-fused benzimidazoles (314) in excellent yields (Scheme 62). ${ }^{115}$<smiles>[R]c1ccc2c(c1)N(c1ccccc1)N=C(c1ccccc1)N2</smiles>

308

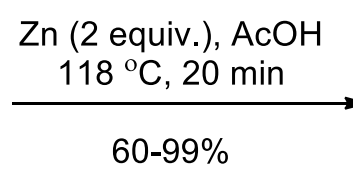

$60-99 \%$

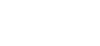<smiles>[R]c1ccc2nc(-c3ccccc3)n(-c3ccccc3)c2c1</smiles>

309

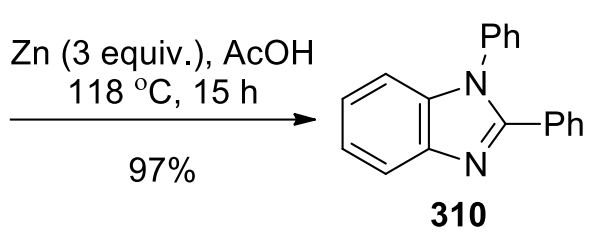

310

If $R=$ I<smiles>O=c1ccc2nc(-c3ccccc3)nn(-c3ccccc3)c-2c1</smiles><smiles></smiles>

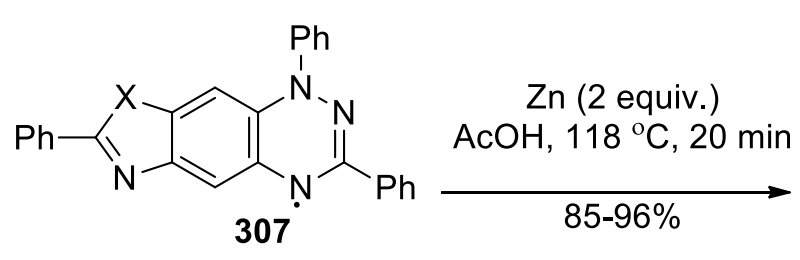

313<smiles>[Z13]c1cc2nc(-c3ccccc3)n(-c3ccccc3)c2cc1[X]</smiles>

$\mathrm{R}=\mathrm{H}, \mathrm{Cl}, \mathrm{Br}, \mathrm{I}, \mathrm{CF}_{3}$, Ph, Fur-2-yl

$\mathrm{X}=\mathrm{O}, \mathrm{S}, \mathrm{NPh}$

Scheme 62. Reductive ring contraction of TPHA (232), 1,2,4-benzotriazinone (8) and imidazolo-, oxazolo- and thiazolo-fused benzotriazinyl radicals (296).

\section{1,2,4-Benzotriazine $\mathrm{N}$-oxides}

\subsection{3-Amino-1,2,4-benzotriazine $\mathbf{N}$-oxides}

Acylation of nitroaniline (315) using phosgene gave compound (316) followed by treatment with ammonia yielded the ureide (317) which then cyclized in basic medium to afford the favored 7-substituted-3-hydroxy1,2,4-benzotriazine 1-oxide (318) within 30 minutes in good yields. Depending on the applied conditions, 
especially on the concentration of $\mathrm{NaOH}$, two different products can be formed from the ureide (317)
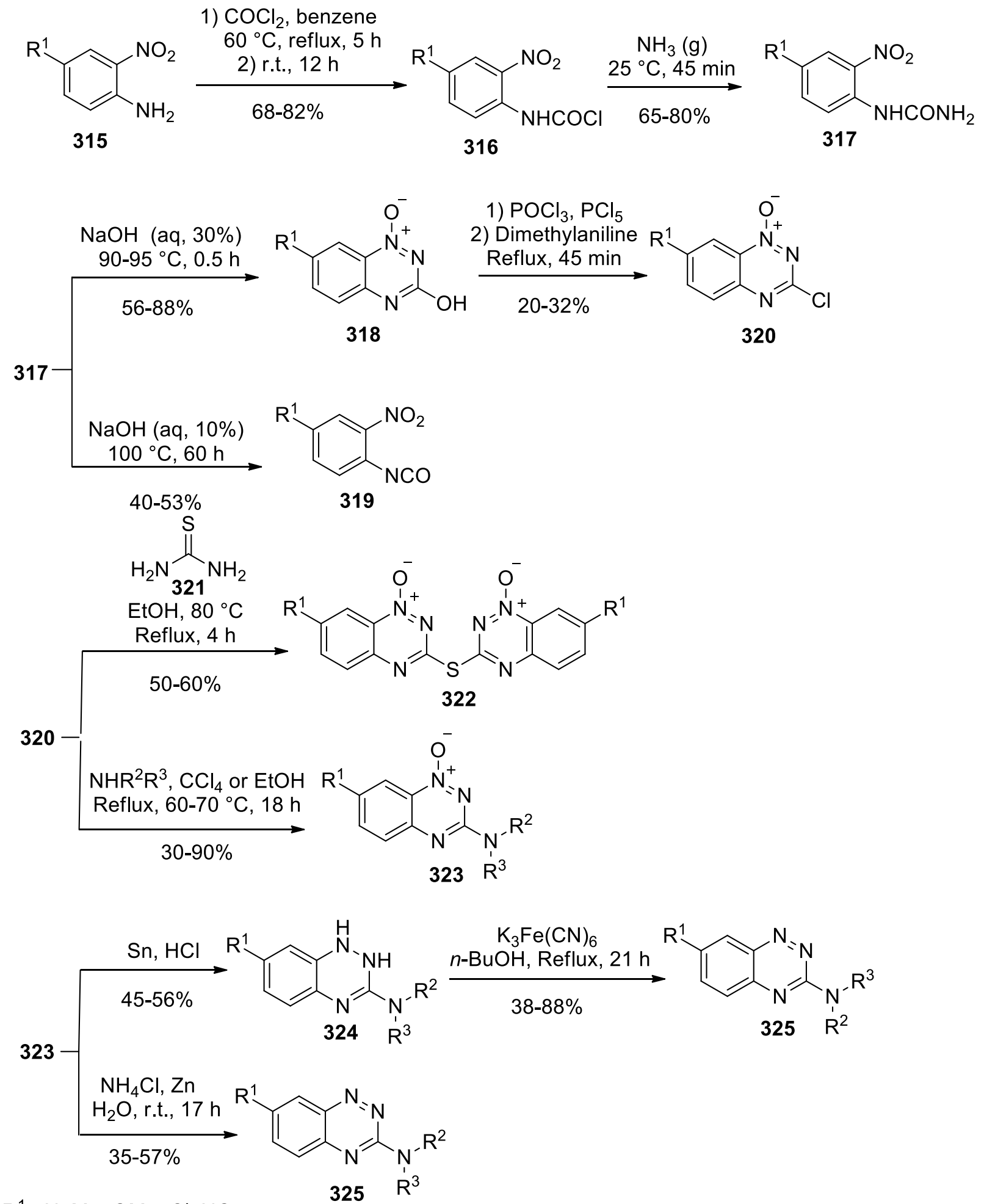

$\mathrm{R}^{1}=\mathrm{H}, \mathrm{Me}, \mathrm{OMe}, \mathrm{Cl}, \mathrm{NO}_{2}$

$325 \mathrm{R}^{3}$

$\mathrm{R}^{2}=\mathrm{H}, n-\mathrm{Bu}, n-\mathrm{Hex},\left(\mathrm{CH}_{2}\right)_{3} \mathrm{~N}(\mathrm{Et})_{2},\left(\mathrm{CH}_{2}\right)_{4} \mathrm{CH}\left(\mathrm{NH}_{2}\right) \mathrm{COOH}, n-\mathrm{Pr}, p-\mathrm{C}_{6} \mathrm{H}_{4} \mathrm{COOH}, p-\mathrm{C}_{6} \mathrm{H}_{4}\left(\mathrm{CH}_{2}\right)_{3} \mathrm{COOH}$,

$\mathrm{CH}(\mathrm{Et}) \mathrm{CH}_{2} \mathrm{OH}, \mathrm{CNHNH}_{2},\left(\mathrm{CH}_{2}\right)_{2} \mathrm{Ph},\left(\mathrm{CH}_{2}\right)_{2}-1,2-(\mathrm{OMe})_{2} \mathrm{C}_{6} \mathrm{H}_{3}, \mathrm{CH}_{2}-\left(5-\left(\mathrm{CH}_{2} \mathrm{OH}\right)-2-\mathrm{Me}-3-\mathrm{OH}\right)-4-p y r i d y l$ $\mathrm{R}^{3}=\mathrm{H}, \mathrm{Me}, n-\mathrm{Pr}, \mathrm{NH}_{2}, \mathrm{MeNH},\left(\mathrm{CH}_{2}\right)_{2} \mathrm{NMe}_{2}$

$\mathrm{R}^{2}, \mathrm{R}^{3}=\mathrm{Cy}, \mathrm{THP},\left(\mathrm{CH}_{2}\right)_{2} \mathrm{NHCOCH}_{2}$

Scheme 63. The synthetic route to 3-amino-7-substituted-1,2,4-benzotriazines (325). 
including the 7-substituted 3-hydroxy-1,2,4-benzotriazine-1-oxide (318), or the corresponding isocyanate (319). ${ }^{116}$ Accordingly, in the last step, ring closure is the favored reaction at high concentrations of sodium hydroxide. Compounds (319) are converted into the desired 3-chloro-1,2,4-benzotriazine 1-oxides (320) in low yield by treating with phosphorus oxychloride or a mixture of phosphorus oxychloride and phosphorus pentachloride under reflux conditions. By reacting the chloro compounds (320) with thiourea (321) in absolute ethanol, the sulfide compounds (322) were obtained. The compound (320) also reacted readily with a variety of amines at $60-70{ }^{\circ} \mathrm{C}$ to give the compounds (323). ${ }^{117}$ Finally, the latter were reduced to form compounds (325) through two methods including: a) reduction with tin and hydrochloric acid to give the 3-substituted-1,2dihydro-1,2,4-benzotriazines (324) which were subsequently oxidized by potassium ferricyanide; b) direct treatment of the 1-oxides (322) with zinc dust and ammonium chloride in water (Scheme 63). ${ }^{118}$
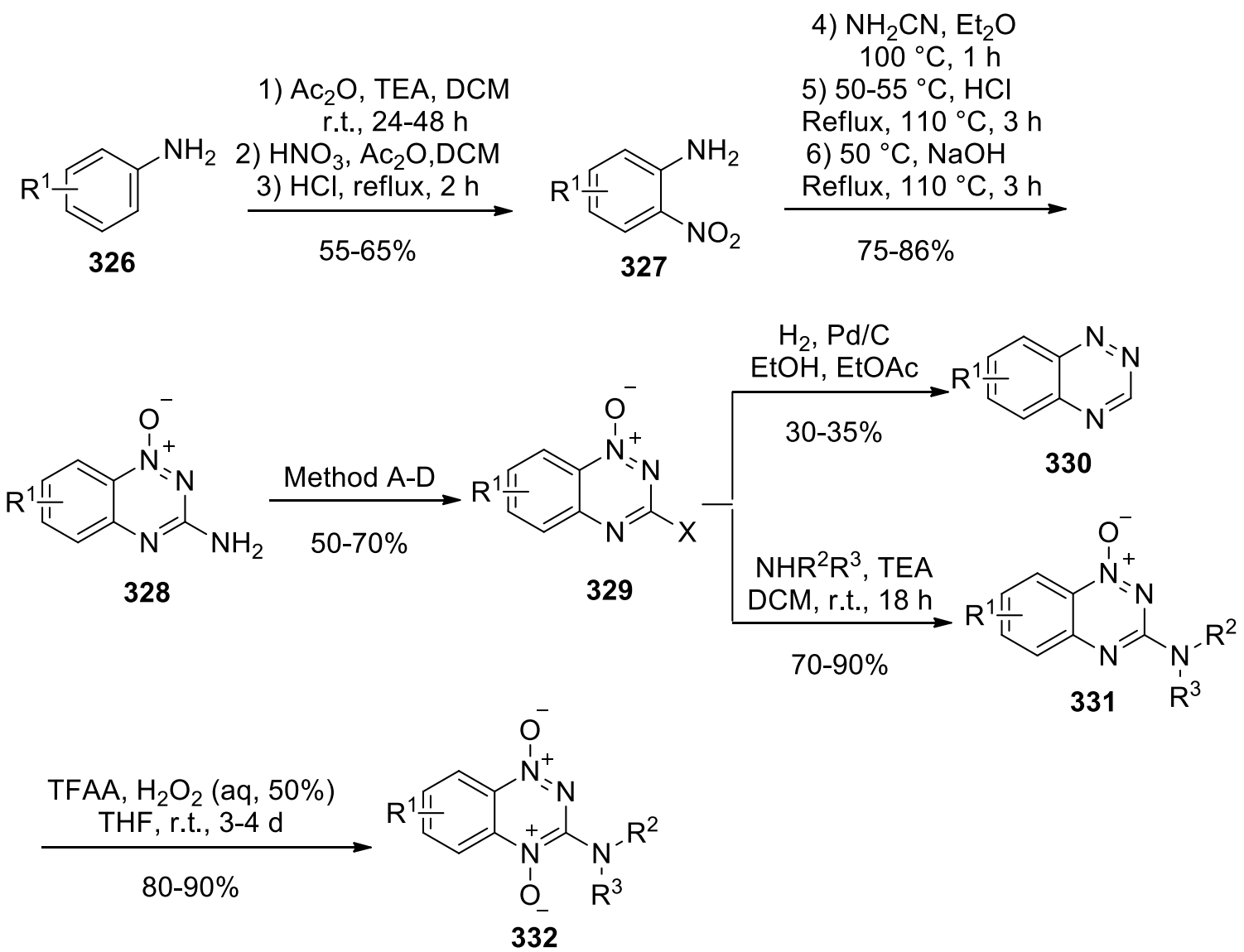

$\mathrm{R}^{1}=\mathrm{H}, 7-\mathrm{F}, 7-\mathrm{Cl}, 7-\mathrm{Br}, 7-\mathrm{OMe}, 7-\mathrm{Me}, 6-\mathrm{F}, 6-\mathrm{OMe}, 6,7=\left(\mathrm{CH}_{2}\right)_{3}$, 5-Me

$\mathrm{R}^{2}=\mathrm{Me}, \mathrm{Et}, \mathrm{CMe}_{3}$, Cyclobutyl, Cyclopentyl, Cy, Cycloheptyl

$\mathrm{R}^{3}=\mathrm{H}, \mathrm{Me}, \mathrm{Et}$

$\mathrm{R}^{2}, \mathrm{R}^{3}=\left(\mathrm{CH}_{2}\right)_{2} \mathrm{O}\left(\mathrm{CH}_{2}\right)_{2},\left(\mathrm{CH}_{2}\right)_{2} \mathrm{SO}_{2}\left(\mathrm{CH}_{2}\right)_{2},\left(\mathrm{CH}_{2}\right)_{4},\left(\mathrm{CH}_{2}\right)_{5}, \mathrm{CH}(\mathrm{Me})\left(\mathrm{CH}_{2}\right)_{4}, \mathrm{CH}_{2}-\mathrm{C}_{6} \mathrm{H}_{4},\left(\mathrm{CH}_{2}\right)_{2}-\mathrm{C}_{6} \mathrm{H}_{4}$

$\mathrm{X}=\mathrm{Cl}, \mathrm{Br}$ I

Method A: 1) $t$-BuONO, $t$-BuOH, $\mathrm{H}_{2} \mathrm{O}, 60^{\circ} \mathrm{C}$, over night; 2) $\mathrm{POCl}_{3}$ or $\mathrm{POBr}_{3}$, reflux, $3 \mathrm{~h}(50-70 \%)$

Method B: 1) $t$-BuONO, $\mathrm{I}_{2}$, Cul, or $\mathrm{Cl}_{2}, \mathrm{CuCl}$, or $\left.\mathrm{Br}_{2}, \mathrm{CuBr}, \mathrm{THF} ; 2\right)$ reflux, $2 \mathrm{~h}(52-82 \%)$

Method C: 1) $\left.\mathrm{NaNO}_{2}, \mathrm{HCl}(\mathrm{aq}, 10 \%), 0{ }^{\circ} \mathrm{C}, 2 \mathrm{~h} ; 2\right) \mathrm{POCl}_{3}, \mathrm{PhNMe}_{2}, 80^{\circ} \mathrm{C}(60-68 \%)$

Method D: 1) $\left.\left.\mathrm{NaNO}_{2}, \mathrm{TFA}, 5^{\circ} \mathrm{C}, 5 \mathrm{~min} ; 2\right) 20^{\circ} \mathrm{C}, 3 \mathrm{~h} ; 3\right) \mathrm{POCl}_{3}$ or $\mathrm{POBr}_{3}$, DMF, $100{ }^{\circ} \mathrm{C}, 1 \mathrm{~h}(60-80 \%)$

Scheme 64. Synthesis of ring substituted 3-amino substituted-1,2,4-benzotriazine di- $N$-oxides (332). 
Chopra et al. used a synthetic route starting from substituted anilines (326) for the construction of ringmodified benzotriazine oxides (BTOs) (328). The anilines were acylated, nitrated with fuming nitric acid, and then deprotected by refluxing in hydrochloric acid to produce 2-nitroanilines (327). Then, the latter were condensed with cyanamide in concentrated hydrochloric acid, followed by treatment with a base to afford the 6-substituted 3-amino-1,2,4-benzotriazine 1-oxides (328). Next, the latter were converted into 3-halo-1,2,4benzotriazines by reaction with either $t$-butyl nitrite or sodium nitrite to form the diazonium intermediates followed by halogenation in refluxing phosphorus oxychloride (method A, C, D) or by addition of iodine and copper (I) iodide mixture (method B) to produce the 3-halobenzotriazine 1-oxide (329). It is noteworthy that method B provides better yields (52-82\%). Catalytic hydrogenation of (329) gave the 1,2,4-benzotriazine (330). ${ }^{119}$ Compounds (329) were then reacted with various primary amine-type side chains to develop drugs with antimicrobial activities. This set of ring-substituted BTOs (331) was then oxidized using TFAA in the presence of hydrogen peroxide to give the final di-N-oxide (332) (Scheme 64). ${ }^{120}$

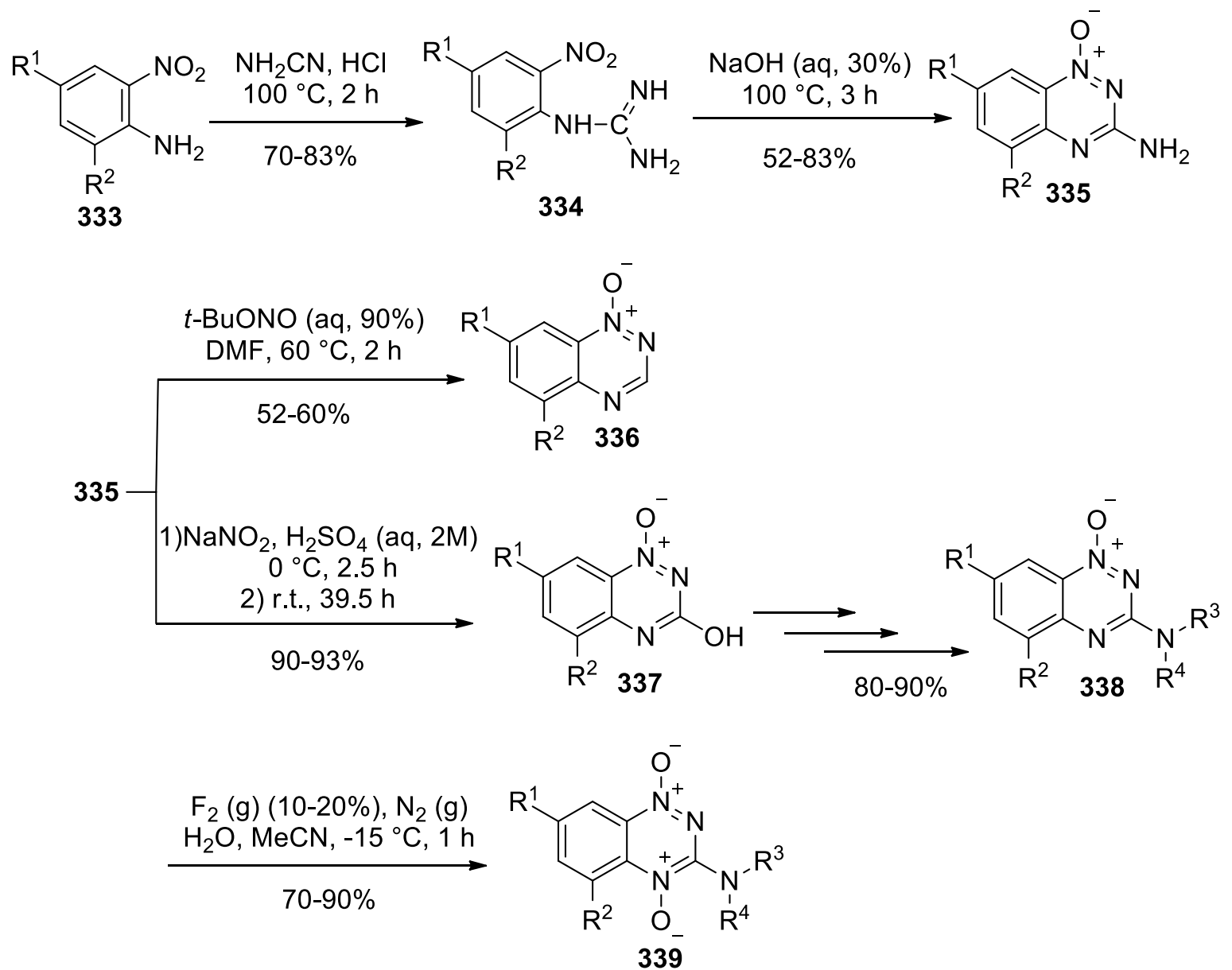

$\mathrm{R}^{1}=\mathrm{H}, \mathrm{Me}, \mathrm{OMe}, \mathrm{OEt}, \mathrm{Cl}, \mathrm{Ph}, \mathrm{OCH}_{2} \mathrm{Cl}, \mathrm{OCH}_{2} \mathrm{OMe}$

$\mathrm{R}^{2}=\mathrm{H}, \mathrm{Me}$

$\mathrm{R}^{3}=\mathrm{H}, \mathrm{Me},\left(\mathrm{CH}_{2}\right)_{3} \mathrm{NMe}_{2},\left(\mathrm{CH}_{2}\right)_{3} \mathrm{NEt}_{2}$

$\mathrm{R}^{4}=\mathrm{H},\left(\mathrm{CH}_{2}\right)_{2} \mathrm{C}_{6} \mathrm{H}_{4},\left(\mathrm{CH}_{2}\right)_{2} \mathrm{NMe}_{2}, \mathrm{C}\left(\mathrm{CH}_{2} \mathrm{OH}\right)_{2} \mathrm{Me}, \mathrm{CH}_{2}(\mathrm{CHOH})_{4} \mathrm{CH}_{2} \mathrm{OH},\left(\mathrm{CH}_{2}\right)_{2}-\mathrm{OH}, \mathrm{CH}_{2}-\mathrm{C}(\mathrm{OH}) \mathrm{Me}_{2}, \mathrm{Ph}$, $\mathrm{N}(n-\mathrm{Bu})_{2}\left(\mathrm{CH}_{2}\right)_{3} \mathrm{NH}_{2},\left(\mathrm{CH}_{2}\right)_{2}$-4-morpholine, $\left(\mathrm{CH}_{2}\right)_{3}$-4-morpholine, $\mathrm{CH}_{2}$-2-furyl

$\mathrm{R}^{3}, \mathrm{R}^{4}=\mathrm{Et},\left(\mathrm{CH}_{2}\right)_{4},\left(\mathrm{CH}_{2}\right)_{5},\left(\mathrm{CH}_{2}\right)_{6},\left(\mathrm{CH}_{2}\right)_{2} \mathrm{O}\left(\mathrm{CH}_{2}\right)_{2}, \mathrm{CH}_{2} \mathrm{CONH}\left(\mathrm{CH}_{2}\right)_{2}$

Scheme 65. Synthesis of 3-amino-5,7-disubstituted-1,2,4-benzotriazine 1-oxides (336-338) and 1,4-dioxides (339). 
Jiu and Mueller synthesized 3-amino-1,2,4-benzotriazine 1-oxides (335) by the reaction of substituted 2nitroanilines (333) with cyanamide under acidic condition yielding 2-nitrophenylguanidines (334). This reaction was followed by the previously described cyclization process and diazotization to obtain 3-hydroxy-I,2,4benzotriazine 1-oxides (337) which were then converted into 3-substituted-amino-1,2,4-benzotriazine 1oxides (338) through the procedure as mentioned before in Scheme $64 .{ }^{121}$ Furthermore, treatment of 1,2,4benzotriazine 1-oxides (335) with t-butyl nitrite in DMF gave 1,2,4-benzotriazines (336). N-Oxidization of the benzotriazine ring system (3) with $\operatorname{HOF}\left(\mathrm{F}_{2}(\mathrm{~g}), \mathrm{H}_{2} \mathrm{O}\right)-\mathrm{MeCN}$ complex resulted in the preparation of 1,2,4benzotriazine 1,4-dioxides (339) in an easy and high-yielding method (Scheme 65)..$^{122}$

Parrick's group synthesized the antiproliferative compound (344) by the conversion of 4-(4-halo or 4methoxybutoxy)-2-nitroaniline (340) to the benzotriazine 1-oxide (341). Theophylline (342) was then reacted with (341) to give the 4-oxide (343) which was subsequently oxidized to the 3-amino-7-[4-(theophyllin-7yl)butyloxy]-1,2,4-benzotriazine 1,4-dioxide (344) (Scheme 66). ${ }^{123}$
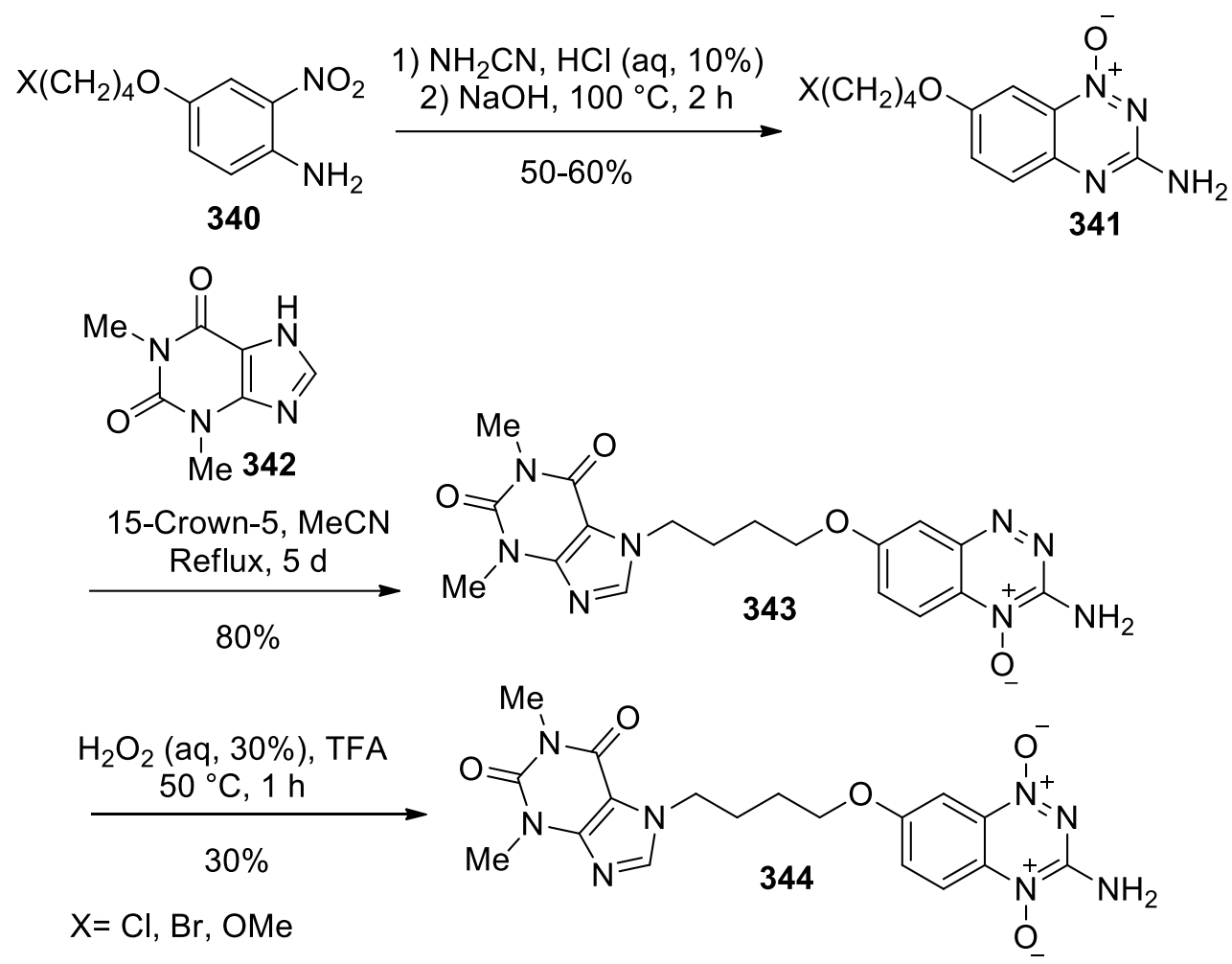

Scheme 66. Formation of 3-amino-7-(purin-7-ylbutyloxy)-1,2,4-benzotriazine 1,4-dioxide (344).

Suzuki and Kawakami used derivatives of either 1,2-dinitrobenzene or 2-fluoronitrobenzene (348) as reactants for treatment with guanidine (18) to provide the desired product (346) which reacted with sodium dithionite in refluxing EtOH to produce the reduced compound (347). Subsequently, the amidines (348) were prepared through the reaction of the aminobenzotriazines (347) with an excess amount of dimethylformamide dimethylacetal or dimethylacetamide dimethylacetal. In addition, treatment of compound (346) with paraformaldehyde and alcohols in the presence of catalytic amount of acetic acid resulted in the formation of 3-(alkoxymethylamino)-1,2,4-benzotriazine 1-oxides (349) in high yields. Further oxidation of monoxides (349) to 1,4-dioxides (350) was performed using hydrogen peroxide in acetic acid (Scheme 67). ${ }^{124}$ 

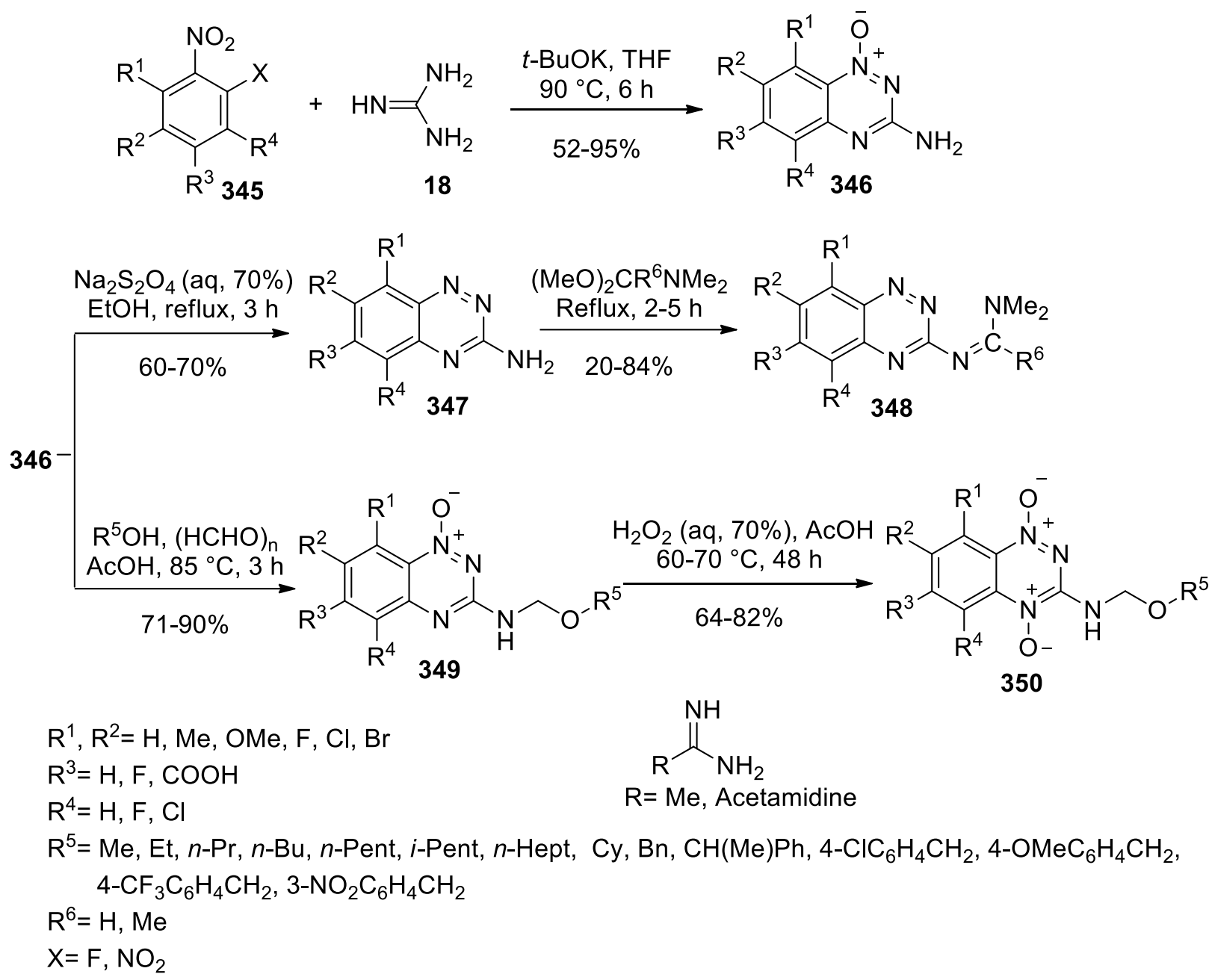

Scheme 67. Synthesis of 3-amino-1,2,4-benzotriazine 1,4-dioxides (350).

Hay and coworkers prepared a series of 1,2,4-benzotriazine 1,4-dioxides (357) by treating 3-chloro-1,2,4benzotriazine 1-oxide (351) with $N$-(3-aminopropyl)-N-methyl-1,3-propanediamine (352) followed by protection with TFAA to avoid oxidation of the terminal amine, to give 3-(\{3-[methyl-(3-trifluoroacetamido)propylamino]propyl\}amino)-1,2,4-benzotriazine 1-oxide (353). Oxidation of (353) with trifluoroperacetic acid (TFPAA) led to 1,2,4-benzotriazine-1,4-dioxide (354). Upon amine-deprotection of the latter following by treatment with aromatic carboxylic acids (356), carboxamide (357) was formed (Scheme 68). These compounds were DNA-targeting pharmacophores which can be attached to the 3-position via a flexible linker. DNA binding affinity was modified through variation of the pharmacophore or the linker chain. ${ }^{125}$ 
<smiles>[O-][n+]1nc(Cl)nc2ccccc21</smiles>

351<smiles>CN(CCCNc1nc2ccccc2[n+]([O-])n1)CCCNC(OC(F)F)C(F)(F)F</smiles>

353
1) $\mathrm{NEt}_{3}, \mathrm{DCM}$ $20^{\circ} \mathrm{C}, 2 \mathrm{~d}$

2) TFAA, DCM Reflux, $16 \mathrm{~h}$

$43 \%$

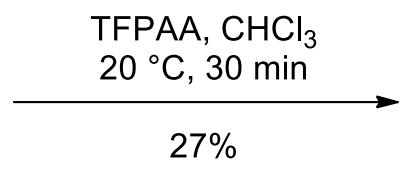<smiles>CC(C)(C)N(CCCNC(=O)F)CCCNc1n[n+]([O-])c2ccccc2[n+]1[O-]</smiles>

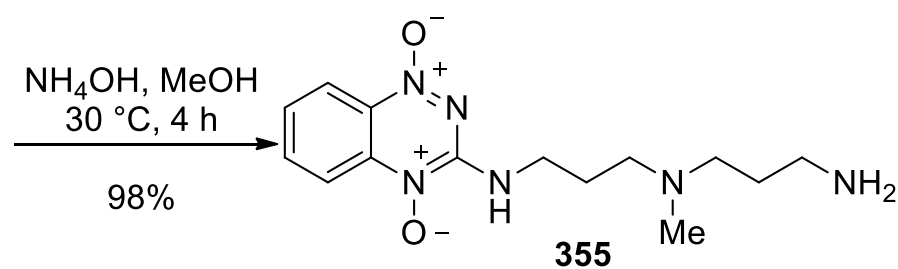

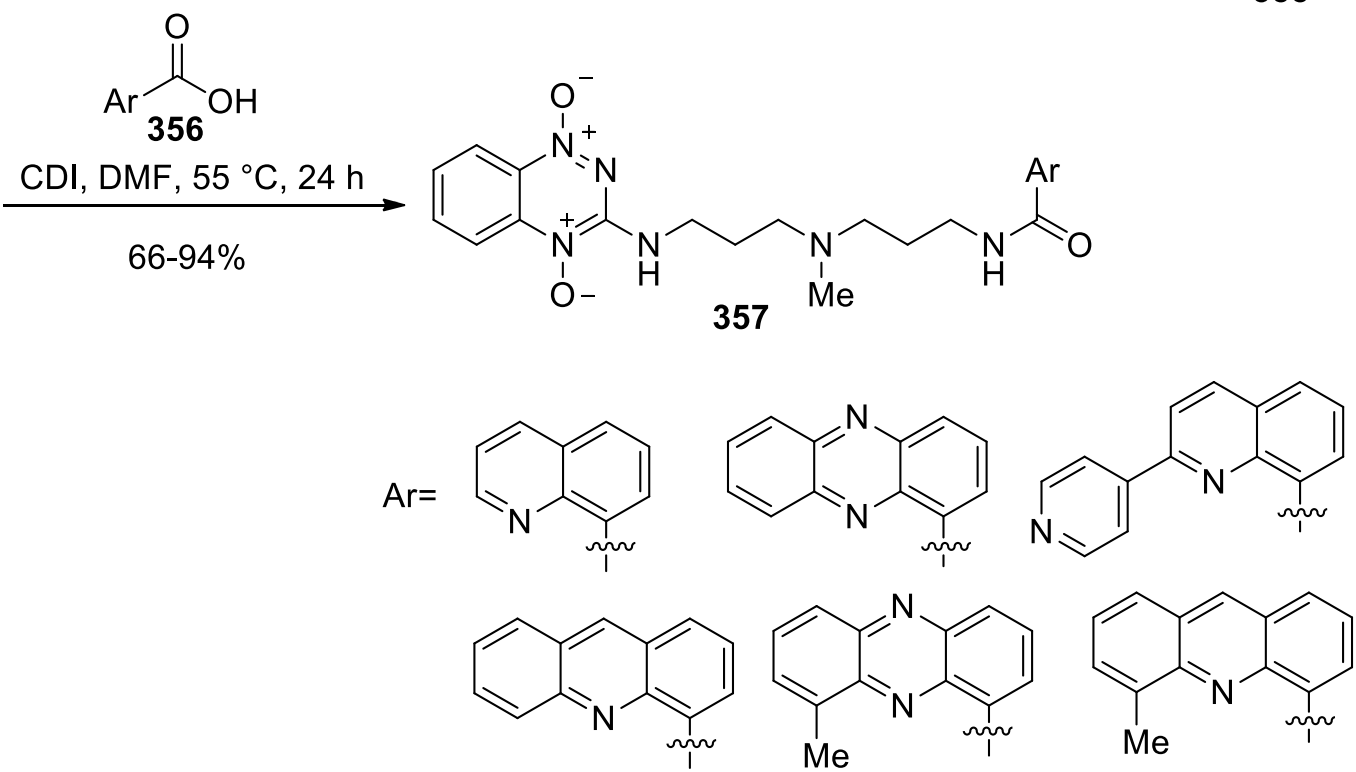

Scheme 68. The synthetic route of 3-amino-1,2,4-benzotriazine 1,4-dioxides linked to a pharmacophore unit (357).

Lee and coworkers synthesized compound (363) (which contains both 1,4-dioxide and 1-oxide moieties) starting from diamine (358). To this end, one of the amine groups of (358) was protected to give compound (359) and then the free amine group was treated with compound (351) to produce 1,2,4-benzotriazine 1-oxide (360) followed by oxidation to give 1,2,4-benzotriazine 1,4-dioxide (361). Further deprotection of the trifluoroacetamido group with ammonium hydroxide produced compound (361) to be converted into the corresponding primary amine (362) in quantitative yield ( 99\%). Finally, the chloride (351) was coupled to the alkylamino groups of (362) in refluxing methanol to yield the corresponding compounds (363) (Scheme 69). ${ }^{126}$ 


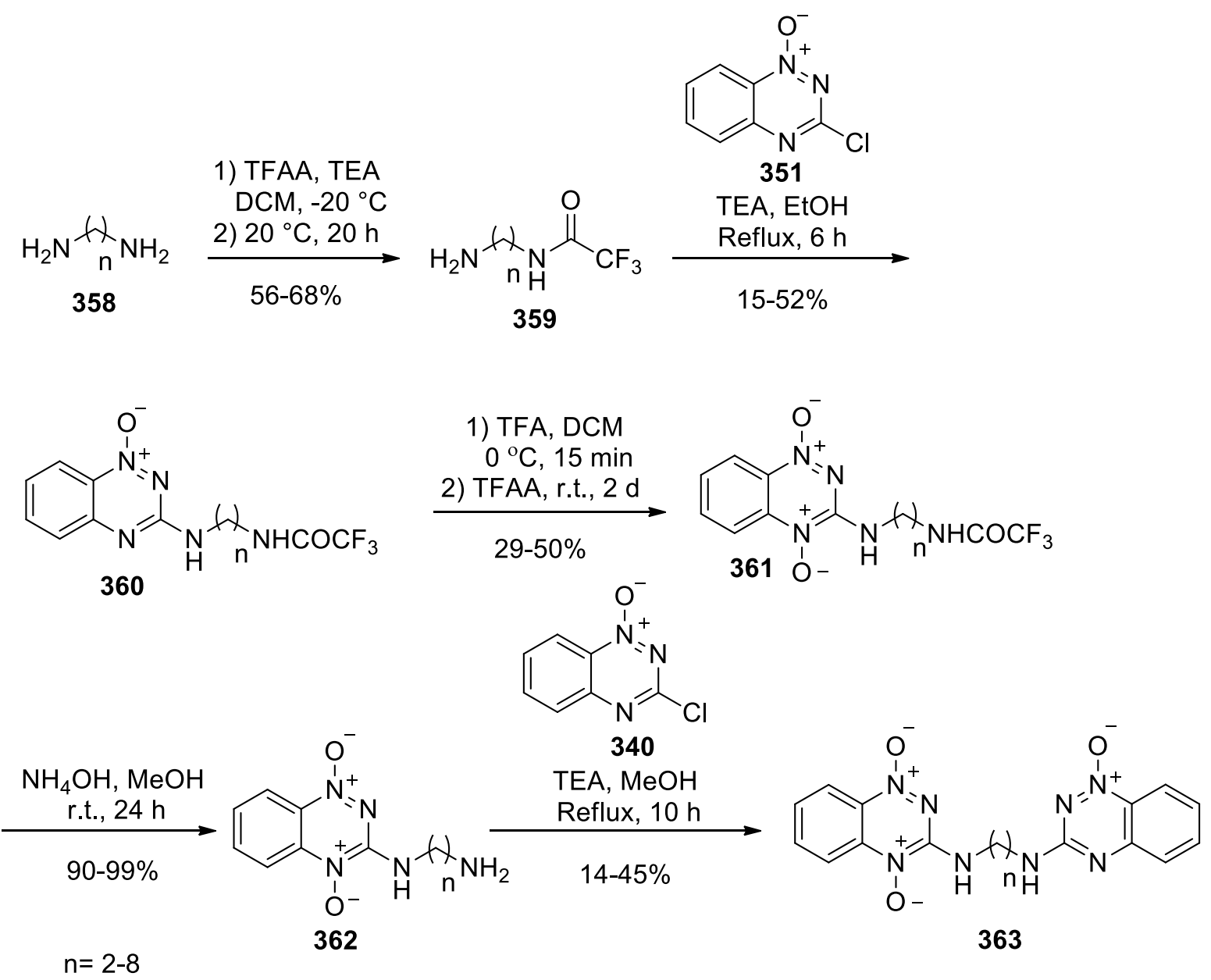

Scheme 69. Formation of 3-amino-bis-1,2,4-benzotriazine 1-oxide and 1,4-dioxide bearing alkyl linkers (363).

1,2-Diaminobenzimidazole (365) was produced through the reaction of the corresponding 2-aminobenzimidazole (364) with hydroxylamine-O-sulfonic acid. Then, oxidative rearrangement using iodobenzene diacetate $\left[\mathrm{PhI}(\mathrm{OAc})_{2}\right]$, polymer-supported iodobenzene diacetate (PSIBD), or lead tetraacetate, provided the desired compound (367) via ring expansion of the nitrene intermediate (366). ${ }^{127}$ Hypervalent iodine reagents led to the formation of product (367) with good efficiency. The probable mechanism for this reaction includes the conversion of compound (365) into the corresponding nitrene in the presence of iodine(III) and subsequent ring expansion to form compound (367). It was found that the reactivity, reaction time and yields of both methods in the presence of $\mathrm{PhI}(\mathrm{OAc})_{2}$ or PSDIB were comparable. However, PSDIB presented advantages including the circumstance that the iodopolystyrene generated during the reaction can be filtered off and regenerated as PSDIB for further use. ${ }^{128}$ 3-Amino-1,2,4-benzotriazine 2-oxides (368) and 3-amino1,2,4-benzotriazine 1,4-dioxides (369) were isolated from the treatment of 3-amino-1,2,4-benzotriazines (367) with hydrogen peroxide at room temperature. Meanwhile, 3-amino-1,2,4-benzotriazine 4-oxides (370) were prepared using the two oxidizing agents, $m$-CPBA (method A) and $t$-butyl peracetate (method B). Both methods produced the target compound (370) in nearly identical, albeit low yield (Scheme 70). ${ }^{129}$ 
<smiles>[R]c1cc2nc(N)[nH]c2cc1[R]</smiles>

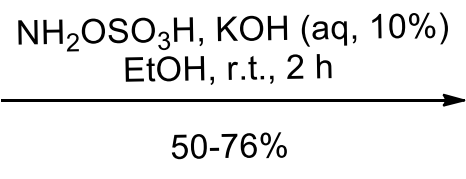<smiles>[R]c1cc2nc(N)n(N)c2cc1[R]</smiles><smiles>[R]c1cc2nnc(N)nc2cc1[R]</smiles>

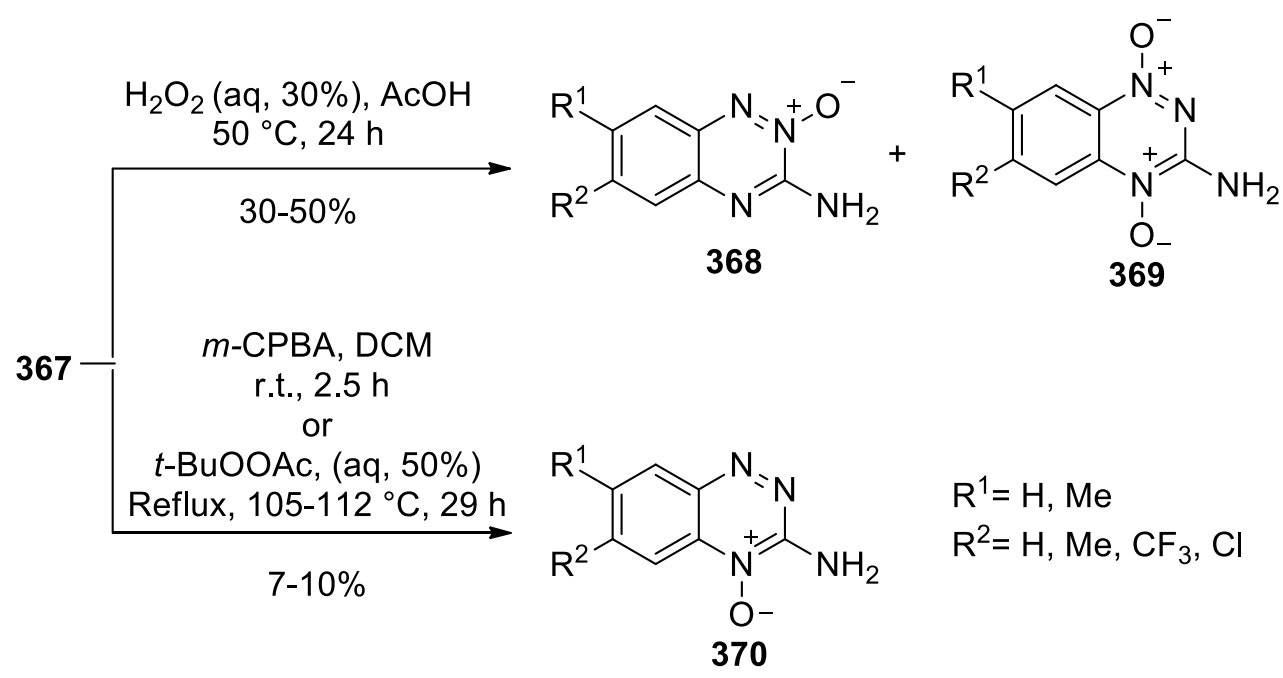

Scheme 70. Synthesis of 3-amino-1,2,4-benzotriazine 2-oxide (368), 4-oxide (370) or 1,4-dioxides (369).

The 3-amino or 3-alkyl-1,2,4-benzotriazine 1-oxide (372), 3-amino or 3-methyl-1,2,4-benzotriazine 2-oxide (373) and 1,4-dioxide analogues (374) were prepared by $m$-CPBA oxidation of 3-amino or 3-methyl-1,2,4benzotriazine (371) and characterized by X-ray crystallography (Scheme 71)..$^{130}$

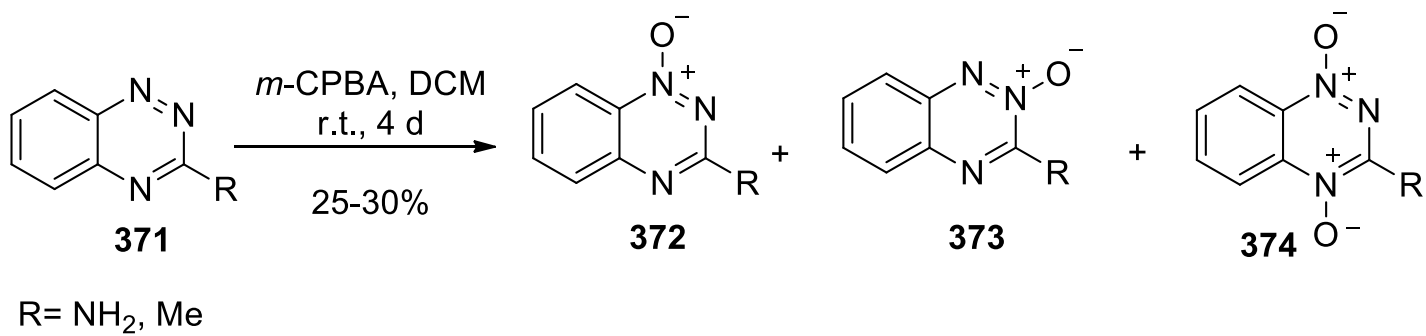

Scheme 71. $\mathrm{N}$-oxides of 3-amino or 3-methyl-1,2,4-benzotriazine (371).

Hay's research group prepared the substituted 1,2,4-benzotriazine 1,4-dioxides (376) through the oxidation of substituted 1,2,4-benzotriazine 1-oxides (375) with peracetic acid or (TFPAA). ${ }^{131}$ Correspondingly, dialkylamino-1,2,4-benzotriazine 1,4-dioxides (377) were prepared by displacement of the corresponding 8halo or 8-methoxy-1,2,4-benzotriazine 1,4-dioxides (376) with a suitable amine. Subsequent treatment of compound (377) with an excess amount of $t$-butyl nitrite in hot dimethylformamide resulted in the formation of $8-N, N^{\prime}$-dialkylamino-benzotriazine 1,4-dioxides (378). Finally, 8- $N, N^{\prime}$-dialkylamino-3-(4-methoxyanilino)- 
1,2,4-benzotriazine 1,4-dioxides (380) were obtained from the one-electron oxidation of 8- $N, N^{\prime}$-dialkylamino3-acetamido-1,2,4-benzotriazine 1,4-dioxide (379) in the presence of $p$-anisidine (255) (Scheme 72). ${ }^{132}$
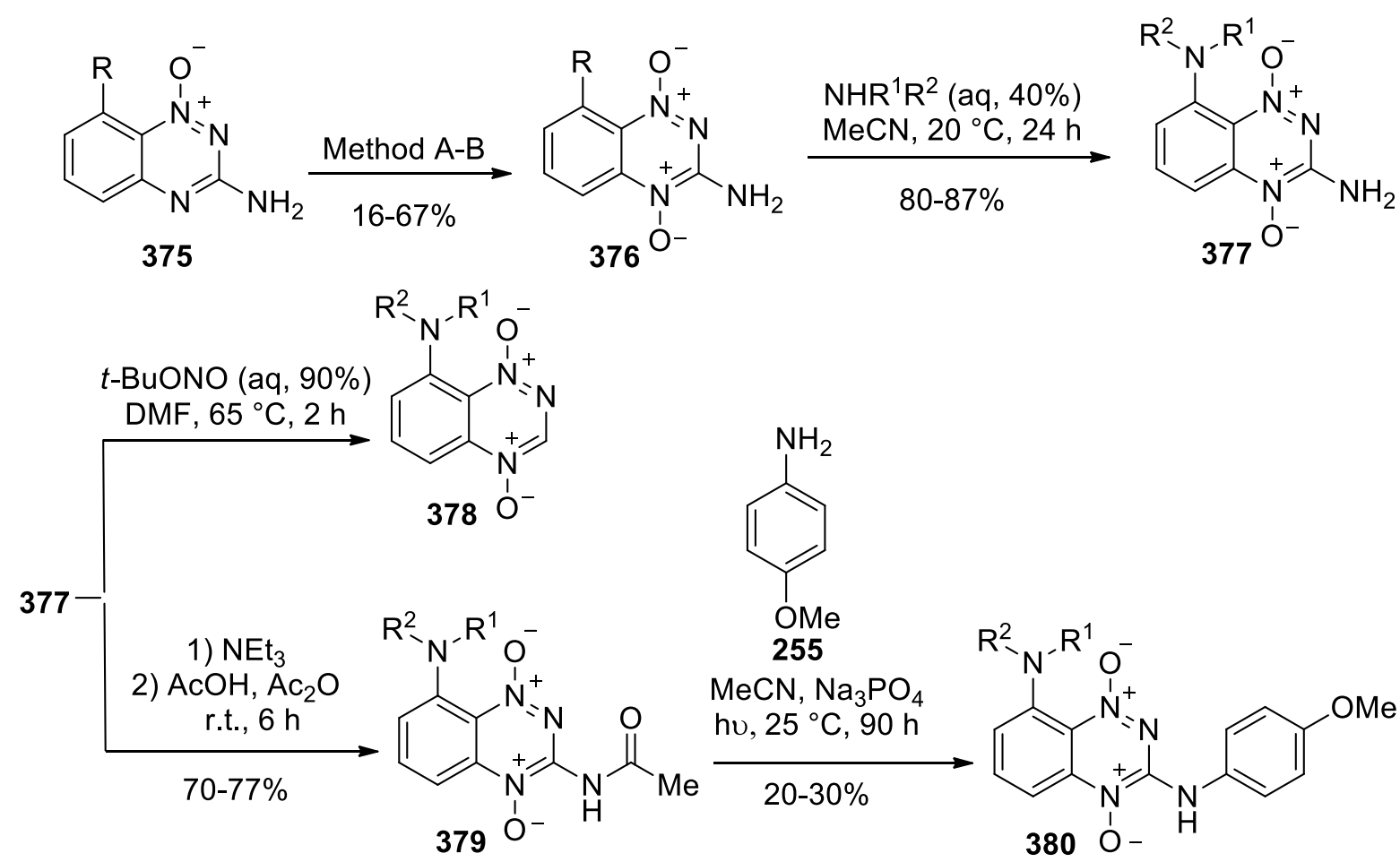<smiles>COc1ccc(N)cc1</smiles>
255 $\mathrm{MeCN}, \mathrm{Na}_{3} \mathrm{PO}_{4}$ hu, $25^{\circ} \mathrm{C}, 90 \mathrm{~h}$

$20-30 \%$

$\mathrm{R}=\mathrm{OMe}, \mathrm{F}, \mathrm{Cl}$ $\mathrm{R}^{1}, \mathrm{R}^{2}=\mathrm{Me}, \mathrm{Et}$ Method $\mathrm{A}: \mathrm{H}_{2} \mathrm{O}_{2}$ (aq, 30\%), $\mathrm{AcOH}, 50{ }^{\circ} \mathrm{C}, 4 \mathrm{~h}(16-67 \%)$ Method B: $\mathrm{H}_{2} \mathrm{O}_{2}$ (aq, $70 \%$ ), TFA, $50{ }^{\circ} \mathrm{C}, 7 \mathrm{~d}(67 \%)$

Scheme 72. Reactions of 8-substituted-3-amino-1,2,4-benzotriazine 1-oxide (375).

\subsection{3 -Aminoalkyl-1,2,4-benzotriazine $\mathbf{N}$-oxides}

Hay and Pchalek developed a versatile protocol using Stille coupling of a 3-chloro-1,2,4-benzotriazine 1-oxide (381) with $\mathrm{R}_{4} \mathrm{Sn}$ to give the corresponding 3-alkyl or 3-allyl-1,2,4-benzotriazine 1-oxide (382). ${ }^{133}$ They applied the Stille reaction to a variety of 6 or 7-alkyl and/or 7-alkoxy-3-chloro-1,2,4-benzotriazine (381) and explored the application of microwave-assisted synthesis to this transformation. Ozonolysis of the allyl side chain of (383) followed by a reduction produced the substituted ethanols (384) which were converted into alkylamines (385) via the substitution of the corresponding mesylates with the appropriate amines. Selective aromatic $N$ oxidation of the 1-oxides (385) was achieved using TFPAA/TFA and afforded moderate yields of the products (386) (Scheme 73). ${ }^{134}$ 
<smiles>[R]c1cc2nc(Cl)n[n+]([O-])c2cc1[R]</smiles><smiles>[R]c1cc2nc(CCO)n[n+]([O-])c2cc1[R]</smiles><smiles>[R]c1cc2nc(CCN([R])[R])n[n+]([O-])c2cc1[R]</smiles><smiles>[R]c1cc2c(cc1[R])[n+]([O-])c(CCN([R])[R])n[n+]2[O-]</smiles>

$\mathrm{R}^{1}, \mathrm{R}^{2}=\mathrm{H}, \mathrm{F}, \mathrm{Me}, \mathrm{OMe}$

$\mathrm{R}^{3}=\mathrm{Et}, \mathrm{CH}_{2}=\mathrm{CH}-\mathrm{CH}_{2}$

$\mathrm{R}^{4}, \mathrm{R}^{5}=\mathrm{Me},\left(\mathrm{CH}_{2}\right)_{2} \mathrm{O}\left(\mathrm{CH}_{2}\right)_{2},\left(\mathrm{CH}_{2}\right)_{5}$

Method A: $\mathrm{SnR}_{4}, \mathrm{Pd}\left(\mathrm{PPh}_{3}\right)_{4}, \mathrm{DME}, 85^{\circ} \mathrm{C}, 20 \mathrm{~h}(60-75 \%)$

Method B: SnR $4, \operatorname{Pd}\left(\mathrm{PPh}_{3}\right)_{4}, \mathrm{MeCN}, \mathrm{MW}, 140^{\circ} \mathrm{C}, 45 \mathrm{~min}(54-88 \%)$

Scheme 73. The Stille coupling of 6,7-disubstituted-3-chloro-1,2,4-benzotriazine 1-oxides (381).

\subsection{3-Alkyl- and $\mathbf{3}$-aryl-1,2,4-benzotriazine $\mathbf{N}$-oxides}

Atallah and Nazer modified the Bamberger procedure ${ }^{135}$ for the preparation of 3-substituted-1,2,4benzotriazines (392) which led to improved yields. They used $\mathrm{BF} / \mathrm{AcOH}$ instead of concd. $\mathrm{H}_{2} \mathrm{SO}_{4} \mathrm{which}$ resulted in a more effective cyclization of the 1,5-diphenyl-3-alkyl or aryl formazan precursors (390). The latter was formed from alkyl or aryl phenylhydrazones (388) produced from phenylhydrazines (244) and aldehydes (387). Then, azo coupling of compound (388) with diazotized aniline (389) resulted in the product 1,5diphenyl-3-alkyl or aryl formazan (390) which converted to 3-substituted-1,2,4-benzotriazine (391) by ring closure. Finally, the oxidation of compounds (391) was carried out by the use of a mixture of hydrogen peroxide and TFA or TFAA. In addition, the use of trimethyl phosphite as a selective deoxygenating agent reduced the dioxides (392) to the 1-oxides (393) (Scheme 74). ${ }^{136}$

An efficient synthesis of substituted 2,3,5,6,7,8-hexahydro-1,2,4-benzotriazine 4-oxides (397) was developed by adding ketones to the intermediate obtained by the reaction of 2-morpholinocyclohexyl-2-en-1one oxime (394) and hydrazine hydrate. The obtained intermediate (396) was cyclized to the desired products (397) (Scheme 75). ${ }^{137}$ 

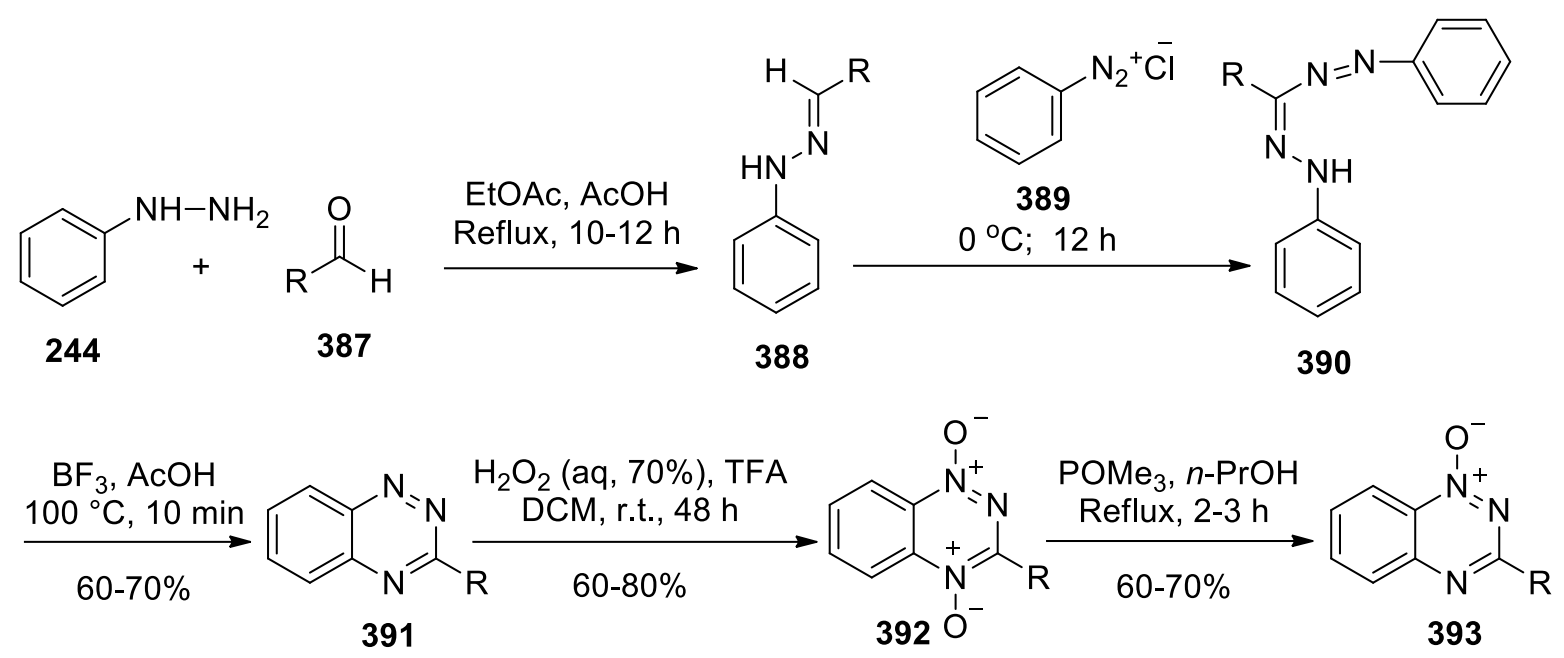

$\mathrm{R}=\mathrm{H}, \mathrm{Me}, \mathrm{Ph}$

Scheme 74. Synthesis of 3-alkyl or aryl-1,2,4-benzotriazine 1-oxides (393).

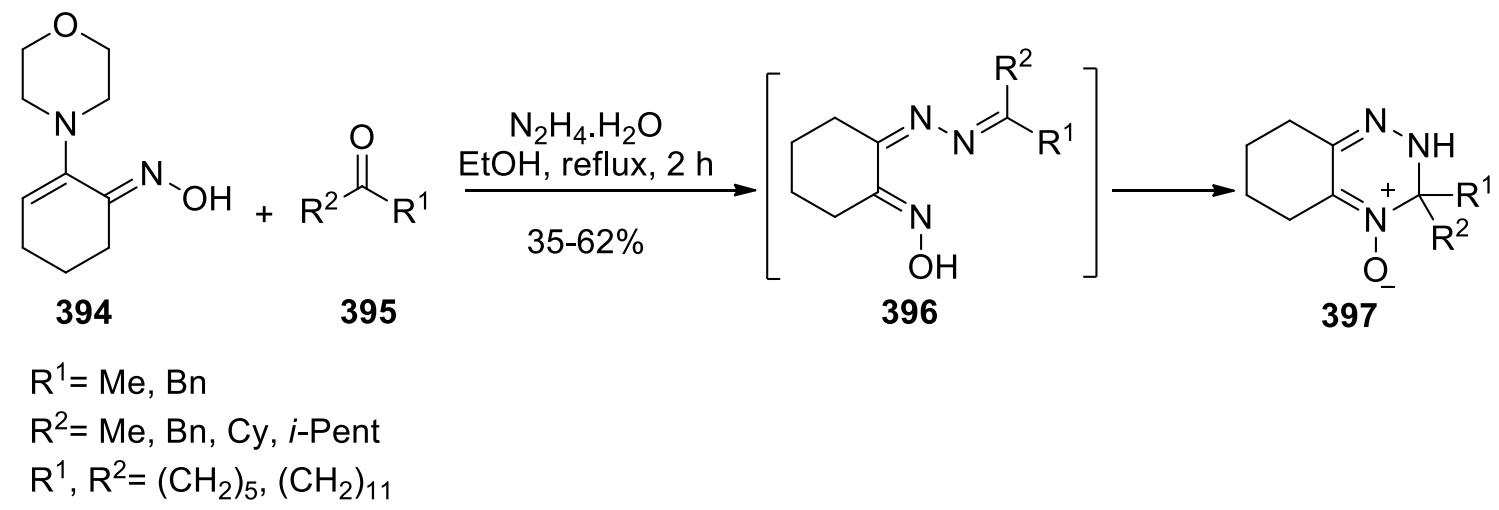

Scheme 75. Synthesis of 2,3,5,6,7,8-hexahydro-3,3-disubstituted-1,2,4-benzotriazine-4-oxide (397).

Hay and Denny employed the Stille and Suzuki coupling reactions ${ }^{138}$ for the alkylation of 1,2,4-benzotriazine 1-oxides (398), ${ }^{139,140}$ using a variety of stannanes in the presence of $\mathrm{Pd}\left(\mathrm{PPh}_{3}\right)_{4}$ in dimethoxyethane (DME) at $85^{\circ} \mathrm{C}$. The adduct (398) was then oxidized with TFAA to give the 3-substituted-1,2,4-benzotriazine 1,4-dioxides (399) (Scheme 76). ${ }^{141}$

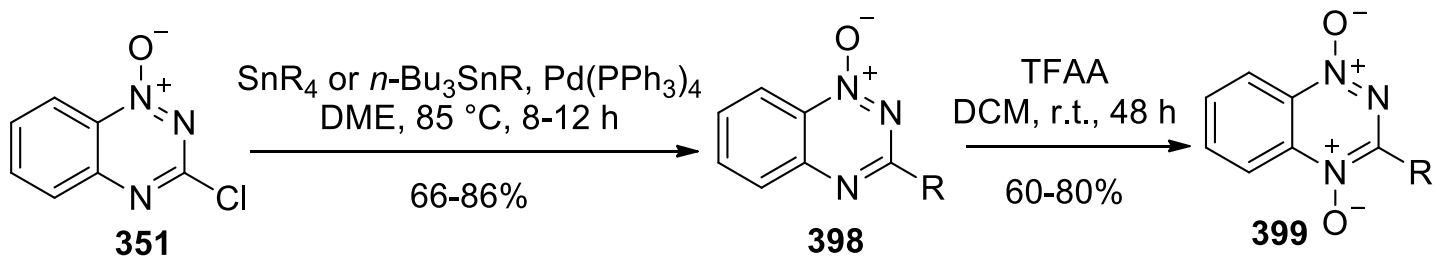

$\mathrm{R}=\mathrm{Me}, \mathrm{Et}, \mathrm{CH}=\mathrm{CH}_{2}, \mathrm{CH}_{2}-\mathrm{CH}=\mathrm{CH}_{2}, \mathrm{Ph}, 4-\mathrm{MeOC}_{6} \mathrm{H}_{4}, 3-\mathrm{MeOC}_{6} \mathrm{H}_{4}$

Scheme 76. Palladium-mediated coupling of 3-chloro-1,2,4-benzotriazine 1-oxide (351). 


\subsection{3-Ureido-1,2,4-benzotriazine $\mathbf{N}$-oxides}

According to the report of Zuilh and coworkers, 3-amino-1,2,4-benzotriazine 1-oxide (179) was obtained in $96 \%$ yield through the reaction of 2-fluoronitrobenzene (61) and guanidine (18) followed by in situ cyclization 1-(2-nitrophenyl)guanidine (400) in the presence of $t$-BuOK. Condensation of the compound (179) with alkyl or aryl isocyanates catalyzed by pyridine under reflux conditions afforded the 3-ureido-1,2,4-benzotriazine 1oxides (401) (Scheme 77). ${ }^{142}$

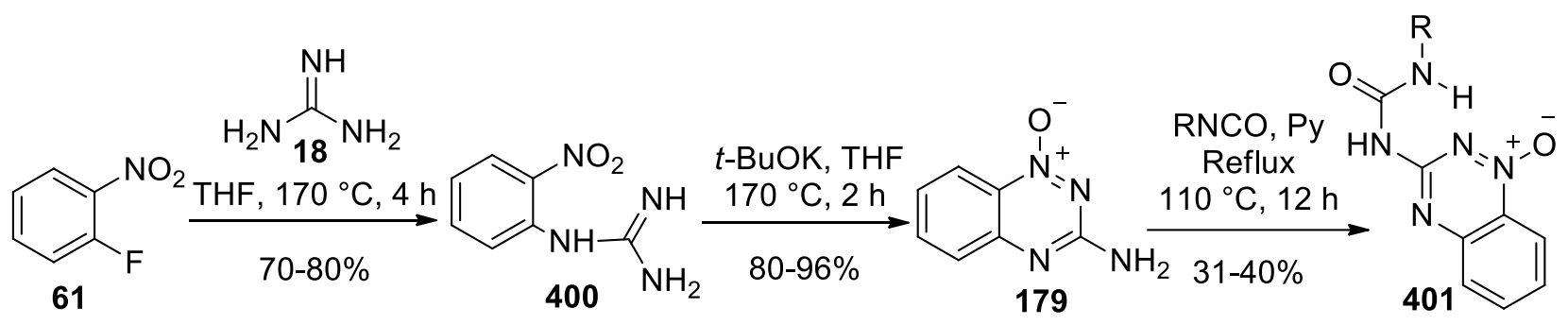

$\mathrm{R}=i-\mathrm{Pr}, t-\mathrm{Bu}, \mathrm{Cy}, \mathrm{Ph}$

Scheme 77. Preparation of 3-ureido-1,2,4-benzotriazine 1-oxides (401).

Seng and Ley prepared 3-amino-1,2,4-benzotriazine 1,4-dioxides (405) from the corresponding salts (404) which were produced by the addition of disodium cyanamide (403) to benzofuroxan (402). Treatment of compound (405) with phosgene in warm toluene produces compound (406) which acts as isocyanate (407) towards nucleophiles. The compound (406) reacted with methylamine (408) to produce the urea (409) (Scheme 78). ${ }^{143}$
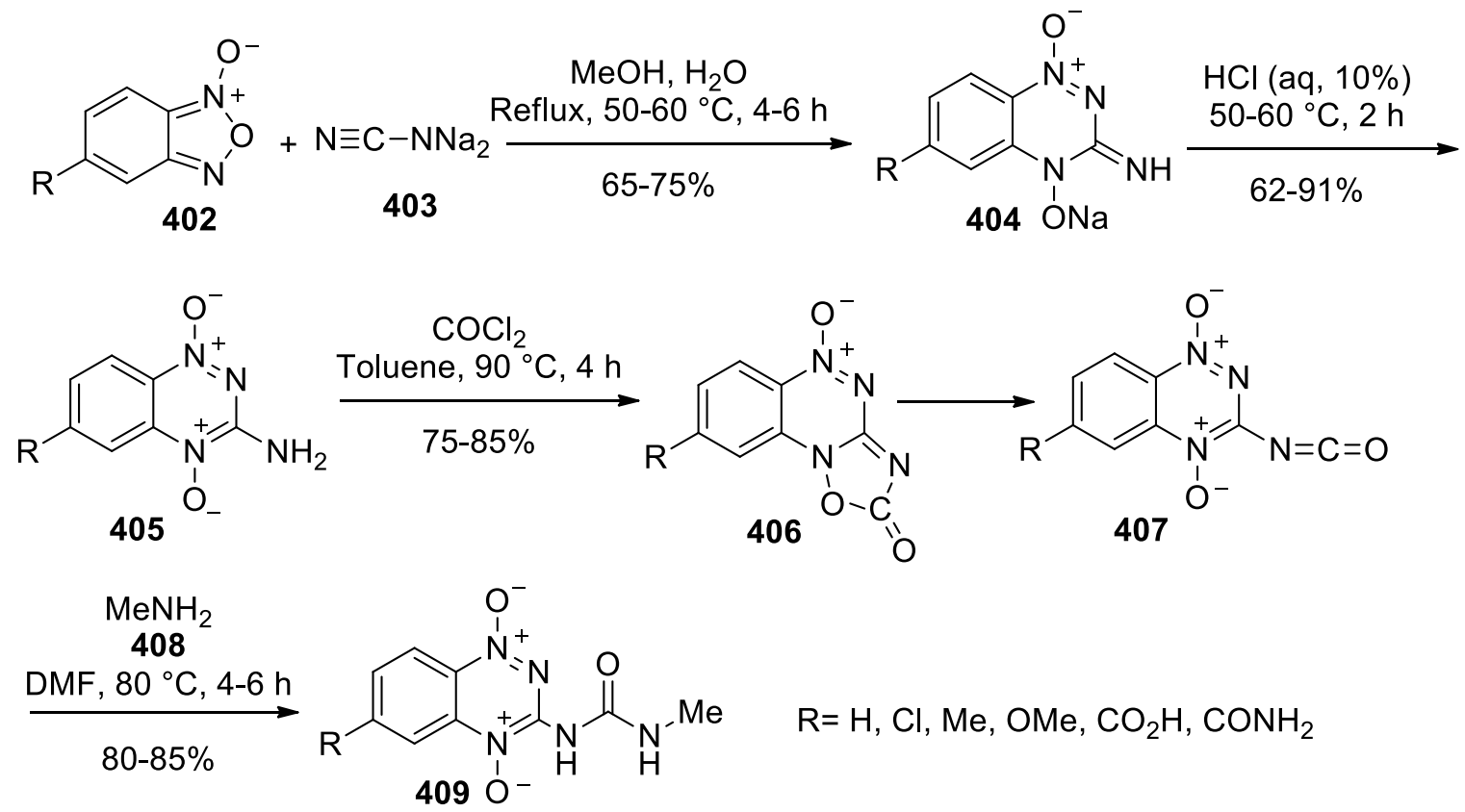

Scheme 78. Synthesis of 3-(3-methylureido)-1,2,4-benzotriazine 1,4-dioxides (409). 


\subsection{3-Alkylthio-1,2,4-benzotriazine $\mathbf{N}$-oxides}

Flash vacuum pyrolysis (FVP) of 3-methylsulfanyl-1,2,4-benzotriazine 1-oxide (410) was carried out between temperatures of 575 and $650{ }^{\circ} \mathrm{C}$. Under these conditions, $\mathrm{N}-\mathrm{O}$ bond cleavage is the only reaction observed, affording compound (411), while at higher temperatures, benzimidazole (413) was obtained instead. Compound (412) could be considered as an intermediate in this route, followed by the cleavage of $\mathrm{N}-\mathrm{O}$ bonds to produce the compound (413) (Scheme 79). ${ }^{144}$

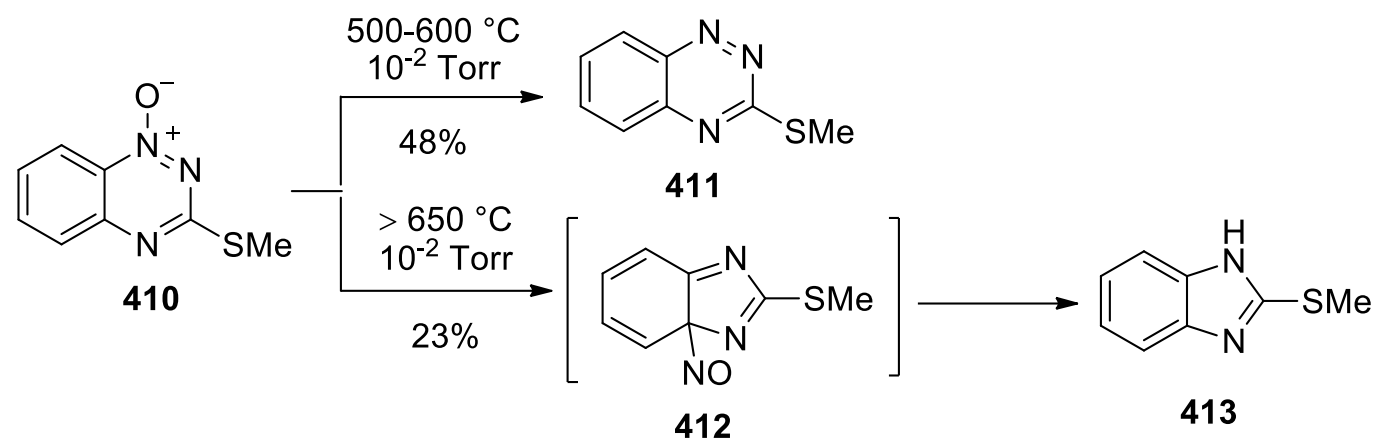

Scheme 79. The pyrolysis of 3-methylthio-1,2,4-benzotriazine 1-oxide (410).

\section{Conclusions}

Although the first synthesis of 1,2,4-benzotriazine was performed at the end of the 19th century, new methods for their preparation are still being developed. 1,2,4-Benzotriazines are important aromatic, fused $\mathrm{N}$ heterocycles which exhibit interesting properties including diverse biological activities. On the other hand, they can be transformed into stable benzotriazinyl radicals which can be converted into diverse supramolecular organic materials or exhibit liquid crystalline phases. 1,2,4-Benzotriazines can be obtained via deoxygenetion of benzotriazine $\mathrm{N}$-oxides, acid-catalyzed cyclizations of arylformazanes, intermolecular condensations, heterocyclizations of $\mathrm{N}$-(2-aminoaryl)hydrazides and ring expansions of 1,2,3-benzotriazoles. In addition, numerous reactions of 1,2,4-benzotriazine systems are presented here. For example, the ring contraction of 1,2,4-benzotriazines to give benzimidazoles has briefly been mentioned. On the other hand, the ring expansion of benzimidazoles to benzotriazines was also presented. This review combines information on the strategies used for the synthesis of 1,2,4-benzotriazines and their reactions.

\section{Acknowledgements}

We are grateful for financial support from the Research Council of Alzahra University.

\section{References}

1. Bischler, A.; Chem. Ber. 1889, 22, 280.

2. Cascioferro, S.; Parrino, B.; Spano, B.; Carbone, A.; Montalbano, A.; Barraja, P.; Diana, P.; Cirrincione, G. Eur. J. Med. Chem. 2017, 142, 328. https://doi.org/10.1016/i.ejmech.2017.08.009.

3. Obijalska, E.; M. K. Kowalski; Chem. Heterocycl. Compd. 2017, 53, 846. http://dx.doi.org/10.1007/s10593-017-2134-5. 
4. Shen, X.; Rajapakse, A.; Gallazzi, F.; Junnotula, V.; Knotts, T. F.; Glaser, R.; Gates, K. S. Chem. Res. Toxicol. 2014, 27, 111.

http://dx.doi.org/10.1021/tx400356y.

5. Palanki, M. S. S.; Cao, J.; Chow, C. P.; Dneprovskaia, E.; Mak, C. C.; McPherson, A.; Pathak, V. P.; Renick, J.; Soll, R.; Zeng, B.; Noronha, G. Expert Opin. Drug Discov. 2009, 4, 33.

http://dx.doi.org/10.1517/17460440802580536.

6. Lioyd, R. V.; Duling, D. R.; Rumyantseva, G. V.; Mason, R. P.; Bridson, P. K. Mol. Pharmacol. 1991, $40,440$.

7. Noronha,_G.;Barrett, K.; Boccia, A.; Brodhag, T.; Cao, J.; Chow, C. P.; Dneprovskaia, E.; Doukas, J.;_Fine, R.; Gong, X.; Gritzen, C.; Gu, H.; Hanna, E.; Hood, J. D.; Hu, S.; Kang, X.; Key, J.; Klebansky, B.; Kousba, A.; Li, G.;_Lohse, D.; Mak, C. C.; McPherson, A.; Palanki, M. S.; Pathak, V. P.; Renick, J.; Shi, F.; Soll, R.; Splittgerber, U.; Stoughton, S.; Tang, S.; Yee, S.; Zeng, B.; Zhao, N.; Zhu, H. Bioorganic Med. Chem. Lett. 2007, 17, 602.

http://dx.doi.org/10.1016/j.bmcl.2006.11.006.

8. Gueto, C.; Ruiz, J. L.; Torres, J. E.; Mendez, J.; Reyes, R. V. Bioorg. Med. Chem. 2008, 16, 2439. http://dx.doi.org/10.1016/i.bmc.2007.11.053.

9. Constantinides, C. P.; Berezin, A. A.; Zissimou, G. A.; Manoli, M.; Leitus, G. M.; Bendikov, M.; Probert, M. R.; Rawson, J. M.; Koutentis, P. A. J. Am. Chem. Soc. 2014, 136, 11906.

http://dx.doi.org/10.1021/ja5063746.

10. Constantinides, C. P.; Koutentis, P. A.; Advances in Heterocyclic Chemistry: Heterocyclic Chemistry in the 21st Century: A Tribute to Alan Katritzky; Scriven, E. F. V.; Ramsden, C. A. Eds.; Elsevier: Oxford, 2016; Vol. 119; p 173.

http://dx.doi.org/10.1016/bs.aihch.2016.03.001.

11. Sweeney, M.; Coyle, R.; Kavanagh, P.; Berezin, A. A.; Lo Re, D.; Zissimou, G. A.; Koutentis, P. A.; Carty, M. P.; Aldabbagh, F.; Bioorg. Med. Chem. 2016, 24, 3565.

http://dx.doi.10.1016/j.bmc.2016.05.066.

12. Arshad, M.; Khan, T. K.; Khan, M. A. Int. J. Pharm. Sci. Res. 2014, 5, 149.

http://dx.doi.org/10.1002/chin.201504278.

13. Srinivasa Rao, D.; Pavan Kumar, G. V.; Pooja, B.; Harika, G.; Anil Kumar, Y.; Sadasiva Rao, G. Der Chemica Sinica 2016, 7, 101.

14. Guerrini, G.; Costanzo, A.; Ciciani, G.; Bruni, F.; Selleri, S.; Costagli, C.; Besnard, F.; Costa, B.; Martini, C.; Siena, G. D.; Malmberg-Aiello, P. Bioorg. Med. Chem. 2006, 14, 758.

http://dx.doi.org/10.1016/i.bmc.2005.08.058.

15. Mohammadi Ziarani, G.; Mostofi, M.; Lashgari, N.; Mahdavi, M. Heterocycles 2018, 96, 1869. http://dx.doi.org/10.3987/REV-18-893.

16. Shen, X.; Laber, C. H.; Sarkar, U.; Galazzi, F.; Johnson, K. M.; Mahieu, N. G.; Hillebrand, R.; Fuchs-Knotts, T.; Barnes, C. L.; Baker, G. A.; Gates, K. S. J. Org. Chem. 2018, 83, 3126.

http://dx.doi.org/10.1021/acs.joc.7b03035.

17. Liu, J. B.; Fu, L.; Hu, Y. Z.; Jiang, F. Q. Acta Pharmaceutica Sinica 2009, 44, 695.

18. Denny, W. A. Curr. Med. Chem. 2004, 4, 395.

http://dx.doi.org/10.2174/1568011043352812.

19. Gandara, D. R.; Lara, P. N.; Goldberg, J. Z.; Le, Q. T.; Mack, P. C.; Lau, D. H. M.; Gumerlock, P. H. Semin. Oncol. 2002, 29, 102.

http://dx.doi.org/10.1053/sonc.2002.31531.

20. Xia, Q.; Zhang, L.; Zhang, J.; Sheng, R.; Yang, B.; He, Q. J.; Hu, Y. Z. Eur. J. Med. Chem. 2011, $46,919$. http://dx.doi.org/10.1016/i.ejmech.2011.01.007.

21. Reddy, R. B.; Williamson, S. K. Expert Opin Investig Drugs 2009, 18, 77. http://dx.doi.org/10.1517/13543780802567250.

22. Marcu, L.; Olver, I. Curr. Clin. Pharmacol. 2006, 1, 71. 
http://dx.doi.org/10.2174/157488406775268192.

23. Anderson, R. F.; Harris, T. A.; Hay, M. P.; Denny, W. A. Chem. Res. Toxicol. 2003, 16, 1477. http://dx.doi.org/10.1021/tx034116v.

24. Gu, Y.; Chang, T. T. A.; Wang, J.; Jaiswal, J. K.; Edwards, J.; Downes, N. J.; Liyanage, H. D. S.; Lynch, C. R. H.; Pruijn, F. B.; Hickey, A. J. R.; Hay, M. P.; Wilson, W. R.; Hicks, K. O. Front. Pharmacol. 2017, 8, 531. http://dx.doi.org/10.3389/fphar.2017.00531.

25. Lindsley, C. W.; Lyton, M. E. Science of Synthesis, Weinreb, S. M.; Schaumann, E. Eds; Thieme, 2004; Vol. $17 ; \mathrm{p} 357$.

http://dx.doi.org/10.1055/sos-SD-017-00553.

26. Henrie, R. N.; Plummer, M. J.; Smith, S. E.; Yeager, W. H.; Witkowski, D. A. Quant. Struct. Act. Relat. 1993, $12,27$.

http://dx.doi.org/10.1002/qsar.19930120105.

27. Noronha, G.; Barrett, K.; Cao, J.; Dneprovskaia, E.; Fine, R.; Gong, X.; Gritzen, C.; Hood, J.; Kang, X.; Klebansky, B.; Li, G.; Liao, W.; Lohse, D.; Mak, C. C.; McPherson, A.; Palanki, M. S. S.; Pathak, V. P.; Renick, J.; Soll, R.; Splittgerber, U.; Wrasidlo, W.; Zeng, B.; Zhao, N.; Zhou, Y. Bioorg. Med. Chem. Lett. 2006, 16, 5546.

http://dx.doi.org/10.1016/j.bmcl.2006.08.035.

28. Kelson, A. B.; McNamara, J. P.; Pandey, A.; Ryan, K. J.; Dorie, M. J.; McAfee, P. A. Anti-Cancer Drug Des. 1998, 13, 575.

29. Costanzo, A.; Ciciani, G.; Guerrini, G.; Bruni, F.; Selleri, S.; Donato, R.; Sacco, C.; Musiu, C.; Milia, C.; Longu, S.; Minnei, C.; La-Colla, P. Med. Chem. Res. 1999, 9, 223.

30. Hay, M. P.; Hicks, K. O.; Pruijn, F. B.; Pchalek, K.; Siim, B. J.; Wilson, W. R.; Denny, W. A. J. Med. Chem. 2007, 50, 6392.

http://dx.doi.org/10.1021/im070670g.

31. Pchalek, K.; Hay, M. P. J. Org. Chem. 2006, 71, 6530.

http://dx.doi.org/10.1021/jo060986g.

32. Horner, J. K.; Henry, D. W. J. Med. Chem. 1968, 11, 946. http://dx.doi.org/10.1021/jm00311a007.

33. Jiang, F.; Weng, Q.; Sheng, R.; Xia, Q.; He, Q.; Yang, B.; Hu, Y. Arch. Pharm. Chem. Life Sci. 2007, $340,258$. http://dx.doi.org/10.1002/ardp.200600201.

34. Bohme, H. R.; Wilde, H. Drug Des. Deliv. 1986, 1, 109.

35. Pang, X.; Zhao, L.; Zhou, D.; He, P. Y.; An, Z. U.; Ni, J. X.; Yan, R. Org. Biomol. Chem. 2017, 15, 6318. http://dx.doi.org/10.1039/C7OB01553D.

36. Kotovskaya, S. K.; Zhumabaeva, G. A.; Perova, N. M.; Baskakova, Z. M.; Charushin, V. N.; Chupakhin, O. N.; Belanov, E. F.; Bormotov, N. I.; Balakhnin, S. M.; Serova, O. A. Pharm. Chem. J. 2007, 41, 62. http://dx.doi.org/10.1007/s11094-007-0014-5.

37. Xua, H.; Fan, L. L. Eur. J. Med. Chem. 2011, 46, 364. http://dx.doi.org/10.1016/j.ejmech.2010.10.022.

38. Regan, B. A.; Hanifin, J. W.; Landes, M. J.; Osterberg, A. C.; Patel, G. J.; Ridge, D. N.; Sloboda, A. E.; Lang, S. A. J. Pharm. Sci. 1980, 69, 789.

http://dx.doi.org/10.1002/ips.2600690711.

39. Rozhkov, V. V.; Shevelev, S. A. Russ. Chem. Bull. 2000, 49, 1640. http://dx.doi.org/10.1007/BF02495174.

40. Miyaura, N.; Yanagi, T.; Suzuki, A. Synth. Commun. 1981, 11, 513. http://dx.doi.org/10.1080/00397918108063618.

41. Paul, F.; Patt, J.; Hartwig, J. F. J. Am. Chem. Soc. 1994, 116, 5969. http://dx.doi.org/10.1021/ja00092a058.

42. Tundel, R. E.; Anderson, K. W.; Buchwald, S. L. J. Org. Chem. 2006, 71, 430. 
http://dx.doi.org/10.1021/jo052131u.

43. Sarkar, U.; Hillebrand, R.; Johnson, K. M.; Cummings, A. H.; Phung, N. L.; Rajapakse, A.; Zhou, H.; Willis, J. R.; Barnes, C. L.; Gates, K. S. J. Heterocycl. Chem. 2017, 54, 155.

http://dx.doi.org/10.1002/ihet.2559.

44. Zhou, Y.; Zhang, Z.; Jiang, Y.; Pan, X.; Ma, D. Synlett 2015, 26, 1586.

http://dx.doi.org/10.1055/s-0034-1378708.

45. Adger, B.; Rees, C. W.; Sale, A. A.; Storr, R. C. Chem. Commun. 1971, 16, 695.

http://dx.doi.org/10.1039/C2971000695A.

46. Cerri, R.; Boido, A.; Sparatore, F. J. Heterocycl. Chem. 1979, 16, 1005.

http://dx.doi.org/10.1002/ihet.5570160534.

47. Andersch, J.; Sicker, D. J. Heterocycl. Chem. 1999, 36, 589.

http://dx.doi.org/10.1002/jhet.5570360302.

48. Gazieva, G. A.; Karpova, T. B.; Nechaeva, T. V.; Kravchenko, A. N. Russ. Chem. Bull. 2016, 65, 2172.

http://dx.doi.org/10.1007/s11172-016-1565-y.

49. Khodja, M.; Moulay, S.; Boutoumi, H.; Wilde, H. Heteroat. Chem. 2006, 17, 166.

http://dx.doi.org/10.1002/hc.20200.

50. Nazer, M. Z.; Issidorides, C. H.; Haddadin, M. J. Tetrahedron 1979, 35, 681.

http://dx.doi.org/10.1016/0040-4020(79)87016-7.

51. Reich, M. F.; Fabio, P. F.; Lee, V. J.; Kuck, N. A.; Testa, R. T. J. Med. Chem. 1989, 32, 2474.

http://dx.doi.org/10.1021/jm00131a010.

52. Abramovitch, R. A.; Schofield, K. J. Am. Chem. Soc. 1955, 8, 2326.

http://dx.doi.org/10.1039/JR9550002326.

53. El Ashry, E. S. H.; Rashed, N.; Mousaad, A.; Ramadan, E. Advances in Heterocyclic Chemistry, Katritzky, A.

R. Ed.; Academic Press: San Diego, 1994, Vol. 61; p 209.

http://dx.doi.org/10.1016/S0065-2725(08)60899-5.

54. Gelvin, C. R.; Turnbull, K. Helv. Chim. Acta 1992, 75, 1931.

http://dx.doi.org/10.1002/hlca.19920750619.

55. Nicolo, F.; Panzalorto, M.; Scopelliti, R.; Grassi, G.; Risitano, F. Acta Cryst. 1998, 54, 405.

http://dx.doi.org/10.1107/S0108270197014972.

56. Risitano, F.; Grassi, G.; Foti, F.; Filocamo, F. Tetrahedron 1997, 53, 1089.

http://dx.doi.org/10.1016/S0040-4020(96)01032-0.

57. Cortes, E.; Abonia, R.; Cobo, J.; Glidewell, C. Acta Crystallogr., Sect. C 2013, 69, 754.

http://dx.doi.org/10.1107/S0108270113013590.

58. Cortes, E.; Mendez, L.; Mata, E. G.; Abonia, R.; Quiroga, J.; Insuasty, B. Mol. Divers. 2012, 16, 839.

http://dx.doi.org/10.1007/s11030-012-9400-3.

59. Sagi, M.; Sato, O.; Konno, S.; Yamanaka, H. Heterocycles 1989, $29,2253$.

http://dx.doi.org/10.3987/COM-89-5156.

60. Raw, S.A.; Taylor, R. J. K. Advances in Heterocyclic Chemistry, Katritzky, A. R. Eds; Elsevier: Oxford, 2010; Vol. 100, p 75.

http://dx.doi.org/10.1016/S0065-2725(10)10003-8.

61. Abdelhamid, A. O.; AlHamidi, A. A. J. Chin. Chem. Soc. 1995, 42, 83.

http://dx.doi.org/10.1002/jccs.199500014.

62. Lipilin, D. L.; Tyurin, A. Y.; Smirnov, O. Y.; Churakov, A. M.; Strelenko, Y. A.; Tartakovsky, V. A. Russ. Chem. Bull. 2006, 55, 1239.

http://dx.doi.org/10.1007/s11172-006-0405-x.

63. Bala, S.; Sachdeva, M. L.; Handa, R. N.; Pujari, H. K. Heterocycles 1980, 14, 149.

http://dx.doi.org/10.3987/R-1980-02-0149.

64. Bakavoli, M.; Seresht, E. R.; Rahimizadeh, M. Heterocycl. Commun. 2006, 12, 273. 
http://dx.doi.org/10.1515/HC.2006.12.3-4.273.

65. El-Ashry, E. H.; Aly, A. A.; Aouad, M. R.; Amer, M. R. Nucleosides, Nucleotides Nucleic Acids 2010, $29,698$. http://dx.doi.org/10.1080/15257770.2010.501777.

66. Siadati, S. A. Iranian J. Org. Chem. 2015, 7, 1559.

67. Wiled, H.; Hauptmann, S.; Kanitz, A.; Franzheld, M.; Mann, G. J. Prakt. Chem. 1985, 327, 297. http://dx.doi.org/10.1002/prac.19853270215.

68. Sparatore, F.; Cerri, R. J. Heterocycl. Chem 1979, 16, 1001. http://dx.doi.org/10.1002/jhet.5570160533.

69. Novelli, F.; Sparatore, F. Il Farmaco 1996, 51, 541.

70. Novelli, F.; Sparatore, F. Il Farmaco 2002, 57, 871. http://dx.doi.org/S0014-827X(02)01293-4.

71. Mahran, A. M.; Farghaly, T. A.; Nada, A. A. Res. Chem. Intermed. 2015, 41, 2961. http://dx.doi.org/10.1007/s11164-013-1404-9.

72. Reissert, A. Ber. Dtsch. Chem. Ges. 1905, 38, 1603.

73. Afsar, A.; Distler, P.; Harwood, L. M.; John, J.; Westwood, J. J. Org. Chem. 2016, 81, 10517. http://dx.doi.org/10.1021/acs.joc.6b01264.

74. Lewis, F. W.; Harwood, L. M.; Hudson, M. J.; Distler, P.; John, J.; Stamberg, K.; Nunez, A.; Galan, H.; Espartero, A. G. Eur. J. Org. Chem. 2012, 2012, 1509.

http://dx.doi.org/10.1002/ejoc.201101576.

75. Gu, Y. C.; Jaiswal, J. K.; Wang, J. L.; Hicks, K. O.; Hay, M. P.; Wilson, W. R. J. Pharm. Sci. 2014, $103,3464$. http://dx.doi.org/10.1002/jps.24099.

76. Gross, H.; Gloede, D. J. Angew. Chem., Int. Ed. Engl. 1963, 2, 262.

http://dx.doi.org/10.1002/anie.196302621.

77. Chakraborty, A.; Jana, S.; Kibriya, G.; Dey, A.; Hajra, A. RSC Adv. 2016, 6, 34146. http://dx.doi.org/10.1039/C6RA03070J.

78. Cheeseman, G. W. H.; Rafiq, M.; Roy, P. D.; Turner, C. J. J. Chem. Soc. C 1971, 2018. http://dx.doi.org/10.1039/J39710002018.

79. Neunhoeffer, H. Comprehensive Heterocyclic Chemistry II; Boulton, A. J. Eds; Elsevier, 1996; Vol. 6; p 507. http://dx.doi.org/10.1016/B978-008096518-5.00127-1.

80. Mixich, G. Helv. Chim. Acta 1968, 51, 532. http://dx.doi.org/10.1002/hlca.19680510317.

81. Heravi, M. M.; Tavalaie, Z.; Sabzevari, O. Indian J. Chem., Sect. B 1998, 37, 585.

82. Heravi, M. M.; Aghapoor, K.; Nooshabadi, M. A.; Mojtahedi, M. M. Monatsh. Chem. 1997, $128,1143$. http://dx.doi.org/10.1007/BF00807564.

83. Curtius, T. Ber. Dtsch. Chem. Ges. 1890, 23, 3023.

84. Abbott, P. A.; Bonnert, R. V.; Caffrey, M. V.; Cage, P. A.; Cooke, A. J.; Donald, D. K. Tetrahedron 2002, 58, 3185.

http://dx.doi.org/10.1016/S0040-4020(02)00269-7.

85. Hasssan, A. Y.; Kadh, M. S.; Saleh, N. M.; Abou-Amra, E. S. Int. J. Adv. Res. 2016, 4, 335. http://dx.doi.org/10.21474/IJAR01/1222.

86. Tennant, G. J. Chem. Soc., C 1967, 2658. http://dx.doi.org/10.1039/J39670002658.

87. Xu, H.; Fan, L. L. Eur. J. Med. Chem. 2011, 46, 364. http://dx.doi.org/10.1016/j.ejmech.2010.10.022.

88. Diana, P.; Martorana, A.; Barraja, P.; Lauria, A.; Montalbano, A.; Almerico, A. M.; Dattolo, G.; Cirrincione, G. Bioorg. Med. Chem. 2007, 15, 343.

http://dx.doi.org/10.1016/j.bmc.2006.09.054. 
89. Catto, M.; Berezin, A. A.; Lo Re, D.; Loizou, G.; Demetriades, M.; Stradis, A. D.; Campagna, F.; Koutentis, P. A.; Carotti, A. Eur J. Med. Chem. 2012, 58, 84.

http://dx.doi.org/10.1016/j.ejmech.2012.10.003.

90. Koutentis, P. A.; Loizou, G.; Lo Re, D. J. Org. Chem. 2011, 76, 5793. http://dx.doi.org/10.1021/jo200966k.

91. Zissimou, G. A.; Kourtellaris, A.; Manoli, M.; Koutentis, P. A. J. Org. Chem. 2018, 83, 9391. http://dx.doi.org/10.1021/acs.joc.8b01311.

92. Heravi, M. M.; Alameh, S.; Bakavoli, M.; Oskooie, S. H. J. Sci. I. R. Iran 1997, 8, 232.

93. Heravi, M. M.; Montazeri, N.; Rahimizadeh, M.; Bakavoli, M.; Ghassemzadeh, M. Phosphorus, Sulfur Silicon Relat. Elem. 2001, 170, 187.

http://dx.doi.org/10.1080/10426500108040595.

94. Ioannou, T. A.; Koutentis, P. A.; Krassos, H.; Loizou, G.; Lo Re, D. Org. Biomol. Chem. 2012, 10, 1339. http://dx.doi.org/10.1039/C1OB06622F.

95. Constantinides, C. P.; Zissimou, G. A.; Berezin, A. A.; loannou, T. A.; Manoli, M.; Tsokkou, D.; Theodorou, E.; Hayes, S. C.; Koutentis, P. A. Org. Lett. 2015, 17, 4026.

http://dx.doi.org/10.1021/acs.orglett.5b01923.

96. Zissimou, A. G.; Constantinides, C. P.; Manoli, M.; Pieridou, G. K.; Hayes, S. C.; Koutentis, P. A. Org. Lett. 2016, 18, 1116. http://dx.doi.org/10.1021/acs.orglett.6b00222.

97. Keane, L. A. J.; Mirallai, S. I.; Sweeney, M.; Carty, M. P.; Zissimou, G. A.; Berezin, A. A.; Koutentis, P. A.; Aldabbagh, F. P. Molecules 2018, 23, 574.

http://dx.doi.org/10.3390/molecules23030574.

98. Savva, A. C.; Mirallai, S. I.; Zissimou, G. A.; Berezin, A. A.; Demetriades, M.; Kourtellaris, A.; Constantinides, C. P.; Nicolaides, C.; Trypiniotis, T.; Koutentis, P. A. J. Org. Chem. 2017, 82, 7564. http://dx.doi.org/10.1021/acs.joc.7b01297.

99. Berezin, A. A.; Zissimou, G.; Constantinides, C. P.; Beldjoudi, Y.; Rawson, J. M.; Koutentis, P. A. J. Org. Chem. 2014, 79, 314.

http://dx.doi.org/10.1021/jo402481t.

100. Morgan, I. S.; Peuronen, A.; Hanninen, M. M.; Reed, R. W.; Clerac, R.; Tuononen, H. M. Inorg. Chem. 2014, 53, 33.

http://dx.doi.org/10.1021/ic402954p.

101. Koutentis, P. A.; Lo Re, D. Synthesis 2010, 2010, 2075. http://dx.doi.org/10.1055/s-0029-1218782.

102. Constantinides, C. P.; Koutentis, P. A.; Loizou, G. Org. Biomol. Chem. 2011, 9, 3122. http://dx.doi.org/10.1039/c1ob05167a.

103. Demetriou, M.; Berezin, A. A.; Koutentis, P. A.; Krasia-Christoforou, T. Polym. Int. 2014, 63, 674. http://dx.doi.org/10.1002/pi.4566.

104. Neugebauer, F. A.; Umminger, I. Chem. Ber. 1981, 114, 2423. http://dx.doi.org/10.1002/cber.19811140709.

105. Neugebauer, F. A.; Rimmler, G. Magn. Reson. Chem. 1988, 26, 595. http://dx.doi.org/10.1002/mrc.1260260712.

106. Gubaidullin, A. T.; Buzykin, B. I.; Litvinov, I. A.; Gazetdinova, N. G. Russ. J. Gen. Chem.2004, 74, 939. http://dx.doi.org/10.1023/B:RUGC.0000042432.08612.2a.

107. Morgan, I. S.; Mansikkamki, A.; Zissimou, G. A.; Koutentis, P. A.; Rouzieres, M.; Clerac, R.; Tuononen, H. M. Chem. Eur. J. 2015, 21, 15843.

http://dx.doi.org/10.1002/chem.201501343.

108. Bodzioch, A.; Zheng, M.; Kaszynski, P.; Utecht, G. J. Org. Chem. 2014, 79, 7294. http://dx.doi.org/10.1021/jo500898e. 
109. Constantinides, C. P.; Berezin, A. A.; Zissimou, G. A.; Manoli, M.; Leitus, G. M.; Koutentis, P. A. Molecules 2016, 21, 636.

http://dx.doi.org/10.3390/molecules21050636.

110. Kaszynski, P.; Constantinides, C. P.; Young, V. G. Angew. Chem. 2016, 128, 1. http://dx.doi.org/10.1002/anie.201605612.

111. Jasinski, M.; Szczytko, J.; Pociecha, D.; Monobe, H.; Kaszynski, P. J. Am. Chem. Soc. 2016, $138,9421$. http://dx.doi.org/10.1021/jacs.6b06444.

112. Constantinides, C. P.; Obijalska, E.; Kaszynski, P. Org. Lett. 2016, 18, 916. http://dx.doi.org/10.1021/acs.orglett.5b03528.

113. Koutentis, P. A.; Krassos, H.; Lo Re, D. Org. Biomol. Chem. 2011, 9, 5228. http://dx.doi.org/10.1039/c1ob05410d.

114. Constantinides, C. P.; Berezin, A. A.; Manoli, M.; Leitus, G. M.; Bendikov, M.; Rawson, J. M.; Koutentis, P. A. New J. Chem. 2014, 38, 949. http://dx.doi.org/10.1039/C3NJ01235B.

115. Berezin, A. A.; Koutentis, P. A. Org. Biomol. Chem. 2014, 12, 1641. http://dx.doi.org/10.1039/c3ob42130a.

116. Wolf, F. J.; Wilson, R. M.; Pfister, K.; Tishler, M. J. Am. Chem. Soc. 1954, 76, 4611. http://dx.doi.org/10.1021/ja01647a032.

117. Jiang, F. Q.; Yang, B.; Fan, L. L.; He, Q. J.; Hu, Y. Bioorg. Med. Chem. Lett. 2006, 16, 4209. http://dx.doi.org/10.1016/j.bmcl.2006.05.095.

118. Jiu, J.; Mueller, G. P. J. Org. Chem. 1959, 24, 813. http://dx.doi.org/10.1021/jo01088a021.

119. Boyd, M.; Hay, M. P.; Boyd, P. D. W. Magn. Reson. Chem. 2006, 44, 948. http://dx.doi.org/10.1002/mrc.1886.

120. Chopra, S.; Koolpe, G. A.; Tambo-ong, A. A.; Matsuyama, K. N.; Ryan, K. J.; Tran, T. B.; Doppalapudi, R. S.; Riccio, E. S.; Iyer, L. V.; Green, C. E. J. Med. Chem. 2012, 55, 6047. http://dx.doi.org/10.1021/jm300123s.

121. Carbon, J. A. J. Org. Chem. 1962, 27, 185. http://dx.doi.org/10.1021/jo01048a046.

122. Gatenyo, J.; Johnson, K.; Rajapakse, A.; Gates, K. S.; Rozen, S. Tetrahedron 2012, 68, 8942. http://dx.doi.org/10.1016/j.tet.2012.08.017.

123. Parrick, J.; Mehta, L. K.; Hodgkiss, R. J. J. Heterocycl. Chem. 1993, 30, 323. http://dx.doi.org/10.1002/ihet.5570300205.

124. Suzuki, H.; Kawakami, T. Synthesis 1997, 1997, 855. http://dx.doi.org/10.1055/s-1997-1283.

125. Hay, M. P.; Pruijn, F. B.; Gamage, S. A.; Liyanage, S. D. S.; Kovacs, M. S.; Patterson, A. V.; Wilson, W. R.; Brown, J. M.; Denny, W. A. J. Med. Chem. 2004, 47, 475.

http://dx.doi.org/10.1021/jm030399c.

126. Lee, C. I.; Huang, C. M.; Huang, W. H.; Lee, A. R. Anticancer Agents Med. Chem. 2014, 14, 1428. http://dx.doi.org/10.2174/1871520614666141014130554.

127. Zeiger, A. V.; Joullie, M. M. Synth. Commun. 1976, 6, 457. http://dx.doi.org/10.1080/00397917508065581.

128. Kumar, A.; Parshad, M.; Gupta, R. K.; Kumar, D. Synthesis 2009, 2009, 1663. http://dx.doi.org/10.1055/s-0028-1088055.

129. Fuchs, T.; Chowdhury, G.; Barnes, C. L.; Gates, K. S. J. Org. Chem. 2001, 66, 107. http://dx.doi.org/10.1021/jo001232j.

130. Junnotula, V.; Sarkar, U.; Barnes, C. L.; Thallapally, P. K.; Gates, K. S. J. Chem. Crystallogr. 2006, $36,557$. http://dx.doi.org/10.1007/s10870-006-9099-z. 
131. Hay, M. P.; Gamage, S. A.; Kovacs, M. S.; Pruijn, F. B.; Anderson, R. F.; Patterson, A. V.; Wilson, W. R.; Brown, J. M.; Denny, W. A. J. Med. Chem. 2003, 46, 169.

http://dx.doi.org/10.1021/im020367+.

132. Daniels, J. S.; Chatterji, T.; MacGillivray, L. R.; Gates, K. S. J. Org. Chem. 1998, 63, 10027. http://dx.doi.org/10.1021/jo981314w.

133. Milstein, D.; Stille, J. K. J. Am. Chem. Soc. 1978, 100, 3636.

http://dx.doi.org/10.1021/ja00479a077.

134. Hay, M. P.; Pchalek, K.; Pruijn, F. B.; Hicks, K. O.; Siim, B. G.; Anderson, R. F.; Shinde, S. S.; Phillips, V.; Denny, W. A.; Wilson, W. R. J. Med. Chem. 2007, 50, 6654.

http://dx.doi.org/10.1021/im701037w.

135. Bamberger, E.; Wheelwright, E. Ber. Dtsch. Chem. Ges. 1892, 25, 3201.

http://dx.doi.org/10.1002/cber.189202502233.

136. Atallah, R. H.; Nazer, M. Z. Tetrahedron 1982, 38, 1793.

http://dx.doi.org/10.1016/0040-4020(82)80252-4.

137. Fischer, R. H.; Weitz, H. M. Synthesis 1975, 1975, 794.

138. Miyaura, N.; Suzuki, A. Chem. Rev. 1995, 95, 2457.

http://dx.doi.org/10.1021/cr00039a007.

139. Stille, J. K. Angew. Chem. Int. Ed. Engl. 1986, 25, 508.

http://dx.doi.org/ 10.1002/anie.198605081.

140. Stille, J. K.; Groh, B. L. J. Am. Chem. Soc. 1987, 109, 813.

http://dx.doi.org/10.1021/ja00237a029.

141. Hay, M. P.; Denny, W. A. Tetrahedron Lett. 2002, 43, 9569.

http://dx.doi.org/10.1016/S0040-4039(02)02417-6.

142. Ligthart, G. B. W. L.; Guo, D.; Spek, A. L.; Kooijman, H.; Zuilhof, H.; Sijbesma, R. P. J. Org. Chem. 2008, 73, 111.

http://dx.doi.org/10.1021/jo7019338.

143. Seng, F.; Ley, K. Angew. Chem. Int. Ed. 1972, 11, 1009.

http://dx.doi.org/10.1002/anie.197210091.

144. Riedl, Z.; Hajos, G.; Pelaez, W. J.; Gafarova, I. T.; Moyano, E. L.; Yranzo, G. I. Tetrahedron 2003, 9, 851. http://dx.doi.org/10.1016/S0040-4020(02)01598-3.

\section{Authors' Biographies}

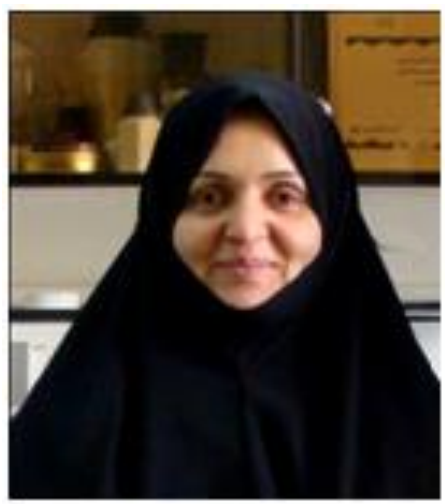

Ghodsi Mohammadi Ziarani was born in Iran, in 1964. She received her BSc. degree in chemistry from Teacher Training University, Tehran, Iran, in 1987, her MSc. degree in organic chemistry from the Teacher Training University, Tehran, Iran, under the supervision of Professor Jafar Asgarian and Professor Mohammad Ali 
Bigdeli in 1991 and her PhD. degree in asymmetric synthesis (Biotransformation) from Laval University, Quebec, Canada under the supervision of Professor Chenevert, in 2000. She is Associate Professor in the Science faculty of Alzahra University. Her research interests include organic synthesis, heterocyclic synthesis, asymmetric synthesis, natural product synthesis, synthetic methodology, and applications of nanoheterogeneous catalysts in multicomponent reactions.

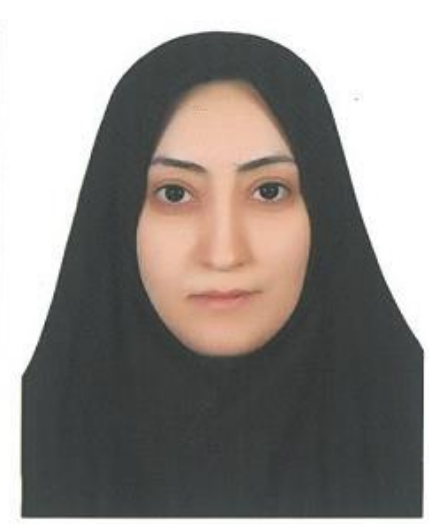

Madine Mostofi was born in 1980 Tehran, Iran. She obtained her B.Sc. degree in chemistry from Azad university of Tehran (2003) and her M.Sc. degree in organic chemistry under the supervision of Prof. Mehdi Adib at the University of Tehran (2006). She is currently a Ph.D. student in organic chemistry at Alzahra University under the supervision of Prof. Ghodsi Mohammadi Ziarani. Her research field is the synthesis of biologically active compounds via multicomponent reactions.

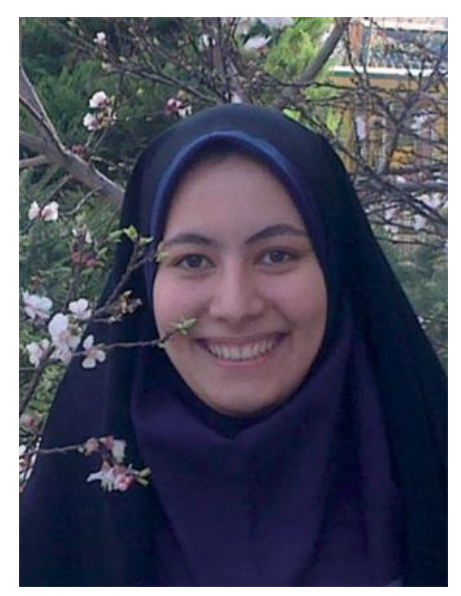

Parisa Gholamzadeh was born in 1986 in Tehran, Iran. She received her Ph.D. degree in organic chemistry from the Alzahra University (2016) under the supervision of Prof. Ghodsi Mohammadi Ziarani. Her research was synthesis of oxindole-based organic compounds. She is currently Post-Doc researcher in the group of Prof. Ghodsi Mohammadi Ziarani. Her scientific interests are the synthesis of organic compounds, study of bioactive natural organic compounds and food chemistry, and connection between chemistry and software. 


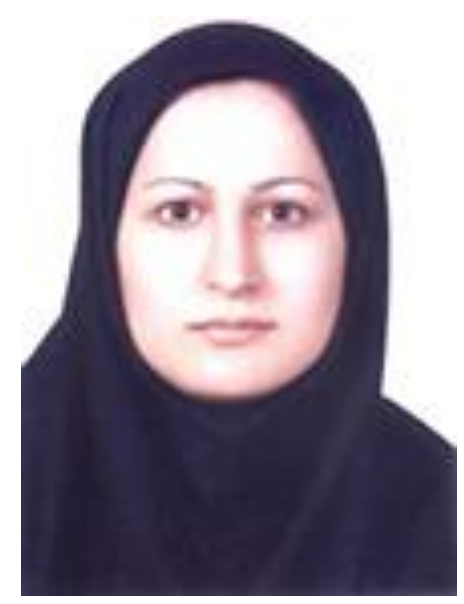

Maryam Mohammadi-Khanaposhtani was born in Iran, in 1984. She received the M.Sc. degree in organic chemistry in new pyrido[2,3-d]pyrimidines as antibacterial agents from the Shahid Beheshti University, Tehran, Iran, in 2008, and the Ph.D. degree in medicinal chemistry in biological evaluation of new acridones from the Tehran University of Medical Science, Tehran, Iran, in 2015. Since August 2017, she has been with the Cellular and Molecular Biology Research Center, Health Research Institute, Babol University of Medical Sciences, Babol, Iran where he is an Assistant Professor. Her current research interests include molecular modeling, antidiabetic, antibacterial, anticancer, anticonvulsant, and anticholinesterase agents.

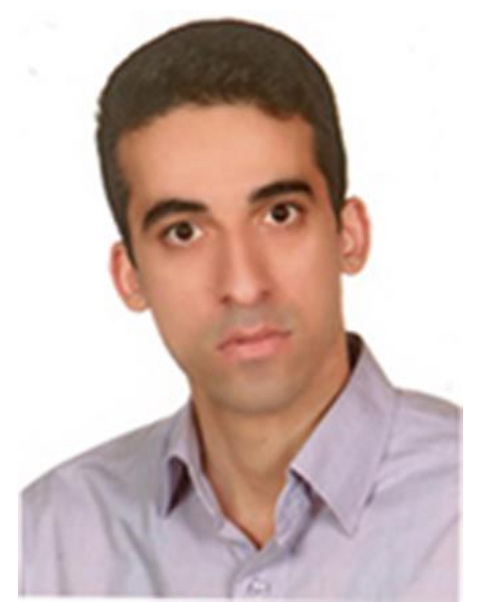

Hossein Yavari was born in 1978 in Karaj, Iran. He received his B.Sc. degree in applied chemistry from Kharazmi University, Karaj, Iran (2003) and his M.Sc. degree in organic chemistry at University of Tehran, Iran (2005) under the supervision of Prof. Mehdi Adib. He obtained his Ph.D. degree in organic chemistry from University of Mazandaran under the supervision of Prof. Heshmatollah Alinezhad and Prof. Abbas Shafiee in 2017. His research interests focus on heterocyclic chemistry, catalysis and organic methodology. 